\title{
MATERIALS SCIENCE DIVISION COAL TECHNOLOGY TENTH QUARTERLY REPORT,
}

\author{
January-March 1977
}

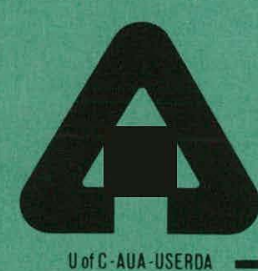

ARGONNE NATIONAL LABORATORY, ARGONNE, ILLINOIS Prepared for the U. S. ENERGY RESEARCH AND DEVELOPMENT ADMINISTRATION under Contract W-31-109-Eng-38 


\section{DISCLAIMER}

This report was prepared as an account of work sponsored by an agency of the United States Government. Neither the United States Government nor any agency Thereof, nor any of their employees, makes any warranty, express or implied, or assumes any legal liability or responsibility for the accuracy, completeness, or usefulness of any information, apparatus, product, or process disclosed, or represents that its use would not infringe privately owned rights. Reference herein to any specific commercial product, process, or service by trade name, trademark, manufacturer, or otherwise does not necessarily constitute or imply its endorsement, recommendation, or favoring by the United States Government or any agency thereof. The views and opinions of authors expressed herein do not necessarily state or reflect those of the United States Government or any agency thereof. 


\section{DISCLAIMER}

Portions of this document may be illegible in electronic image products. Images are produced from the best available original document. 
The facilities of Argonne National Laboratory are owned by the United States Government. Under the terms of a contract (W-31-109-Eng-38) between the U. S. Energy Research and Development Administration, Argonne Universities Association and The University of Chicago, the University employs the staff and operates the Laboratory in accordance with policies and programs formulated, approved and reviewed by the Association.

\section{MEMBERS OF ARGONNE UNIVERSITIES ASSOCIATION}

The University of Arizona Carnegie-Mellon University Case Western Reserve University The University of Chicago University of Cincinnati Illinois Institute of Technology University of Illinois Indiana University Iowa State University The University of Iowa
Kansas State University The University of Kansas Loyola University Marquette University Michigan State University The University of Michigan University of Minnesota University of Missouri Northwestern University University of Notre Dame
The Ohio State University Ohio University The Pennsylvania State University Purdue University Saint Louis University Southern Illinois University The University of Texas at Austin Washington University Wayne State University The University of Wisconsin

\section{NOTICE}

This report was prepared as an account of work sponsored by the United States Government. Neither the United States nor the United States Energy Research and Development Administration, nor any of their employees, nor any of their contractors, suhcontractors, or their employees, makes any warranty, express or implied, or assumes any legal liability or responsibility for the accuracy, completeness or usefulness of any information, apparatus, product or process disclosed, or represents that its use would not infringe privately-owned rights. Mention of commercial products, their manufacturers, or their suppliers in this publication does not imply or connote approval or disapproval of the product by Argonne National Laboratory or the U. S. Energy Research and Development Administration.

Printed in the United States of America Available from

National Technical Information Service

U. S. Department of Commerce 5285 Port Royal Road

Springfield, Virginia 22161

Price: Printed Copy $\$ 5.50 ;$ Microfiche $\$ 3.00$ 
Distribution Category:

Coal Conversion and Utilization--

Materials and Components (UC-90h)

ANL-77-41

ARGONNE NATIONAL LABORATORY

9700 South Cass Avenue

Argonne, Illinois 60439

MATERIALS SCIENCE DIVISION

COAL TECHNOLOGY TENTH QUARTERLY REPORT, JANUARY-MARCH 1977

Principal Investigator

W. A. Ellingson

Project Leader

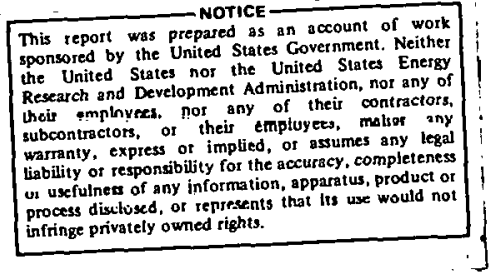

Previous reports in this series

$\begin{array}{lrr}\text { ANL-76-7 } & \text { July-September } & 1975 \\ \text { ANL-76-22 } & \text { October-December } & 1975 \\ \text { ANL-76-60 } & \text { January-March } & 1976 \\ \text { ANL-76-111 } & \text { April-June } & 1976 \\ \text { ANL-76-125 } & \text { July-September } & 1976 \\ \text { ANL-77-5 } & \text { October-December } & 1976\end{array}$


THIS PAGE

WAS INTENTIONALLY

LEFT BLANK 
Task A -- Evaluation of Ceramic Refractories for Slagging Gasifiers .. . . . . . . . . . . . . . .

Task B -- Evaluation of Ceramic Coatings for Coal-conversion Plants . . . . . . . . . . . . . . . . .

Task C -- Application and Development of Nondestructive Evaluation Methods for Coal-conversion Processes . . . . . . .

1. Erosive-wear Detection and Monitoring . . . . . . . .

a. Metallic Transfer Lines . . . . . . . . . . 2

(1) Laboratory U1trasonic Studies . . . . . . 2

(2) Field Studies .............. . . 3

b. Refractory-lined Transfer Lines . . . . . . . 3

(1) Gamma Radiography Development ......... 3

(2) Infrared Imaging -- Pattern Recognition ..... 4

2. Refractory-installation Practices . . . . . . . . 5

a. Acoustic Emission ................ . 5

3. Component Inspection ................ . . 7

a. Infrared Thermal Profiling of Valves . . . . . . 7

b. Acoustic Monitoring of Valves............ 8

(1) Valve Leak Detection by Acoustic Emission . . . 8

(2) Laboratory Studies ............. 11

Task D -- Corrosion Behavior of Materials in Coal-conversion Processes ...................... 11

Task E -- Erosion Behavior of Materials in Coal-conversion Processes . . . . . . . . . . . . . . . . 
TABLE OF CONTENTS (Contd.)

Task F-- Component Performance and Failure Analysis . . . . . . . 17

1. Analysis of Cracks in the ERDA-MERC Rabble Arm . . . . . 17

2. Alonized Coupons from the HYGAS Pilot Plant . . . . . . . 18

3. Ballooned Pipe from the Synthane Pilot Plant . . . . . . . 19

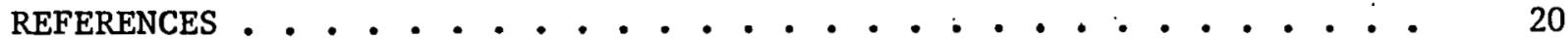


1 Top and Side Views of the New Bottom Section of the Slag-

2 Thermocouple Positions in a Full Length (228.6 mm) Brick . . . . 33

3 Temperatures in Bricks at Beginning of Test at Four Locations in Full-length Bricks and at Three Locations in 3/4- and 1/2-1ength Bricks . . . . . . . . . . . . . . . . .

4 (a) Azimuthal Distribution of Measurements Location allong the Inlet Centerline of the HYGAS Cyclone and (b) Assumed Erosion Pattern Based on Elbow Studies . . . . . . . . . . . . .

5 Azimuthal Distribution of Wear along the Inlet Centerline of the HYGAS Cyclone . . . . . . . . . . . . . . 35

6 Average Wear Rate along the Inlet Centerline of the HYGAS Cyclone as a Function of the Number of Hours of Operation . . . . 36

7 Erosive Wear of Refractory-lined Transfer Line After 200-h Exposure .................... 36

8 Schematic of the Ash 502 Direction Change Transfer Lines . . . 37

9. Isotherma1 Distance from Center Line of a Synthesized Cavity in a 76-mm-thick Refractory Bonded to a 6.5-mm-thick Steel Plate . . 38

10 Schematic of (a) Refractory-steel Lamination with Rectangular Cavity Defect and (b) Thermal Profile Observed in a Single Line

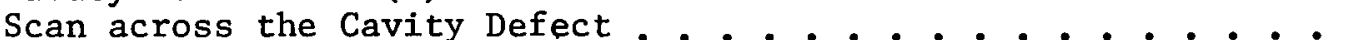

11 Schematic of Sample and Embedded Acoustic Waveguide . . . . .

12 Total Acoustic-emission Counts as a Function of Temperature for Three Heating Cycles on the Same Sample . . . . . . . . . .

13 Total Acoustic-emission Counts as a Function of Time for (a) the $120^{\circ} \mathrm{C}$ Linear Heating Ramp, (b) the $500^{\circ} \mathrm{C}$ Linear Heating Ramp, and (c) the $1000^{\circ} \mathrm{C}$ Linear Heating Ramp, all with Furnace Cooling . .

Schematic Showing Metallographic Sample Locations . . . . . .

15 Transverse Metallographic Sample . . . . . . . . . . 
18 Measurement of Reference Temperatures Using a Contact

Pyrometer . . . . . . . . . . . . . . . . . .

19 Thermal Profile Sequence of the Top Ash Lockhopper Valve (Thermovision Range $=50$ )................. . 45

Thermal Profile Sequence of the Top Ash Lockhopper Valve (Thermovision Range $=20$ ) ....................

Thermal Profile Sequence of the North Bottom Coa1-feed Lockhopper Valve

Thermal Profile Sequence of Top Cyclone Lockhopper Valve . . .

Acoustic-emission Measurement Locations on the MERC Top Cyclone Lockhopper Valve

24 Acoustic-emission Measurement Locations on Structure Near Cyclone Lockhopper Valve . . . . . . . . . . . . . .

25 Acoustic-emission Measurement Locations on the MERC Top Ash Lockhopper Valve . . . . . . . . . . . . . . . .

26 Acoustic-emission Measurement Locations for the MERC North Bottom Coal-feed Lockhopper Valve . . . . . . . . . . . .

27 Acoustic-emission Measurement Locations for the Synthane North Lnwer Petrnrarh Feed Valves .................

28 Acoustic-emission Measurement Locations for the Synthane South Lower Petrocarb Feed Valves and Nearby Structure . . .

Macroscopic Photographs of Specimens That Have Repn Fixpnser to Multicomponent Gas Environment at $875^{\circ} \mathrm{C}$ for $25 \mathrm{~h}$ (Top) and

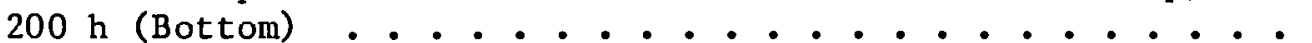

30 X-ray Specimen Image and the $\mathrm{Fe}$ and $\mathrm{S}$ Distributions for an Iron Specimen Exposed to a Complex Gas Mixture at $875^{\circ} \mathrm{C}$ for $25 \mathrm{~h}$

$31 \mathrm{X}$-ray Specimen Image and $\mathrm{Cr}, \mathrm{S}, \mathrm{Fe}$, and $\mathrm{Si}$ Distributions in Type 310 Stainless Steel Exposed to the Gas Mixture Listed in Table X for $25 \mathrm{~h}$ at $875^{\circ} \mathrm{C}$. . . . . . . . . . .

32 X-ray Specimen Image and $\mathrm{Cr}, \mathrm{S}, \mathrm{Fe}, \mathrm{Ni}$, and $\mathrm{Si}$ Distributions in Incoloy 800 Exposed to the Gas Mixture Listed in Table X for $25 \mathrm{~h}$ at $875^{\circ} \mathrm{C}$. . . . . . . . . . . . . . . 


\section{LIST OF FIGURES (Contd.)}

No:

$\underline{\text { Title }}$

Page

$33 \mathrm{X}$-ray Specimen Image and $\mathrm{Cr}, \mathrm{S}, \mathrm{Fe}, \mathrm{Ni}$, and $\mathrm{Si}$ Distributions in U. S. Steel Alloy 18-18-2 Exposed to the Gas Mixture Listed in Table $\mathrm{X}$ for $25 \mathrm{~h}$ at $875^{\circ} \mathrm{C}$. . . . . . . . . . . .

$34 \mathrm{X}$-ray Specimen Image and $\mathrm{Cr}, \mathrm{Ni}$, and $\mathrm{S}$ Distributions in Inconel 671 Exposed to the Gas Mixture Listed in Table X for $25 \mathrm{~h}$ at $875^{\circ} \mathrm{C}$. . . . . . . . . . . . . .

$35 \mathrm{X}$-ray Specimen Image and $\mathrm{Cr}, \mathrm{Fe}, \mathrm{Ni}$, and $\mathrm{Si}$ Distributions in Type 310 Stainless Steel Exposed to the Gas Mixture Listed in Table X for $200 \mathrm{~h}$ at $875^{\circ} \mathrm{C}$. . . . . . . . . . .

$36 \mathrm{X}$-ray Specimen Image and $\mathrm{Cr}, \mathrm{S}, \mathrm{Fe}, \mathrm{Ni}, \mathrm{Si}$, and $\mathrm{A} 1$ Distributions in Incoloy 800 Exposed to the Gas Mixture Listed in Table X

for $200 \mathrm{~h}$ at $875^{\circ} \mathrm{C}$. . . . . . . . . . . . .

$37 \mathrm{X}$-ray Specimen Image and $\mathrm{Cr}, \mathrm{Si}$, and $\mathrm{S}$ Distributions in the Alloy Regions of U. S. Steel Alloy 18-18-2 Exposed to the Gas Mixture Listed in Table X for $200 \mathrm{~h}$ at $875^{\circ} \mathrm{C}$. . . . . .

38 SEM Photograph of Inconel 671 Specimen Exposed to the Gas Mixture Listed in Table X for $200 \mathrm{~h}$ at $875^{\circ} \mathrm{C}$. . . . . . . .

39 SEM Photograph of Scale/Alloy Interface Regions of U. S. Steel Alloy 18-18-2 Exposed to the Gas Mixture Listed in Table X for

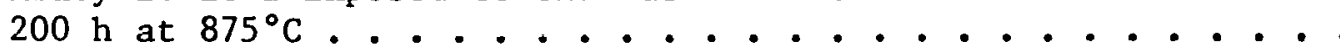

40 Macroscopic Photographs of Different Alloy Specimens after 25-h Exposure at $750^{\circ} \mathrm{C}$ to the Gas Mixtures Listed in Table XII . . .

41 Macroscopic. Photographs of Different Alloy Specimens after 25-h Exposure at $875^{\circ} \mathrm{C}$ to the Gas Mixtures Listed in Table XII . . .

42 SEM Photographs of Type 310 Stainless Steel Specimens after 25-h Exposure at $750^{\circ} \mathrm{C}$ to the Gas Mixtures Listed in Table XII .

SEM Photograph of Type 310 Stainless Steel Specimen after 25-h Exposure at $750^{\circ} \mathrm{C}$ to the Gas Mixture Listed in Table XII . . .

44 SEM Photographs of Type 310 Stainless Steel Specimens after 25-h Exposure at $875^{\circ} \mathrm{C}$ to the Gas Mixtures Listed in Table XII . . .

45. X-ray Specimen Image and $\mathrm{Fe}, \mathrm{Cr}, \mathrm{S}$, and $\mathrm{Si}$ Distributions in Type 310 Stainless Steel after $25-\mathrm{h}$ Exposure at $875^{\circ} \mathrm{C}$ to the Gas Mixture without Stecm Listed in Table XII (Identified by an Arrow) 
LIST OF FIGURES (Contd.)

No.

$\underline{\text { Title }}$

Page

46 X-ray Specimen Image and $\mathrm{Fe}, \mathrm{Cr}, \mathrm{S}, \mathrm{Ni}$, and $\mathrm{Si}$ Distributions in Type 310 Stainless Steel after $25-\mathrm{h}$ Exposure at $875^{\circ} \mathrm{C}$ to the Gas Mixture with Steam Listed in Table XII . . . . . . . 70

47 Particle Trajectories in a $90^{\circ}$ Elbow . . . . . . . . . . 71

48 ERDA-MERC Stirred-bed Gasifier . . . . . . . . . . . 72

49 Schematic of the Rabble Arm . . . . . . . . . . . 73

50. Photographs of the Cracked Corrosion Scale and the Crack Tip . . 74

51 Photographs of the Crack that had been Electroetched . . . . . 75

52 Optical Photograph (a) and Electron-microprobe Data (b) of an

"Alonized" Type 316 Stainless Steel Coupon That Had Been

Exposed to the HYGAS Gasifier Environment and Removed after

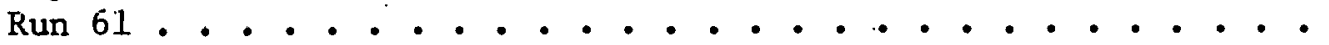

53 Optical Photograph (a) and Electron-microprobe Data (b) of an

"Alonized" Type 316 Stainless Steel Coupon That Had Been Exposed to the HYGAS Gasifier Environment and Removed after Run 67 ...

54 Optical Photograph and Electron-microprobe Data of an "Alonized" Type 446 Stainless Steel Coupon 'that Had Been Exposed to the HYGAS Gasifier Environment and Kemoved atter Run 6I . . . . . 78

55 Geometry of Machined Coupons Used for the Anger Fxperiment . . - 79

56 Auger Spectra of the As-fractured Type 316 Stainless Stee1 . • 79

57 Auger Spectra of the Corrosion Scale at the Type 316 Stainless

Steel Surface ... . . . . . . . . . . . . . 80

58 SEM Micrographs of the Fracture Surface of Type 316 Stainless

Steel Showing Embrittled Grain Boundaries . . . . . . . .

59 SEM Micrograph of the Corrosion Scale and the Fracture Surface of Type 316 Stainless Stee1 . . . . . . . . . . . . . .

60 SEM Micrographs of the Fractured Surface of Type 446 Stainless Steel ..........................

61 SEM Micrograph of the Fractured Surface of Type 446 Stainless Steel . . . . . . . . . . . . . . . . . . . .

62 Schematic Showing the Elbow, Bulged Pipe, and Letdown Valve • . 
I Initial Composition of Slag in Corrosion Test Run 4 . . . . 22

II Coating Materials and Substrates Used in the 3.6 Ms Exposure to High-velocity Char at $980^{\circ} \mathrm{C}$. . . . . . . . . . 23

III Parameters Used in Heat-transfer Calculations . . . . . . . . 24

IV Heating Schedules Followed for Samples Examined This Quarter (All Samples of KAOTAB) . . . . . . . . . . . . . 25

$\mathrm{V}$ Acoustic-emission Measurements on the Top Cyclone Lockhopper Valve ...................... . . 25

VI Acoustic-emission Measurements on the Top Ash Lockhopper Valve . . . . . . . . . . . . . . . . . . 26

VII Acoustic-emission Measurements on the Bottom Coal-feed Lockhopper Valve . . . . . . . . . . . . . . . 26

VIII Acoustic-emission Measurements on the North Lower Petrocarb Feed Valve ..........................

IX Acoustic-emission Measurements on the South Lower Petrocarb Feed Valve and Nearby Structural Components . . . . . . . 28

$\mathrm{X}$ Gas Environment Used for Preliminary Corrosion Experiments at $875^{\circ} \mathrm{C}$. . . . . . . . . . . . . . .

XI Chemical Composition (wt \%) of Alloys Used in Corrosion Experiments .........................

XII Gas Compositions (vo1 \%) Used in the Evaluation of Material Rehavinr at 750 and $875^{\circ} \mathrm{C}$. . . . . . . . . . . 


\section{MATERIALS SCIENCE DIVISION \\ COAL TECHNOLOGY TENTH QUARTERLY REPORT, JANUARY-MARCH 1977}

\section{HIGHLIGHTS}

Task A -- Evaluation of Ceramic Refractories for Slagging Gasifiers (C. R. Kennedy, R. J. Fousek, D. J. Jones, and R. B. Poeppe Z)

Construction of the bottom section of the slag-corrosion furnace, redesigned to provide prototypic thermal gradients, has been completed and the fourth 500-h corrosion test has been initiated. Three types of silicon carbide and one type of silicon-oxynitride brick are being exposed to an acidic slag.

Task B -- Evaluation of Ceramic Coatings for Coal-conversion Plants (S. Dany Zuk, R. B. Poeppel, and G. M. Iragel)

Samples that were exposed to the corrosion-erosion furnace by Solar, Inc., were shipped to ANL on March 11, 1977.

Task C -- Application and Development of Nondestructive Evaluation Methods for Coal-conversion Processes (W. A. Ellingson, W. J. Shack, and C. L. Johnson)

The first field data on erosive wear of an installed refractorylined transfer line was obtained this quarter. This has shown that $100 \%$ of the lining could be eroded in less than $300 \mathrm{~h}$ of exposure to $\mathrm{Al}_{2} \mathrm{O}_{3}$ partir.1es, Acoustic-emission data on high-density isothermally heated refractory bar specimens has shown that most crack damage occurs below $500^{\circ} \mathrm{C}$ and the cooling rate may be as important as the heat-up rate. Field tests on acoustic-valve-leak-detection systems have shown that known leaks can be detected and separated from structure-borne noise using a frequency window between 375 and $800 \mathrm{kHz}$.

Task D -- Corrosion Behavior of Materials in Coal-conversion Processes (K. Natooar ard O. K. Chupia)

Preliminary corrosion experiments were conducted in gas mixtures that have been selected for exposure of uniaxial tensile specimens of Type 310 stainless steel, Incoloy 800 , Inconel 671, and U. S. Steel alloy 18-18-2. The results after a 200-h exposure showed that the first three of the abuve alloys developed Cr-rich oxide scale. The U. S. Steel alloy 18-18-2 developed a $(\mathrm{Cr}, \mathrm{Fe})$ sulfide scale that had a significantly larger growth rate than the oxide scales in other specimens. It seems that the $22 \mathrm{wt} \% \mathrm{Si}$ in the U. $\mathrm{S}$. Steel alloy 18-18-2 alters the mode of attack from oxidation to sulfidation. Results are presented on the corrosion behavior of materials, as a function of oxygen partial pressure in a multicomponent gas environment, and on the experiments to evaluate the role of steam in the gas mixture on the corrosion 
behavior of Type 310 stainless steel. The results showed that steam is not an essential component to establish the corrosion behavior of an alloy as long as the same oxygen, sulfur, and carbon potentials are simulated by adjusting the relative amounts of different molecular gas species.

Task E -- Erosion Behavior of Materials in Coal-conversion Processes (W. J. Shack)

A brief literature review of analytical models for the two-phase flow of particles and fluids is presented. A qualitative discussion of a set of simplified equations is given, and a dimensionless group that describes the fraction of particles actually impacting the wall of an elbow is developed. Quantitative results, which show the importance of particle diameter, are given for particle trajectories in an elbow that carries fluid.

Task F -- Component Performance and Failure Analysis (S. Danyluk, G. M. Dragel, and M. D. Gorman)

Components from the Morgantown Energy Research Center high-pressure gas producer (rabble arm), the HYGAS Pilot Plant (alonized coupons), and the Synthane Pilot Plant (steam line) were analyzed to determine the cause of the failure. Three final reports have been issued: "EBV Ball-valve stem Failure -- Synthane Coal-gasification Pilot Plant," "Analysis of the Gatevalve Failure -- Grand Forks Energy Research Center Fixed-bed Slagging Gasifier Pilot Plant," and "Fallure Analysis of the Thermocouple Assembly. in the HYGAS Coal Pretreatment Vesse1." 
MATERIALS SCIENCE DIVISION

COAL TECHNOLOGY TENTH QUARTERLY REPORT,

JANUARY-MARCH 1977

\begin{abstract}
This broad-base materials engineering program, begun in October 1974, includes studies on both ceramic (refractory) and metallic materials presently being used or intended for use in coal-conversion systems. Appropriate laboraory and field experiments are integrated such that the results have immediate impact on the present pilot-plant and proposed demonstration-plant designs. This quarterly report, for the period January-March 1977, presents the technical accomplishments.
\end{abstract}

\title{
INTRODUCTION
}

The economical conversion of coal into cleaner and more usable fuels will be advanced through use of durable materials systems. The present report is the tenth quarterly progress report submitted by Argonne National Laboratory to the Division of Materials and Exploratory Research/ERDA Fossil Energy under project Number 7106, "Materials Technology for Coal Conversion Processes."

The project includes six tasks: (A) evaluation of ceramic refractories exposed to coal-slag abrasion-corrosion typical of that encountered in slagging gasifiers; (B) evaluation of coat performance under erosive environments; (C) development, evaluation, and application of nondestructive evaluation methods applicable to coal-conversion systems, such as in-situ ernsive-wear detection/monitoring; (D) development of analytical models to predict corrosion behavior, e.g., phase transformations, of iron- and nickel-base alloys in gaseous environments; (E) development of analytical models to predict the erosive-wear behavior of materials used in coalconversion plants, and (F) analysis of failed coal-gasification plant components. Progress in all Tasks is discussed in the present report.

Task A -- Evaluation of Ceramic Refractories for Slagging Gasifiers (C. R. Kennedy, R. J. Fousek, D. J. Jones, and R. B. Poeppel)

The purpose of Task $A$ is to evaluate the resistance of various refractory bricks to attack by molten coal slag. Three tests in the slagabrasion rig have been reported.1-5 These tests were characterized by an atypiral temperature gradient within the bricks. During this quarter, the rig was modified to produce prototypic gradients, and the fourth $50 n-h$ test was initiated.

In the modified rig (Fig. 1), the bricks are provided with watercooled chills. Water temperature and flow are monitored so heat flux can be calculated. Standard $9 \times 4-1 / 2 \times(3,2)-i n$. wedge bricks are used (if wedges are not available, straights are cut to $f_{i t}$ ). The narrow ends of the bricks are exposcd to the slag. The wedges are cut to three different lengths so 
that three temperature gradients can be studied. Bricks of four compositions can be tested simultaneously. Each chill cools three bricks of one length and composition. The center brick is thereby shielded from the effects of neighboring bricks of different lengths and/or compositions.

The fourth test includes silicon carbide with three bond systems: (1) nitride bonded (number 91), (2) silicate bonded (number 93), and (3) oxynitride bonded (number 37). A silicon oxynitride (number 36) composition is also included. Thermocouples have been inserted in the center brick in each group of three at $12.7 \mathrm{~mm}(0.5$ in.), $38.1 \mathrm{~mm}$ (1.5 in.), $88.9 \mathrm{~mm}$ (3.5 in.), and $177.8 \mathrm{~mm}$ ( $7 \mathrm{in.}$ ), for full-length bricks, from the hot face (Fig. 2). To enhance heat transfer between the chills and bricks, a high thermal conductivity silicon carbide cement* mixed with a monoaluminum phosphate solutiont has been utilized. Thermal profiles in each of the brick types and lengths, prior to the addition of the slag, are shown in Fig. 3.

The slag composition utilized in the fourll Lest 15 simulated Montana Rosebud ( $\mathrm{Table} \mathrm{I}$ ). (The initially high $\mathrm{Fe}_{2} \mathrm{O}_{3}$ content resulted from a batching error and was corrected shortly after the test began.) The slag temperature was maintained at $\sim 1500^{\circ} \mathrm{C}$.

Task B -- Evaluation of Ceramic Coatings for Coal-conversion Plant:s (S. Danyluk, R. B. Poeppel, and G. M. Dragel)

Metallic specimens with partial or total coatings were exposed to high-velocity $(\sim 38 \mathrm{~m} / \mathrm{s})$ char particles at $980^{\circ} \mathrm{C}$ and a pressure of $240 \mathrm{kPa}$ $(35 \mathrm{ps} 1)$ for $3.6 \mathrm{Ms}(1000 \mathrm{~h})$. The coating materials and substrates are listed in Table II. The exposure was conducted in the ERDA-owned corrosionerosion furnace by Solar, Inc. The samples were shipped to $\Lambda \mathrm{NL}$ on March 11, 1977. Métallographlc investigation of the samp100 will be cunducted in the cumluy quarter.

Task C -- Application and Development of Nondesl:rucclve Evaluation Methods for Coal-conversinn Proceeces (W. A. Eliingson, W. J. Shack, and C. L. Johnsonl)

1. Erosive-wear Detection and Monitoring

a. Meta.11fr. Transfer Lines

(1) Laboratory Ultrasonic Studies. The erosive-wear data on the HYGAS cyclone separator, which was reported in Ref. 5, were analyzed to obtain estimates of the wear rate of the Stellite liner and the azimuthal. distribution of wear within the syclone.

The most severe wall-thickness reduction observed in the cyclone inlet region occurred along the inlet centerline. The azimuthal distribution of measurement locations along the centerline is shown in Fig. 4a. Bitter 6 has presented a qualitative argument to describe the distribution of erosive

*Carborundum Company, Keasbey, NJ.

+Mobil Chemical Company, Richmond, VA. 
wear in the elbow of a pipe (Fig. 4b). The results reported by Bitter suggest that maximum erosion for the cyclone should occur in the $20-50^{\circ}$ azimuthal range. The actual distribution of erosive wear for $\sim 1000 \mathrm{~h}$ of coal feed between February 1976 and June 1976 is shown in Fig. 5. Little wear is observed in the $20-50^{\circ}$ range. Actually, it is difficult to predict the pattern of wear a priori. As the modeling studies reported under Task $\mathrm{E}$ show, the distribution of particle impacts is a complex function of the fluid-flow properties and the particle size and density.

An average thickness loss for the Stellite lining can be obtained by averaging the measured values for positions ranging from $73-153^{\circ}$. This average value can then be plotted as a function of exposure time, 7 as shown in Fig. 6. In Fig. 6, the thickness loss at the time of the first measurement at $1 \times 10^{8} \mathrm{~s}(200 \mathrm{~h})$ was obtained by taking the difference between the measured thickness and the initial thickness. Since the value of the initial thickness could vary because of counterbore misalignment, differences in coating thickness, etc., the values of the total thickness loss shown in Fig. 6 are only approximate. The changes in thickness between measurements are independent of these errors, however, and thus the data shown in Fig. 6 can be used to estimate the wear rate (i.e., loss of thickness per day). A straight-line fit through the three data points gives a wear rate of $0.063 \mathrm{~mm} / 100 \mathrm{~h}$ for a nominal particle velocity in the cyclone of $14 \mathrm{~m} / \mathrm{s}$, a particle loading of $1.5 \mathrm{~kg} / \mathrm{acm}$ ( $\mathrm{acm} \equiv$ actual cubic meter of gas), and a cyclone operating temperature of $315^{\circ} \mathrm{C}$. Since the original thickness of the Stellite overlay was $3.2 \mathrm{~mm}$, the data indicate that the overlay will have an operating lifetime of $25000 \mathrm{~h}$.

report.

(2) Field Studies. Progress will be reported in the next quarterly

\section{b. Refractory-lined Transfer Lines}

(1) Gomma Radiogrophy Development. Previous work ${ }^{2-4}$ using gamma radiography to examine refractory-lined transfer lines has shown that this method can be used to define the bore and hence can be used to determine the extent of erosive wear. During this quarter, a set of radiographic images of the 502 Ash transfer line at the Battelle Agglomerating Ash gasifier were taken after $2200 \mathrm{~h}$ of solids $\left(\mathrm{Al}_{2} \mathrm{O}_{3}\right.$ particles) circulacton and compared with the initial images obtained in February 1976. Figure 7 shows the bore geometry before and after the 200-h exposure. Higure 8 is a schematic of the entire flow directional change system and shows that part for which the erosive wear data were obtained. It is interesting to note that the erosive wear on the outside radius of the inner bore could be expected, but the erosive wear on the inside radius of the bore would not. The inner surface wear was not caused by erosive wear due to particle impact of the normal flow but rather by the air-lift injection lines blowing normal stream particles into the wall. The transfer line is presently being recast, and baseline radiographic images of the complete section shown in Fig. 8 have been obtained for future examination.

The results of this radiography development program to date have shown that gamma radiographic imaging can be used to 
(a) Inspect refractory-lined transfer lines for bore definition.

(b) Inspect refractory-lined transfer lines for proper installation of air-lift line injections, including angle and wall thickness.

(c) Determine plugging of air-lift injectors.

(d) Determine time-dependent erosive wear of installed. refractory.

A more complete analysis of the erosive-wear data obtained to date will appear in the next quarterly report.

(2) Infrared Imaging -- Patterm Recognition. During this quarter, a study of the potential use of thermal patterns obtained by infrared imaging to determine erosive wear in refractory-lined transfer lines wao continued. This technique is needed to supplement the gamma-radiography development because of personnel problems encountered when the high-strength ( $8 \mathrm{i} 75 \mathrm{Ci}$ ) $60_{\mathrm{Co}}$ source is used. The passive infrared-imaging camera can be used at all times but requires an appropriate heat-transfer model. to allow calculation of the defect size trom the thermal patterns obtained. Analytical heat-transfer models were used to determine theoretical thermal patterns from synthesized cavity defects.

The structure being modeled is a cylindrical pipe with an inner refractory layer bonded to a steel shell. The boundary conditions imposed on the two surfaces consisted of a prescribed ourface teiuperature $\left(750^{\circ} \mathrm{C}\right)$ on the inside (hot) surfare and convoctive cooling on the outside surface. The computer model is being developed to study the heat transfer through the pipe under steady-state conditions.

The computer program was used to study thermal patterns in the four cases shown in Table III. Table III also shows the data used in the calculations. The selection of Case 2 permits assessment of the effects of the increase in the convective heat-transfer coefficient on thermal patterns due to, e.g., wind speed at test stte. Selection of Case 3 allows examination of the effecl of a refractory of lower thermal conductivity; the thermal conductivity of the steel shell is nearly invariant to minor composition changes and is therefore treated as constant in all cases. Finally, Case 4 was selected to determine the effect of changes in both the thermal conductivity and the convective heat-transfer coefficient.

Preliminary data showing the effect of changes in rectangular cavity size on the thermal patterns have been obtained. Figure 9 shows the temperature versus distance from the cavity centerline for several rectangular cavities when a steady-state temperature of $750^{\circ} \mathrm{C}\left(1500^{\circ} \mathrm{F}\right)$ is applied to the cavity side for the thermal conductivities, convective coefficients and refractory sizes listed in Table III. The data obtained from Fig. 9 suggest that the thermal distribution across the cavity can be modeled as a parabola. Figure 10 shows a rectangular cavity and a typical temperature distribution across the surface. From such an analysis, the temperature is 
available as a parameter for extraction and also (a) the integrated area $A$, (b) the span $W$ of any isotherm, and (c) the area change between selected isotherms. These features will be examined for applicability, and the most promising features will be used as the discriminating parameters for erosivewear calculations.

In the studies to date, the results show that the hot-spot temperature has been found to increase rapidly with an increase in the depth of the cavity (see x-intercepts of curves in Fig. 9). When the depth of the cavity increases from 62 to $68 \mathrm{~mm}$ for all widths, this hot-spot temperature increases by $\sim 400^{\circ} \mathrm{C}$. (The family of curves for the 68-mm-cavity depth lies outside the Fig. 9 region and is therefore not shown.) As mentioned above, the analysis given represents only preliminary studies. A more detailed investigation, which will include error analysis and additional parametric studies, is scheduled for the next quarter of work. Future studies will include the effect of contact resistance and implement the thermal-conductivity data being obtained in other ERDA/FE-sponsored programs.

\section{Refractory-installation Practices}

\section{a. Acoustic Emission}

Work has continued on the evaluation of the use of acoustic emission as a means to control the firing schedule of castable refractories. As previously reported, 4 an apparent correlation existed between the temperature internal to a thick refractory wall and the total acoustic-emission counts,
$\mathrm{N}$. This is not a totally unexpected result, since previous investigations have shown that selected acoustic-emission parameters can be used as discriminators between refractory types as well as a clear indication of imminent fracture. However, the intent of this program is to show that the final response of the refractory, i.e., lifetime and mechanical reliability, can be improved by following a heating schedule which minimizes the amount of crack damage the refractory undergoes during the actual firing schedule. This means that reliable acoustic-emission data must be obtained from refractory samples during curing to $1000^{\circ} \mathrm{C}$. Since commercially available acousticemission transducers have a maximum service temperature of $500^{\circ} \mathrm{C}$, an acoustic waveguide is necessary between the specimen and the sample. The acoustic coupling between the specimen and the waveguide is very critical because the acoustic energy released in the specimen (i.e., micro- and/or macrocrack formation) must be transferred to the waveguide. Presently available couplant material cannot be used above $300-400{ }^{\circ} \mathrm{C}$. Thus, an alternative coupling mechanism must be employed. Robinson et. al.8 employed spring-loaded mullite rods in direct contact with the specimen to obtain their results. During this quarter, we have employed embedded quartz waveguides, as shown in Fig. 11. The sample was supported in the furnace on knife edges made of high density, prefired refractory. The transducer was attached to a 25-mm-dia quartz cylinder that had been fused to the $6-\mathrm{mm}-\mathrm{dia}$ quartz waveguide. The waveguide was cast into the refractory sample such that $38 \mathrm{~mm}$ of waveguide were in direct contact with the sample. All samples studied this quarter were made of KAOTAB,*

\footnotetext{
*KAOTAB is a product of Babcock and Wilcox with a fired density of $2.4 \times 10^{3} \mathrm{~kg} / \mathrm{m}^{3}$.
} 
which had been cast with a water content of $12 \%$ so that significant cracking would occur. The cast samples were $25 \mathrm{~mm}$ wide $\times 25 \mathrm{~mm}$ high and $254 \mathrm{~mm}$ long. The cold and hot muduli of rupture, after being exposed to different firing schedules, will be determined. During this reporting period, all samples were cured with the controlled heat-up rates shown in Table IV.

One obvious variable is the capability to reproduce samples. Presently, the samples are prepared by using a Hobart mixer and vibrated on a shaker table for a fixed amount of time, typically 60-90 s. To ensure that the procedure did not permit segregation to occur, metallographic samples have been prepared from the "bar" specimens, as shown schematically in Fig. 14. The samples are vacuum impregnated with an epoxy solution and polished, yielding a clear distribution of particle size. Figures 15 and 16 show, respectively, typical results of a transverse section (3.4X) and a longitudinal section $(3.6 \mathrm{X})$. The transverse section shows no apparent segregated grain structure.

'Two samples were run simultaneously for statistical data variation. Figure 12 shows the total acoustic-emission count as a function of temperature for two castings run at the same heating and cooling rate but at different times. The data for castings 2 and 3 were averaged for the two samples run simultaneously. It is very interesting to note that, since the data were generated from the heating schedule shown in Table IV, significant counts do not accumulate until the maximum previous temperature has been exceeded. This was especially true when heating to $500^{\circ} \mathrm{C}$ after heating to $120^{\circ} \mathrm{C}$. Little activity was detected during the $1000^{\circ} \mathrm{C}$ run. Figuree $13 \mathrm{a}-\mathrm{C}$ are plots of counts versus time, and the temperature ramp is superimposed for ease of interpretation. Note that, during cooling from $1000^{\circ} \mathrm{C}$, a significant increase was detected, which was probably the result of damage caused by the severe cooling rate. This suggests that controlled cool-down shnuld bo conoidered just ao controlled heat-up. An increase in acoustic activity was detected in the 120 and $500^{\circ} \mathrm{C}$ cool-down cyciles, although not to the same extent.

Al1 data reported herein were obtained using a $175-\mathrm{kHz}$ resonant transducer with a band-pass filter of $125-250 \mathrm{kHz}$. Also, data have been taken with a $375-\mathrm{kHz}$ center-frequency transducer, and the comparison will be reported next quarter.

'The embedment of the quarta waveguide in the refractory gives rise to the question of whether the acoustic-emission detected is from rubbing noise caused by differences in thermal expansion or from the curing of the refractory, i.e., water evaporation, microcracking or phase transformations. In an attempt to determine whether the detected acoustic activity was caused by rubbing of the waveguide by the refractory, a two-mimensional locating system was employed with waveguides coupled to each end of the specimen. Specimens were cast and acoustic data and location information were obtained. The data show that the acoustic activity is uniform over the length of the specimen, implying that the effect of the embedded waveguide was not significant. A more complete analysis will be given next quarter. 


\section{Component Inspection}

\section{a. Infraied Thermal Profiling of Valves}

In the development of a valve-testing program for coal-gasification systems, one important objective of the program is to verify that the valve can operate satisfactorily at high temperatures. To obtain a valid test, the heating in the tests must be accomplished in a manner that simulates actual thermal gradients, thermal stresses, and internal temperatures. Unfortunately, the temperature fields within valves in actual service are not well known, since it is difficult to make direct temperature measurements. Modeling studies are useful, but uncertainty always exists in the choice of heat-transfer coefficients, and direct confirmation by experimental techniques is desirable. During this quarter, infrared scans were made on a number of valves at the Morgantown Energy Research Center low-Btu gasification facility in an attempt to obtain direct in-situ thermal profiles.

The valves examined were the top cyclone lockhopper valve (a 6-in. full-port ball valve, MERC valve number 060), Fig. 17a, the top ash 1ockhopper valve (a 12-in. full-port ball valve, MERC valve number 1207), Fig. 17b, and the north bottom coal lockhopper feed valve (a 10-in. full-port ball valve, MERC valve number 1002), Fig. 17c. Reference temperatures were measured on each of the valves using a contact pyrometer, as shown in Fig. 18.

The infrared scanning system used was an AGA Thermovision Model 750 , a lightweight completely portable system designed for field use. It is basically a scanning camera designed to detect emissions in the 2 to 5- $\mu \mathrm{m}$ wavelength infrared spectrum rather than the visual spectrum. The resultant image is displayed on a black and white television monitor and a picture of the object is produced where darker portions correspond to cooler sections of the object and lighter portions correspond to warmer sections of the object. The temperature range spanned by the thermal picture can be selected by the operator. Quantitative temperature measurements are made by knowing a reference temperature at one point and then using available calibration curves to identify isothermal regions (i.e., areas of equal temperature) above and below the known temperature. The isothermal regions correspond to equal tones of gray. The system enables the isothermal regions to be readily identifled by superposing brightened isothermal areas on the thermal picture. The isotherm level (i.e., the isothermal area selected for brightening picture (see, e.g., Fig. 19). The ten divisions of the scale represent fractions of the temperature range spanned in the picture. A quantitative relation between the isotherm level and the temperature can be determined by using the calibration curves for the instrument.

A sequence of thermal pictures of the ash-removal valve, with the isotherm level varied to identify different isothermal areas, is shown in Fig. I $(9-g)$. The temperature range from the hottest to the coldest part is $\sim 11^{\circ} \mathrm{C}$. Not only are the surface thermal gradients small, but the actual surface-temperature levels [maximum temperature $264^{\circ} \mathrm{C}\left(147^{\circ} \mathrm{F}\right.$ )] are surprisingly low. A second sequence of pictures at a narrower temperature range is shown in Fig. 20a-e. At this temperature range setting, it is impossible to scan the entire valve body, but greater detail and resolution are possible over a porllun of the body. 
Thermal pictures of the coal-feed lockhopper valve are shown in Fig. $21 a$ and $b$. Although the camera is set on a sensitive range (nominally $2^{\circ} \mathrm{C}$ ), little temperature varlation can be observed; the "hot spots" visible in Fig. $21 b$ are $<2^{\circ} \mathrm{C}$ hotter than the remainder of the valve body. The actual temperature of the hot spot is $37^{\circ} \mathrm{C}\left(98^{\circ} \mathrm{F}\right)$, as measured with a contact py rometer.

The infrared scans of the top cyclone lockhopper valve are shown in Fig. 22a-e. The reference temperature on the upstream side of the valve was measured as $60^{\circ} \mathrm{C}\left(140^{\circ} \mathrm{F}\right)$ with the contact pyrometer. As indicated in Fig. 22a, little temperature variation occurs over the upper and lower halves of the valve (i.e., they appear in the picture as a uniform gray tone), although the flanges appear slightly cooler, i.e., a darker gray tone. Because the temperatures were so uniform when the isotherm level was adjusted to brighten isothermal areas, it was difficult to obtain properly expused pictures for: a permanent record. When the shutter speed was increased, it was possible to obtain Fig. 22b. The high shutter speed decreases visual resolution because the faster speed captures the raster lines of the scanning camera. It is clear from the picture, however, that the upper and lower housings of the valve are quite uniform in temperature. The flange was examined separately at a more sensitive range $(=5)$; as Fig. $22 \mathrm{e}$ shows, the flange is also nearly isothermal.

It should be noted that variations in emissivity are not significant for the valves examined. The painted surface of the top cyclone was in good condition, but the surfaces of the other valves were more weathered. Painted surfaces and oxidized surfaces have emissivities close to the ideal blackbody value $(=1)$ assumed in the calculation of the temperatures from the infrared data. A few new bright metal scratchee were visible on the top cyclone lockhopper valves, which gave spurious readings because of the low emlssivity of brightly polished metal.

The thermal profiles obtained for the three valves are eimilar in character. The surface temperatures were rather low, and no significant thermal gradients were observed.

It is tempting to conclude that this implies the only significant temperature gradients in the valves are through the thickness of the body. However, the use of infrared techniques for the analysis of temperature variations in compact, thick-walled objects constructed from materials of high thermal conductivity is not well developed, and some comparisons with our modeling studies must be made before any firm conclusions can bc drawn.

b. Acoustic Munitor1ng of Valves

(1) Valve Ireak Detection by Acoustic Emission. Field testings of an acoustic-emission valve leak-detection system was carried out at the MERC low-Btu coal-gasification facility and the Synthane high-Btu pilot plant. The objectives of the field measurements were to investigate the sensitivity of the acoustic-emission measurements to the background "noise" present in an operating coal-gasification facility and to determine whether leakage indications could actually be obtained on in-service valves. 
The acoustic-emission system used for the field tests consisted of an AET Model 140A preamplifier, an AET Model 201 single-channel processor, and a HP 3475B digital multimeter. A Tektronix Mode1 314 portable oscilloscope was used to visually monitor the acoustic-emission signals. Three transducers were examined: AET Models 175L, 375L, and 750L. These are resonant-response transducers with peaks at 175,375 , and $750 \mathrm{kHz}$, respectively.

Tests were run on the top cyclone lockhopper valve (a 6-in. fullport ball valve), the top ash lockhopper valve (a 12-in. full-port ball valve) and the north bottom coal feed lockhopper valve (a 10-in. full-port ball valve) at MERC. In addition, measurements were made on structural members in an attempt to distinguish between a "local" flow noise generated by a leaking valve and general background structure-borne noise associated with the overall operation of the gasifier.

The top cyclone valve is, in the opinion of MERC personnel, a "good" valve with very little leakage. Acoustic-emission data were taken at five points on the valve body and at two points on the gasifier structure near the valve. The measurement points on the valve are indicated in Fig. 23a-e. The measurement points on the nearby structure are indicated in Fig. $24 \mathrm{a}$ and b. The measurements taken with the $175-\mathrm{kHz}$ resonance transducer are listed in Table V. The AET 201 processor and preamplifier combination were adjusted to amplify the signals detected by the transducer by $80 \mathrm{~dB}$. The valves given in Table $\mathrm{V}$ are root-mean-square (rms) acoustic-emission. outputs. The readings, in the column labeled "noise" are rms voltages due to electrical system noise and airborne noise. Although the 175-kHz transducer is a shear-wave-type device, it did appear to detect sound waves (i.e., dilatation waves) at the high gain used. The values shown in Table $V$ indicate that acoustic-emission signals could be detected on the valve and these signals are not simply general structure-borne noise. It is not clear that the signals can be attributed to leakage through the valve. MERC personne1 ${ }^{11}$ have suggested that the signals could be due to acoustic-emissions generated by particles striking the cyclone.

The measurement locations for the top ash lockhopper valve are shown in Fig. 25a-e. The acoustic-emission measurements are summarized in Table VI. The system gain was again $30 \mathrm{~dB}$. The measured values showed large fluctuations in contrast to the measurements on the top cyclone lockhopper valve. Again, the acoustic emissions detected in the vicinity of the valve are significantly higher than the background noise detected on a nearby structure.

The measurement locations for the north bottom coal-feed lockhopper valve are shown in Fig. 26a-c. Acoustic-emission measurements on this valve were made with $176-$ and $375-\mathrm{kHz}$ transducers. The results of the measurements are shown in Table VII. Again, the signals fluctuated rapidly over a rather wide range. The amplitude of the signal produced by the $375-\mathrm{kHz}$ transducer is substantially smaller than that produced by the $175-\mathrm{kHz}$ transducer. If the signal is actually produced by gas leakage, it is in agreement with our laboratory studies, which show the emitted acoustic signals produced by turbulent flow through an orifice or leak decrease with an increase in frequency. Huwever, the decrcase can also be explained by the increase in attenuation with frequency of structure-borne nolse. 
Acoustic-emission measurements were also made at the Synthane Pilot Plant. The valves examined here were the north and south lower Petrocarb feed valves, which are located between the lockhoppers and the primary injection system. Although the audible noise level at the Morgantown and Synthane installations seems to be similar, much more difficulty was encountered at Synthane with stray airborne noise. The $175-\mathrm{kHz}$ resonant transducer was particularly affected. With the system gain at $80 \mathrm{~dB}$ and the transducer simply exposed to the air, readings ranged from $0.170 \mathrm{~V}$ (the transducer held at arm length outside the structure) to $1.0 \mathrm{~V}$ (in the interior of the gasifier structure). A leak from a gasket below the south valve was audible; extraordinarily large readings were obtained from the flange areas near the leak, and it seems likely that the leak also produced a large amount of airborne high-f requency noise.

The measurement locations for the north valve are shown in Fig. 27a-e, and the results of the noise measurements for the 176,375 , and $750 \mathrm{kHz}$ transducers are summarized in Table VITT. Again, $2 x$ expoctcd, the 175-kHz Lransducer is a more sensitive detector of structure-borne sound; according to Synthane personnel, it is likely that some leakage occurred in these valves, however, it is not certain at this time that leakage was, in fact, the source of the structure-borne sound detected.

The measurement locations on the south feed valve and nearby structural components are shown in Fig. 28a-e. On the south coal-feed valve, a gasket between the valve and the primary injection system was leaking. This type of leak is similar to a valve leak in that it involves a gas flow from high pressure to low pressure through a small orifice. Of course, the gasket leak is audible because the sound is free to radiate, but the structure-borne signals due to the gasket leak should be similar to. those produced by an inLerilal valve leak. 'l'he leak was near the location shown in Fig. 78 . . The acoustic-emission measurements are summarized in Table IX. A11 three transducers were able to lorate the leak near mcasurement localiun (c). However, the 175- and 375-k.Hz transducers aleo picked up considerable alr and structureborne noise, althnigh the $375 \mathrm{kHz}$ transducer was much less sensitive in this regard. The 750-kHz transducer seems totally unaffected by airborne noise. It was alsu sufficiently sensitive to identify the leak on the south valve; however, it is still uncertain whether it is sufficiently sensitive to detect the smallest leaks of interest.

These results suggest that to develop a leak-detection system for use in an operating gasification plant, $375-750 \mathrm{kHz}$ is a desirable operating range; certainly, transducers operating at $<175 \mathrm{kHz}$ (e.g., low g-level accelerometers) seem unsuitable for such systems. Although the acoustic noise generated by a leak is broadbanded with frequencieo ranging from $1 \mathrm{kHz}$ to $1 \mathrm{MHz}$, most of the energy appears to be concentrated below $150 \mathrm{kHz}$, thus, an unavoidable trade off occurs between sensitivity and immunity to background noise. Additional signal processing can, to a certain extent, overcome this problem. To develop a workable system, additional tests will be needed on full-size valves with known leak rates. The MERC valve test facility has the capability to monitor flow rates through full-size valves, and MERC personnel have expressed their desire to cooperate in performing additional tests using their facility. 
quarterly report.

(2) Laboratory Studies. Progress will be reported in the next

Task D -- Corrosion Behavior of Materials in Coal-conversion Processes

The objectives of this program are to (I) develop uniaxial tensile data on four selected commercial alloys upon exposure to simulated multicomponent gas environments, (2) experimentally evaluate the high-temperature corrosion behavior of iron- and nickel-base alloys in gas environments with a wide range of oxygen, sulfur, and carbon potentials, and (3) develop a systems approach based upon available thermodynamic and kinetic information so that possible corrosion problems in different coal-conversion processes can be evaluated.

The experimental program that involves generation of uniaxial tensile data on four selected alloys upon exposure to the multicomponent gas environments has been discussed in detail in an earlier report. 4 As a consequence of the severe corrosion rates that have been observed at hightemperatures $\sim 1010^{\circ} \mathrm{C}\left(1850^{\circ} \mathrm{F}\right)$ in the IIT Research Institute program, the temperatures for the exposure of tensile specimens in the present program have been lowered to $750^{\circ} \mathrm{C}\left(1380^{\circ} \mathrm{F}\right), 871^{\circ} \mathrm{C}\left(1600^{\circ} \mathrm{F}\right)$, and $982^{\circ} \mathrm{C}\left(1800^{\circ} \mathrm{F}\right)$. Preliminary corrosion experiments were conducted at $875^{\circ} \mathrm{C}$ for $25-$ and $200-\mathrm{h}$ durations using gas mixture No. 1 , the composition of which is listed in Table $X$. The oxygen, sulfur, and carbon potentials that correspond to the selected gas mixture for a reaction temperature of $875^{\circ} \mathrm{C}$ were calculated using the computer program and are also listed in Table $\mathrm{X}$. These experiments were conducted to establish the type and thickness of corrosion-product scale (oxide versus sulfide) that forms upon exposure to the selected complex gas mixture prior to the exposure of uniaxial tensile specimens for a 1000-h time period in the same environment. Apart from the four alloys selected for tensile property evaluation, four additional alloys were included in the corrosion experiments. The chemical compositions of the alloys are listed in Table XI. The experiments were conducted in a corrosion testing rig, the details of which were reported earlier. 5

Figure 29 shows macroscopic photographs of the corrosion specimens after 25- and 200-h exposures to the gas environment at $875^{\circ} \mathrm{C}$. The samples from both' experiments were examined using optical metallography, and the phases present were identified using a scanning-electron microscope (SEM) equipped with an energy-dispersive $x$-ray analyzer. Extensive analyses were made on specimens of Type 310 stainless steel, Incoloy 800 , Inconel 671 , and U. S. Steel alloy 18-18-2 during this quarter. Figure 30 shows the $x$-ray image of the iron specimen and the Fe and $S$ distribution in the scale/alloy interface region of the sample after a 26-h exposure. The scale is predominantly iron sil.fide, which indicates that the sulfur potential established in these experiments was higher than that for the $\mathrm{Fe} / \mathrm{FeS}$ equilibrium. A similar behavior was observed for iron exposed for $200 \mathrm{~h}$ at $875^{\circ} \mathrm{C}$. Figures $31-34$ are $x$-ray photographs showing the specimen image, metallic element ( $\mathrm{Cr}, \mathrm{Ni}, \mathrm{Fe}, \mathrm{Si}$, and $\mathrm{Al}$ ) distribution, and sulfur distribution in the scale/alloy interface regions of the samples of Type 310 stainless steel, Incoloy 800, Inconel 671, and U. S. Steel alloy 18-18-2, respectively, after a $25-h$ exposure to the gas environment at $875^{\circ} \mathrm{C}$. The photographs clearly 
indicate the presence of sulfur in the scale region in all the alloys, although the chromium content of the alloys ranges from 18 to $48 \mathrm{wt} \%$. The thickness of the scale layer is in the range of 10 to $25 \mu \mathrm{m}$ in these specimens after a 25-h exposure. Intergranular penetration of sulfur in the alloy regions is minimal in these specimens. Based upon the oxygen and sulfur potentials calculated for the gas composition listed in Table X, only the oxide layer should be observed in iron- and nickel-base alloys containing $>18 \mathrm{wt} \% \mathrm{Cr}$ upon exposure to this gas environment. Since the apparatus had been used earlier for experimental runs with high partial pressures of sulfur, it is possible that the sulfur from the reactor walls may be contributing to the sulfidation of the alloys. As a result, the reactor chamber was fired with hydrogen for $50 \mathrm{~h}$ at $875^{\circ} \mathrm{C}$, and subsequently another experiment was made with the same alloys exposed to the same gas environment for $200 \mathrm{~h}$.

Figures 35-37 show the $x$-ray specimen images, metal1ic element distributions, and the sulfur distribution in the scale/alloy interface regions of the samples. of Type 310 stainless steel, Incoloy 800 , and U. S. Steel alloy 18-18-2, respectively, after a 200-h exposure to a gas environment at $875^{\circ} \mathrm{C}$. Figures 38 and 39 are SEM photographs of the scale/alloy regions in specimens of Inconel 671 and U. S. Steel alloy 18-18-2 after a 200-h exposure to the gas environment at $875^{\circ} \mathrm{C}$. Figures $35-39$ show that in all the alloys, except U. S. Steel alloy 18-18-2, the scales werp predominantly chromium-rich oxide and sulfur was essentially absent, which indicates that the mode of interaction is oxidation rather than sulfidation in this particular environment. This observation is in excellent agreement with the calculated partial pressures for oxygen and sulfur in the gas mixture and the thermochemical diagrams for different $\mathrm{Fe}-\mathrm{Cr}-\mathrm{Ni}$ alloys. In the case of U. S. Steel alloy 18-18-2, the scale was predominantly chromium and iron sulfide (Fig. 39), and the alloy/scale interface had a large concentration of silicon. It seems that the silicon at the interface lowers the oxygen potential sufficiently to change the type of interaction from an oxidation to a sulfidaliun mode. S1licon enrichment at the scale/alloy interface was also observed in Type 310 stainless steel and Incoloy 800 , but no deleterious effect due to silicon was observed in these alloys. The Silicon concentration in Type 310 stainless steel and Incoloy 800 is in the range of 0.35 to 0.40 wt $\%$ and is 2.05 wt $\%$ in U. S. Steel alloy 18-18-2. Since the two former alloys behave differently than the U. S. Steel alloy, it is essential to establish the role of alloy additions such as silicon on the protective scale formation upon exposure to multicomponent gas environments. During the next quarter, uniaxial tensile specimens of the selected alloys will be exposed for $1000 \mathrm{~h}$ to the gas mixture with the composition listed in Table $\mathrm{X}$.

The experimental program is being continued to evaluate the corrosion behavior of iron- and nickel-base alloys in gas environments with a wide range of oxygen, sulfur, and carbon potentials. The composition of the alloys selected for this phase of the program is given in Table XI. Figure 40 shows the macroscopic photographs of specimens of different alloys that have been exposed for $25 \mathrm{~h}$ at $750^{\circ} \mathrm{C}$ to gas environments that contained the same sulfur potential $\left(2.8 \times 10^{-8} \mathrm{~atm}\right)$ but different oxygen potentials. The partial pressure of oxygen was varied from $1 \times 10^{-20}$ to $4.2 \times 10^{-23}$ atm (from left to right in Fig. 40). A macroscopic photograph of different specimens exposed for $25 \mathrm{~h}$ at $875^{\circ} \mathrm{C}$ to several oxygen pressures between $1.9 \times 10^{-18}$ and $1.7 \times 10^{-20}$ atm is shown in Fig. 41. The oxygen, sulfur, and 
carbon potentials established in these experiments are listed in Table XII. It is evident from Figs 40 and 41 that the mode of interaction changes from oxidation to sulfidation as the oxygen potential decreases (from left to right in Figs. 40 and 41). Iron specimens formed iron sulfide scales in all instances, which indicates that the partial pressure of sulfur in these experiments was larger than that established by $\mathrm{Fe} / \mathrm{FeS}$ equilibrium. At $875^{\circ} \mathrm{C}$, the Inconel 671 specimen that was exposed to the lowest oxygen pressure showed the formation of liquid nickel sulfide upon exposure to the environment (the rightmost specimen of Inconel 671 in Fig. 41).

The samples of Type 310 stainless steel, after exposure to different gas environments listed in Table XII, were examined with the SEM equipped with an energy-dispersive x-ray analyzer. Figures $42 a-c$ are photographs of cross sections of specimens exposed at $750^{\circ} \mathrm{C}$ and oxygen pressures of $1.0 \times 10^{-20}, 2.4 \times 10^{-21}$, and $4.1 \times 10^{-22} \mathrm{~atm}$, respectively. The SEM photographs of a specimen exposed to an oxygen pressure of $4.2 \times 10^{-23}$ atm are shown in Fig. 43. (identified as d). The sulfur partial pressure in these experiments was $22.8 \times 10^{-8}$ atm. Figure $42 a$ and $b$ shows that specimens develop predominantly Cr-rich oxide scales, the thicknesses of which were approximately 2 to $4 \mu \mathrm{m}$. The alloy specimens also developed some internal sulfide particles to a depth of 3 to $8 \mu \mathrm{m}$. The specimens in Figs. $42 \mathrm{c}$ and 43 developed $(\mathrm{Cr}, \mathrm{Fe})$ sulfide scales, the thicknesses of which were 50 and $210 \mu \mathrm{m}$, respectively. The internal sulfidation and intergranular penetration of sulfur were also significant in the specimens shown in Figs. 42c and 43 . The thicknesses of the internally affected zones in these specimens were 40 and $150 \mu \mathrm{m}$, respectively.

Figure 44 shows SEM photographs of Type 310 stainless steel samples that have been exposed at $875^{\circ} \mathrm{C}$ for $25 \mathrm{~h}$ to mixed gas environments with the following partial pressures of oxygen: $1.9 \times 10^{-18}, 5.5 \times 10^{-19}$, $2.4 \times 10^{-19}$, and $1.7 \times 10^{-20}$ atm. The sulfur partial pressure in these experiments was $2.9 \times 10^{-7}$ atm. The figure shows that the specimens develop 5- $\mu \mathrm{m}$-thick $\mathrm{Cr}$-rich oxide scales at all oxygen potentials, except at $1.7 \times 10^{-20}$ atm where an $210-\mu m-t h i c k(\mathrm{Cr}, \mathrm{Fe})$ sulfide scale was observed. The thickness of the internal sulfidation zone was in the range of 20 to $40 \mu \mathrm{m}$ in specimens that developed oxide scale. The thickness of the internal sulfidation and intergranular penetration zone in the specimen exposed to the lowest oxygen pressure was $\sim 170 \mu \mathrm{m}$. It is evident from these results that the chemical interaction between an alloy of a given chemical composition and the gas environment is strongly dependent on the oxygen and sulfur potentials that are prevalent in the environment. The results also show that the growth rates of the sulfide scales are larger than those of oxides, and the extent of intergranular penetration of sulfur is significantly greater when the alloys do not develop oxide scales. Additional experiments are being conducted to evaluate the kinetic aspects of scale formation and the influence of alloy chemistry on the interaction processes between. materials and complex gas environments.

Steam is one of the major oxidizing species in multicomponent gas environments in different coal-gasification processes. The steam content in the gas mixtures can range from 14 vol \% in the Battelle-Union Carbide process to 52 vol \% in the Bi-Gas process.12,13 As a result, it is essential 
to establish the role of steam on the oxidation-sulfidation behavior of materials. This can be accomplished by the exposure of materials to gas mixtures with the same oxygen, sulfur; and carbon potentials that are established with and without steam in the gas mixtures. Such a comparison would also establish the degree to which a thermodynamic equilibrium is achieved at the test temperature by the reactions of different molecular gas species employed in the experiments. For this purpose, two experiments were conducted in which the same oxygen, sulfur, and carbon potentials were established by mixing various gas species of $\mathrm{CO}, \mathrm{CO}_{2}, \mathrm{H}_{2}, \mathrm{CH}_{4}, \mathrm{H}_{2} \mathrm{~S}$, and $\mathrm{H}_{2} \mathrm{O}$. The established gas compositions are listed in Table XII (colums 7 and 10 indicated by the arrows at the bottom of the table). In one run, a steam content of 8.6 vol.\% was used, whereas no steam was used in the other rup. Oxygen and sulfur partial pressures in both experiments were $25.5 \times 10^{-1} 9^{\circ}$ and $\sim 2.9 \times 10^{-7}$ atm, respectively, and the carbon activity was 0.070 . Type 310 stainless steel specimens that were exposed for $25 \mathrm{~h}$ at $875^{\circ} \mathrm{C}$ in these two experiments were examined with SEM. X-ray images for the distribution of metallic elements and sulfur in the scale/alloy interface regions of the specimens were also obtained. Figures 45 and 46 show the specimen image and $x$-ray distribution of elements for the samples exposed in environments without steam and with steam, respectively. The figures show that the scales in both specimens are predominantly $\mathrm{Cr}$-rich oxide and some internal sulfidation occurred. The thickness of the oxide layer is $\sim 2$ to $3 \mu \mathrm{m}$. Silfonn enrichment at the scale/alloy interface is observed in both specimens. From these results, it can be concluded that steam is not an essential component to establish the corrosion behavior of an alloy as long as the same oxygen, sulfur, and carbon potentials are simulated by adjusting the relative amounts of different molecular gas species.

Task E $-\frac{\text { Erosion Behavior of Materlals in Coal-converoion Processes }}{(W, J . \text { Shack) }}$

To Lulerpret and compare erosion data being generated in the field tests at Synthane and $B i-G a s$ with laboratory data, it is necessary to estimate the cocal flux of particles actually striking the wall. Similarly, when using experimental data to decide whether a specific material has adequate erosivewear resistance in a particular application, knowledge of the flux of particles onto the material, their velocities, and the impingement angle is required. It is difficult to estimate these quantities in actual flow situations. During this quarter, some preliminary modeling studies were begun in order to study the dependence of the particle flux on the properties of the gas flow for geometries similar to the elbow in the Synthane main coal-feed line.

A brief literature review of previous work in the two-phase flow of particles and gases was made. Much of this work (see, e.g., Refs. 14-17) is concerned with the calculation of quantities (pressure drops, saltation velocity, choking velocity, etc.) that are required for the overall design of pneumatic or hydraulic conveying systems and not with the detailed study of particle flow patterns necessary to determine erosive-wear patterns. A rather sophisticated treatment of particle-flow interactions is available for low Reynolds number flows (see, e.g., Ref. 18), but this theory is inapplicable to the high Reynolds number flows typically found in coal-gasification plants. 
Similarly, models have been developed to describe the behavior of finely dispersed gas-particle systems; these are useful in studies of air pollution ${ }^{19}$ and aerosol systems 20 but of little relevance to the flows encountered in coalgasification systems.

The problem of analyzing fluid-particle flows is greatly simplified if it is assumed the particles do not affect the fluid-flow field but that the fluid is responsible for the motion of the particle. This "one way" coupling is in reality valid only if the particle loading is small, but may be a useful approximation when analyzing local flow fields. This approach was originally developed 21,22 to describe water droplet impact and icing of aircraft, but was also used in Ref. 23 to study the interaction of particle-fluid flow and erosive wear. Models have been developed that describe a genuine "two way" particle-fluid interaction. 24,25 The formulation in Ref. 24 is especially effective, because it is amenable to numerical solution by the wellknown "tank and tube" approach developed by Spalding and co-workers. 26 Thus, stable numerical solutions can be obtained even for large Reynolds numbers. The model developed in Ref. 24 has been used to analyze the flow field in an axial-inlet peripheral-discharge cyclone separator. 27

Because of its simplicity, it was decided to first examine fluidparticle interactions using the uncoupled particle-flow model. In this case, the flow pattern is calculated ignoring the presence of the particles, and the particle trajectories can then be calculated by considering the fluid loadings on the particle. The equations of motion for the particle can be " written

$$
\frac{d V_{x}}{d t}=-\rho \frac{C_{D}^{A}}{2}|\underset{v}{V}-\underset{d}{U}|\left(V_{x}-U_{x}\right)
$$

and

$$
m \frac{d V_{y}}{d t}=-\rho \frac{C_{D} A}{2}\left|V-U_{v}\right|\left(V_{y}-U_{y}\right) .
$$

Here $V_{x}, V_{y}$ and $U_{x}, U_{y}$ and the $x, y$ components of the particle and fluid velocities, respectively; $m$ is the mass of the particle; $\rho$ is the fluid density; $C_{D}$ is the drag coefficient for the particle; $A$ is the projected area of the particle; and $|\downarrow-V|$ is the absolute magnitude of the vector difference between the particle velocity and the fluid velocity, where

$$
|\mathrm{X}-\mathrm{U}|=\left[\left(\mathrm{v}_{\mathrm{x}}-\mathrm{U}_{\mathrm{x}}\right)^{2}+\left(\mathrm{v}_{\mathrm{y}}-\mathrm{u}_{\mathrm{y}}\right)^{2}\right]^{1 / 2}
$$

The drag coefficient. $C_{D}$ is a function of the Reynolds Number $R$

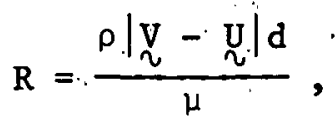


where $d$ is a typical particle diameter, and $\mu$ is the viscosity of the fluid. The drag coefficient can then be calculated from the empirical relation

$$
C_{D}=24\left(1+0.197 \mathrm{R}^{0.63}+0.00026 \mathrm{R}^{1.38}\right) / \mathrm{R}
$$

given in Ref. 22. From eqs. (1)-(5), it can be shown that the characteristic "lag" time, i.e., the time it takes for a particle placed in a fluid stream to acquire the fluid velocity, is.

$$
t_{I}=\frac{1}{18}\left(p_{p} d^{2}\right) / \mu
$$

where $p_{p}$ is the density of the particle. This can be compared with the transit time $t_{T}$ for fluid particles, For example, for an elbow,

$$
t_{T}=\pi r / 4 U_{0}
$$

where $r$ is the radius of the elbow, and $U_{0}$ is a typical fluid velocity. The ratio of these two times yields a dimensionless group (an "erosion number")

$$
E=t_{T} / t_{L}=(9 \pi \mu r) /\left(\rho_{d_{o d}}{ }^{2}\right)
$$

which can be used to characterize the fraction of the fluid particles that lapact onto the wall. If $\vec{E} \gg 1$, little particle impact and scour occurs; if $\mathrm{E} \ll 1$, virtually all the particles carried by the fluid stream will impact the wall. Unfortunately, it is impoosible to oblain expllclely the function $f(E)$, which describes the fraction of particles scouring the wall in terms of E. However, by actually carrying out the numerical calculations, it should be possible to develop simple equations for $f(E)$ for some practical geometries such as the $90^{\circ}$ elbow and the $45^{\circ}$ sweepline geometry. Such design formulas will be presented in the next quarterly.

The effect of particle size on the fraction is illustrated by the particle trajectories shown in Fig. 47a-c, which were calculated by numerical integration of Eqs. (1) and (2). The flow conditions and geometry are similar to those in the Synthane main coal-feed line. The particle diameters are $10 \mu$ (Fig. 47a), $100 \mu$ (Fig. 4 h), and $1000 \mu$ (Fig. 47c). The influence of particle size on the fraction of particles actually impacting the p1pe wall is readily apparent.

In the next quarter, (a) more extensive calculations will be carried out to develop simple furmulas for use by designers to estimate the fraction of the particles actually striking the pipe walls, (b) the fluid-particle model will be coupled with the erosive-wear equations developed in Ref. 4 to predict the wear patterns for the Synthane and Bi-Gas main coal field lines, and (c) 
work will begin on a more sophisticated fully coupled fluid-particle model that can be used to check the validity of the simpler analyses and to analyze more complicated flow situations such as the "blocked-tee" geometry utilized at Bi-Gas. Task F -- Component Performance and Faflure Analysis (S. DanyZuk, G. M. DrageZ,

The activity during the quarter involved the examination of components from the Morgantown Energy Research Center high-pressure gas producer (rabble arm), the HYGAS pilot plant (alonized coupons), and the Synthane pilot plant (steam line). Final reports summarizing the results of the investigations of these components will be issued in the coming quarter. A summary of these aralyses is given below. Three final reports have been issued: "EBV Bal1valve Stem Failure -- Synthane Coal-gasification Pilot Plant," "Analysis of the Gate-valve Failure -- Grand Forks Energy Research Center Fixed-bed Slagging Gasifier Pilot Plant," and "Failure Analysis of the Thermocouple Assembly in the HYGAS Coal Pretreatment Vessel."

\section{Analysis of Cracks in the ERDA-MERC Rabble Arm}

A vertical water-cooled stirrer and rabble arm from the Energy Research and Development Administration -- Morgantown Energy Research Center (ERDA-MERC) developed cracks at weld fusion lines and at the OD of the carbon steel pipe that is used in the stirrer construction. A schematic of the stirred-bed gasifier is shown in Fig. 48. The stirrer (agitator) is rotated and moved up and down to mix air, steam, and coal and to minimize ash and coal agglomeration. A schematic of the lowest section of the rabble arm is shown in Fig. 49. The arm is assembled by welding carbon steel pipe and fitting it to the central shaft.

Cracks developed because of stress corrosion and possibly crevice corrosion. The corrosion scale cracked, detached from the base metal, and did not provide protection against subsequent attack. A series of photographs of an as-polished crack is shown in Fig. 50. These photographs show the cracked corrosion scale and the blunted crack tip representative of pitting corrosion. A series of photographs showing the electroetched crack morphology is shown in Fig. 51. The crack-tip morphology suggests corrosion attack. Electronmicroprobe analysis showed that the corrosion scale was rich in sulfur, which probably participated in the corrosion process. Slag inclusions were observed in the weld metal but were not related to the cracking. The causes of the cracking are as follows: local surface inhomogeneities such as the heataffected-zone next to the weld bead; loss of passivity due to mechanical rupture of the protective oxide coating; residual stresses due to weld shrinkage; and stresses induced at the OD of the rabble arm due to rotation.

A recommendation was made to change the construction design of the stirrer and not weld the pipes together. If welding is necessary, then the arm should be annealed to remove the welding residual stresses. Also, an austenitic stainless steel with a chromium content of $>17 \%$ would resist the hightemperature corrosion better than the low-carbon steel. 


\section{Alonized Coupons from the HYGAS Pilot P1ant}

Coupons of alonized Type 316 stainless steel and Type 446 stainless steel were exposed to the HYGAS ash-agglomerating gasifier (AAG) environment for $20.13 \mathrm{Ms}(36 \mathrm{~h})$ and $1.04 \mathrm{Ms}(288 \mathrm{~h})$. The approximate bed temperature was $1038^{\circ} \mathrm{C}\left(1900^{\circ} \mathrm{F}\right)$ and the product gas composition was $31 \% \mathrm{CO}, 7.7 \% \mathrm{CO}_{2}, 15 \% \mathrm{H}_{2}$, and $46.3 \% \mathrm{~N}_{2}$. The approximate sulfur content of the feed is $3 \%$ FMC char and $0.5 \%$ coke. The intent was to examine the effeciveness of alonizing in inhibiting corrosion. After removal from the gasifier, cross sections of the coupons were polished and examined by optical microscopy and with the electron microprobe to measure the extent of the penetration of corrosion scale. In addition, specimens were machined from the coupons and fractured in an ultrahigh vacuum system and examined by Auger electron spectroscopy. These data are used to examine the extent of grain-boundary penetration by sulfides, grain-boundary segregation, and the effects of sulfur on grain-boundary embrittlement. The samples that were fractured in the Auger spectroscopy system were retrieved and subjected to scanning-electron microscopy to determine the fracture mode and morphology of the fracture surface.

Optical photographs and electron microprobe data from the alnnized Iype 316 stainless steel are presented in Figs. 52 and 53 . These data represent exposures of $20.13 \mathrm{Ms}$ (sample removed after Run 61) and 21.04 Ms (sample removed after Run $6 \%$ ). The optical photographs in these two figures show the extent of corrosion product buildup as a function of exposure. Significantly, more penetration of the corrosion product has occurred in the sample that was exposed for a longer period of time. Also, grain-boundary penetration by sulfur has occurred. Electron microprobe data show that nickel is depleted and sulfur and aluminum are enriched at the OD surface of the coupons.

The results of exposing a Type 446 martensitis stainlecc otocl for $0.13 \mathrm{Ms}$ to the HYGAS gasifier environment are shown in Fig. 54. This steel was not alonized. The optical photograph shows the corrosion scale had not penetrated as deeply into the sample as had occurred in the alonized Type 316 stainless steel. The electron-microprobe data show that the corrosion scale is enriched in sulfur and some aluminum and silicon are also present. Iron is depleted from the scale except for a thin layer at the OD of the corrosion scale, and a slight enrichment of nickel was observed. Chromium is enriched in the corrosion scale, depleted from the base metal, and a gradient in chromium concentration was found, with the highest concentration being adjacent to the base metal.

The coupons were machined, notched, and inserted into a scanning Auger electron spectroscopy system. The geometry of the machined specimens is shown in Fig. 55. Care was taken to preserve one portion of the surface that had the corrosion scale. The samples were fractured in an ultrahigh vacuum environment, and the derivative Auger spectra (dN/dF) were recorded as a function of energy. The derfivative Auger spectra taken from the center of the alonized Type 316 stainless steel specimen that was exposed for $1.04 \mathrm{Ms}$ and from the corrosion scale are shown in Figs. 56 and 57. The positive and negative excursions represent electron transitions and are used to identify the chemical makeup of the top monolayers of surface atoms. Figure 56 shows that chromium, iron, nickel, and a carbide comprise the central region of the fracture surface. Figure 57 shows that sulfur, carbon, oxygen, and aluminum compose the corrosion scale. Similar results were obtained on the Type 446 stainless steel. 
The samples were retrieved and subjected to SEM investigation to determine the mode of fracture. Figure 58 shows a series of photographs of the Type 316 stainless steel. The photograph with the lowest magnification shows that the fracture mode is intergranular, and the successive photographs show one grain from which the Auger spectra were recorded. An oxide scale is observed. A higher magnification photograph of the corrosion scale and the interface between the corrosion scale and base metal is shown in Fig. 59. The morphology of these two regions is different.

SEM photographs of fractured Type 446 stainless steel are shown in Fig. 60. The fracture mode was transgranular brittle-cleavage fracture. Cleavage steps are readily seen on the higher magnification micrographs.

Another SEM micrograph showing the corrosion scale and the interface. between the scale and base metal is shown in Fig. 61. The transgranular nature of the fracture surface is again readily visible.

\section{Ballooned Pipe from the Synthane Pilot Plant}

A 10.16-cm (4-in.) ID Schedule 40 carbon-molybdenum steel pipe was ballooned on the elbow side of a $5.08-\mathrm{cm}$ (2-in.) letdown valve PCV-338. The piping carries steam at $404^{\circ} \mathrm{C}\left(760^{\circ} \mathrm{F}\right)$ and $4.8 \mathrm{MPa}(700 \mathrm{psi})$. A partial schematic of the piping showing the elbow, bulged pipe, and letdown valve is shown in Fig. 62. Steam on the up side of the letdown valve is at $421^{\circ} \mathrm{C}$. $\left(790^{\circ} \mathrm{F}\right.$ ) and $7.9 \mathrm{MPa}$. The cause for the bulging has not been determined. 'The following preliminary data has been accumulated:

(a) The maximum stresses in the pipe, assuming the stress can be calculated using $\sigma=\mathrm{Pr} / t$, range from 44-72 $\mathrm{MPa}$ (6400-10,500 psi), but the handbook values of yield stress are $207 \mathrm{MPa}$ (30 ksi) with a tensile strength of $448 \mathrm{MPa}(65 \mathrm{ksi})$ at $427^{\circ} \mathrm{C}$ $\left(800^{\circ} \mathrm{F}\right)$. The calculated stresses are much lower than the handbook values.'

(b) The pipe oD diameter increased from $11.28(4.44-1 \mathrm{n}$.$) to 11.68 \mathrm{~cm}$ (4.60-in.).

(c) A chemical analysis of the pipe showed the following concentrations (wt\%): total carbon $0.11-0.10$, chromium 1.26, molybdenum 0.43, sulfur 0.012 , nickel 0.08 , and manganese 0.47 .

Hardness testing, tensile testing, and optical and SEM analyses will be performed in the coming quarter. 


\section{REFERENCES}

1. Materials Science Division Coal Technology Fifth Quarterly Report, October-December, 1975, Argonne National Laboratory, ANL-76-22.

2. Materials Science Division Coal Technology Seventh Quarterly Report, Apri1-June, 1976, Argonne National Laboratory, ANL-76-111.

3. Materials Science Division Coal Technology Eighth Quarterly Report, July-September, 1976, Argonne National Laboratory, ANL-76-125.

4. Materials Science Division Coal Technology Ninth Quarterly Report, October-December, 1976, Argonne National Laboratory, ANL-77-5.

5. Materials Science Division Coal Technology Sixth Quarterly Report, January-March, 1976, Argonne National Laboratory, ANL-76-60.

6. J. G. A. Bitter, Wear 6 , 169-190 (1963).

7. W. P. Orchard, HYGAS, to W. A. Ellingson, private communication (October 1976).

8: G. C. Robinson, C. R. Reese, and E. A. La Roche, Jr., "Determination of Thermally Induced Acoustic Emissions of Ceramics," Amer. Ceram. Bull., 53, 482-485 and 488 (1974).

9. M. Arrington, and B. M. Evans, "Acoustic Emission Testing of High Alumina Cement Concrete," NDT Internationa1, 10(2), 81-87 (April 1977).

10. J. J. Schuldies, "The Acoustic Emission Response of Mechanically Stressed Ceramics,: Mater. Eval., Vol. XXXI(10), 209-213 (1973).

11. J. F. Gardner, MERC, to W. J. Shack, personal communication (March 1977).

12. A. J. MacNab, Workshop on Materials Problems and Research Opportunities in Coal Conversion, Vol. II, Ohio State University, Columbus, Ohio, 1974, p. 33.

13. K. Natesan and 0. K. Chopra, "Corrosion Behavior of Materials for Coalgasification Applications," Proc. Symp. on Properties of High Temperature Alloys, The Electrochemical Society, Princeton, New Jersey, 77-1, 493-510 (1977).

14. F. A. Zenz and D. F. Othmar, Fluidization and Fluid Particle Systems, Reinhold, 1960.

15. R. G. Boothroyd, Flowing Gas-solids Suspensions, Chapman and Hall, London, 1971.

16. H. E. Rose and R. A. Duckworth, "Transport of Solid Particles in Liquids and Gases," The Engineer, 227(5903,5904,5905), 392-396, 430-433, and 478-483, (March 14, 21, 28, 1969). 
17. W. Yang and D. L. Keairns, "Estimating the Acceleration Pressure Drop and the Particle Acceleration Length in Vertical and Horizontal Pneumatic Transport Lines," Pneumontransport 3, Third International Conference on the Pneumatic Transport of Solids in Pipes, University of Bath, U.K., April 7-9, 1976.

18. R. G. Cox and S. G. Mason, "Suspended Particles in Fluid Flow through Tubes "Annual Review of Fluid Mechanis, 3, 291-317 (1971).

19. J. A. Fay, "Buoyant Plumes and Wakes," Annual Review of Fluid Mechanics, 5, 151-160 (1972).

20. G. M. Hidy and J. R. Brock, The Dynamics of Aerocolzoidal Systems, Pergamon, New York, 1970.

21. G. I. Taylor, "Notes on Possible Equipment and Techniques for Experiments on Icing of Aircraft," R\&M 2024, ARC Tech. Rept. HMSO, London, 1940.

22. I. Langmuir and K. Blodgett, "Mathematical Investigation of Water Droplet Trajectories," U. S. Army Air Force Tech. Rept. 5418, 1946.

23. G. P. Tilly, "Erosion Caused by Airborne Particles," Wear, 14, 63-79 (1969).

24. A. Hamed and W. Tabakoff, "Numerical Method for Solution of Particulate Flow Equations," AIAA J., 13, 715-716 (1975).

25. C. T. Crowe and D. E. Stock, "A Computer Solution for Two-Dimensional Fluid-particle Flows," Int. J. For Num. Method in Eng., 10, 185-196 (1976).

26. A. D. Gosman, W. M. Pun, A. K. Runchal, D. B. Spalding, and M. Wolfstein, Heat and Mass Transfer in Recirculating Flows, Academic Press, New York, 1969.

27. C. T. Crowe and D. T. Pratt, "Analysis of the Flow Field in Cyclone Separators," Computers and Fluids, $\underline{2}$, 249-260 (1974). 
TABLE I. Initial Composition of Slag in Corrosion Test Run 4

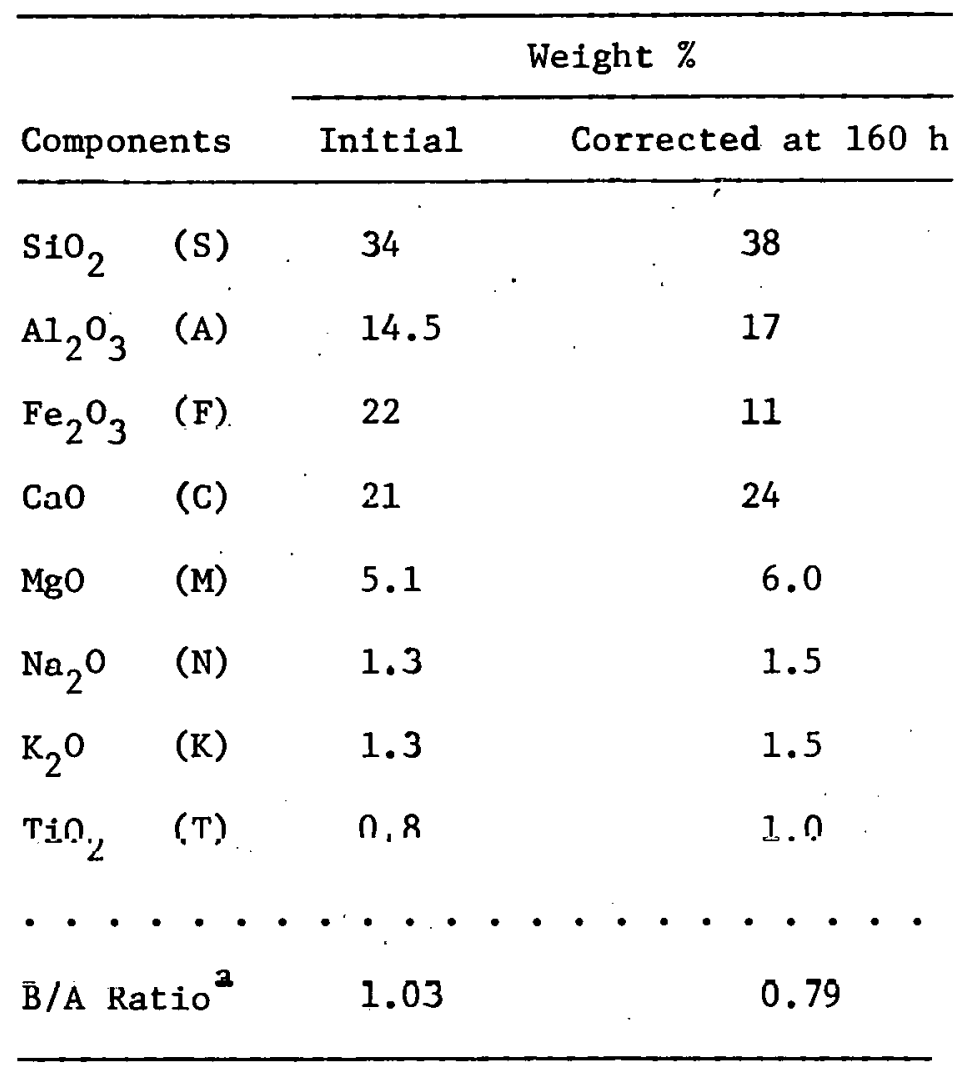

$a_{B / A}=(F+C+M+N+K) /(S+A+T)$. 
TABLE II. Coating Materials and Substrates Used in the 3.6 Ms Exposure to High-velocity Char at $980^{\circ} \mathrm{C}$

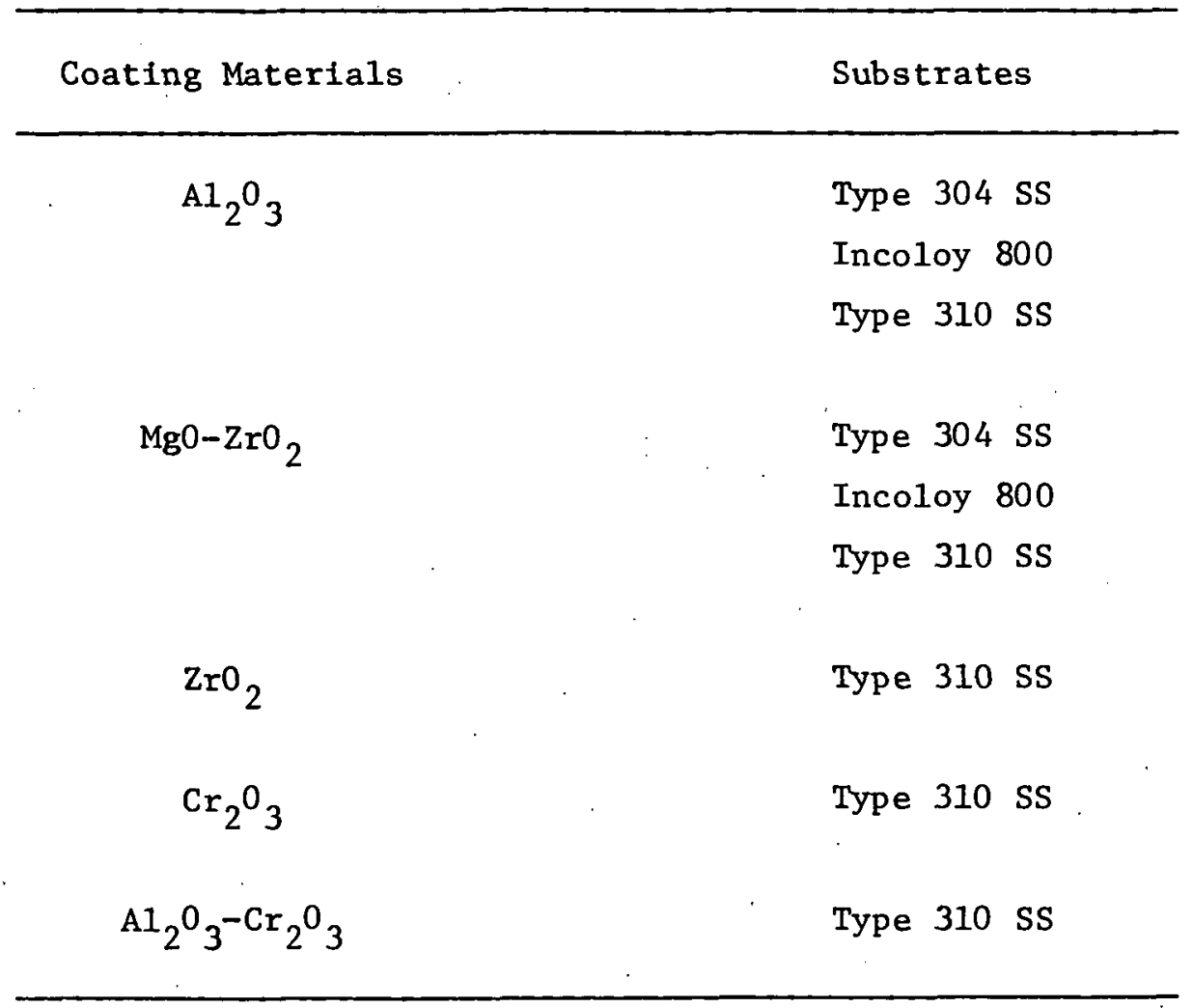


TAB_E III. Parameters Used in Heat-transfer Calculations

\begin{tabular}{|c|c|c|c|c|c|c|c|}
\hline \multirow[b]{2}{*}{ Case } & \multicolumn{2}{|c|}{ Cavity Size, ${ }^{a} \mathrm{~mm}$} & \multicolumn{2}{|c|}{$\begin{array}{l}\text { Thermal Conductivity, } \\
\mathrm{N} / \mathrm{m}-{ }^{\circ} \mathrm{K}\end{array}$} & \multirow{2}{*}{$\begin{array}{l}\text { Convective } \\
\text { Coefficient, } \\
\text { W/ }-{ }^{\circ} \mathrm{K}\end{array}$} & \multirow{2}{*}{$\begin{array}{c}\text { Refractory } \\
\text { Size, } \\
\text { mm }\end{array}$} & \multirow{2}{*}{$\begin{array}{c}\text { Steel Shell } \\
\text { Size, } \\
\text { mm }\end{array}$} \\
\hline & Depth & Halī Width & $x_{1}$ & $k_{2}$ & & & \\
\hline 1 & $\begin{array}{c}6.5 \sim 70 \\
(6.5,13)\end{array}$ & $\begin{array}{c}25-1.25 \\
(50)\end{array}$ & D. 563 & 46.69 & 1.441 & $76 \times 152$ & $6.5 \times 152$ \\
\hline 2 & $19.0 \sim 70$ & $25-125$ & 0.563 & 46.69 & $2 . \varepsilon 82$ & $76 \times 152$ & $6.5 \times 152$ \\
\hline 3 & $19.0 \sim 70$ & $25-125$ & 0.519 & 46.69 & 1.441 & $76 \times 152$ & $6.5 \times 152$ \\
\hline 4 & $19.0 \sim 70$ & $25-125$ & 0.519 & 46.69 & 2.882 & $76 \times 152$ & $6.5 \times 152$ \\
\hline
\end{tabular}

a Numbers in parentheses represent spatial increments. 
TABLE IV. Heating Schedules Followed for Samples Examined This Quarter

(All Samples of KAOTAB)

1. Heat from room temperature to $120^{\circ} \mathrm{C}$ in $8 \mathrm{~h}$

2. Furnace cool to room temperature

3. Heat from room temperature to $500^{\circ} \mathrm{C}$ in $8 \mathrm{~h}$

4. Furnace cool to room temperature

5. Heat to $1000^{\circ} \mathrm{C}$ in $24 \mathrm{~h}$

6. Furnace cool to room temperature

TABLE V. Acoustic-emission Measurements on the Top Cyclone Lockhopper Valve

\begin{tabular}{ccc}
\hline $\begin{array}{c}\text { Valve-body } \\
\text { Location }\end{array}$ & $\begin{array}{c}\text { Noise } \\
\text { Level, V }\end{array}$ & $\begin{array}{c}\text { Structure-borne } \\
\text { Signal and Noise, V }\end{array}$ \\
\hline (a) & 0.166 & 0.230 \\
(b) & 0.166 & 0.196 \\
(c) & 0.166 & 0.315 \\
(d) & 0.166 & 0.195 \\
(e) & 0.166 & 0.178 \\
Nearby Structure & & \\
(a) & 0.166 & 0.171 \\
\hline
\end{tabular}


TABLE VI. Acoustic-emission Measurements on the Top Ash Lockhopper Valve

\begin{tabular}{|c|c|c|c|}
\hline \multicolumn{2}{|c|}{$\begin{array}{l}\text { Valve-body } \\
\text { Location }\end{array}$} & \multirow{2}{*}{$\begin{array}{c}\begin{array}{c}\text { Noise } \\
\text { Leve1, V }\end{array} \\
0.166 \\
0.162 \\
0.162\end{array}$} & \multirow{2}{*}{$\begin{array}{c}\begin{array}{c}\text { Structure-borne } \\
\text { Signal and Noise, V }\end{array} \\
0.180-0.400 \\
0.180-0.400 \\
0.653\end{array}$} \\
\hline . & $\begin{array}{l}\text { (a) } \\
\text { (b) } \\
\text { (c) }\end{array}$ & & \\
\hline Nearby & $\begin{array}{l}\text { Structure } \\
\text { (d) } \\
\text { (e) }\end{array}$ & $\begin{array}{l}0.163 \\
0.163\end{array}$ & $\begin{array}{c}0.180-0.500 \\
0.220\end{array}$ \\
\hline
\end{tabular}

TABLE VII. Acoustic-emission Measurements on the Bottom Coal-feed Lockhopper Valve

\begin{tabular}{ccc}
\hline $\begin{array}{c}\text { Valve-body } \\
\text { Location }\end{array}$ & $\begin{array}{c}\text { Noise } \\
\text { Leve1, V }\end{array}$ & $\begin{array}{c}\text { Structure-borne } \\
\text { Signa1 and Noise, } V\end{array}$ \\
\hline & $\frac{175-\mathrm{kHz} \text { Transducer }}{\text { (a) }}$ & \\
(b) & 0.170 & $0.375-0.875$ \\
(c) & 0.170 & $0.225-0.430$ \\
& 0.170 & $0.220-0.460$ \\
(a) & 375-kHz Transducer & \\
(b) & 0.153 & $0.186-0.480$ \\
(c) & 0.152 & $0.153-0.186$ \\
& 0.152 & $0.153-0.350$ \\
\hline
\end{tabular}


TABLE VIII. Acoustic-emission Measurements on the North Lower Petrocarb Feed Valve

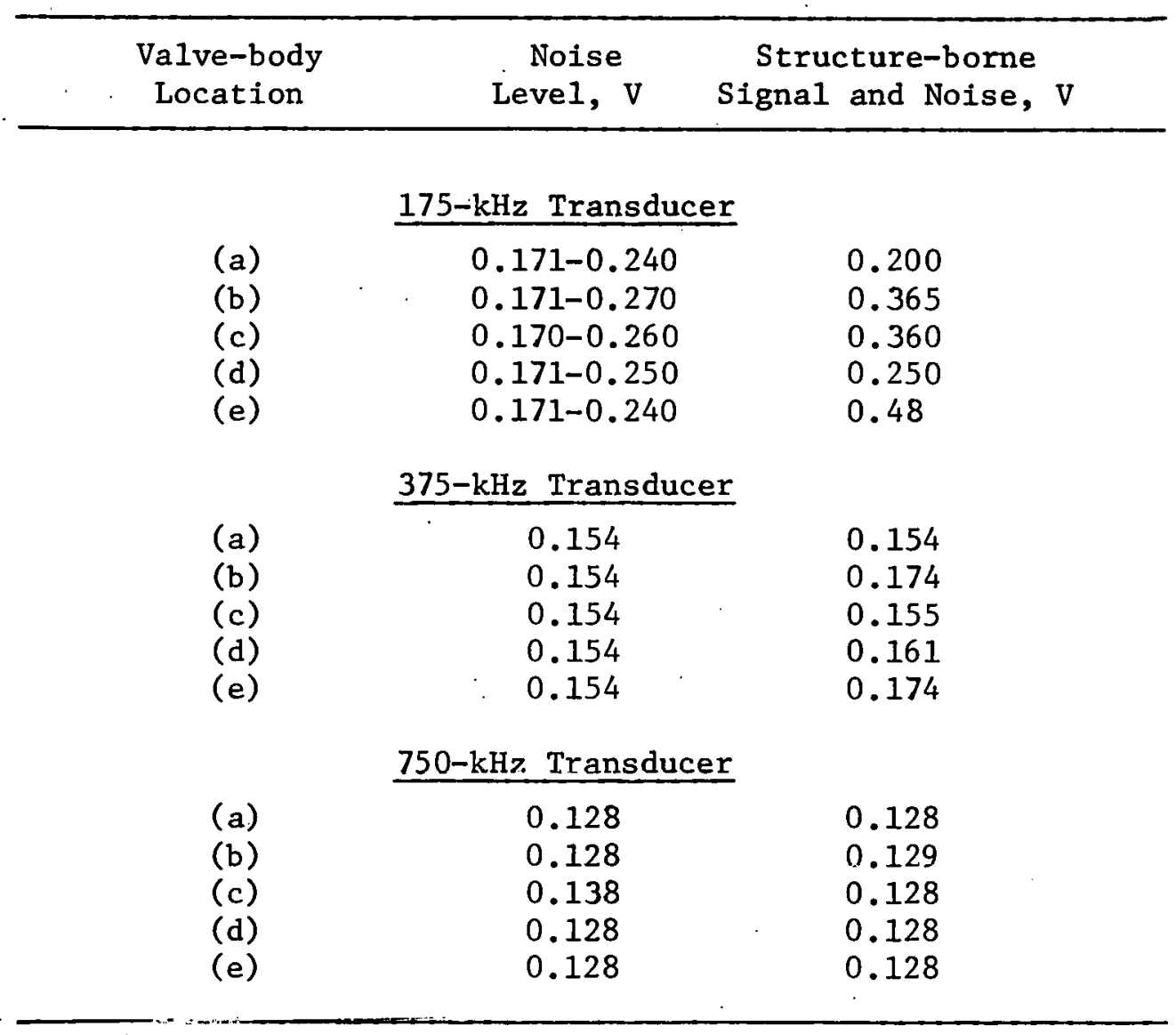


TABLE IX. Acoustic-emission Measurements on the South Lower Petrocarb Feed Valve and Nearby Structural Components

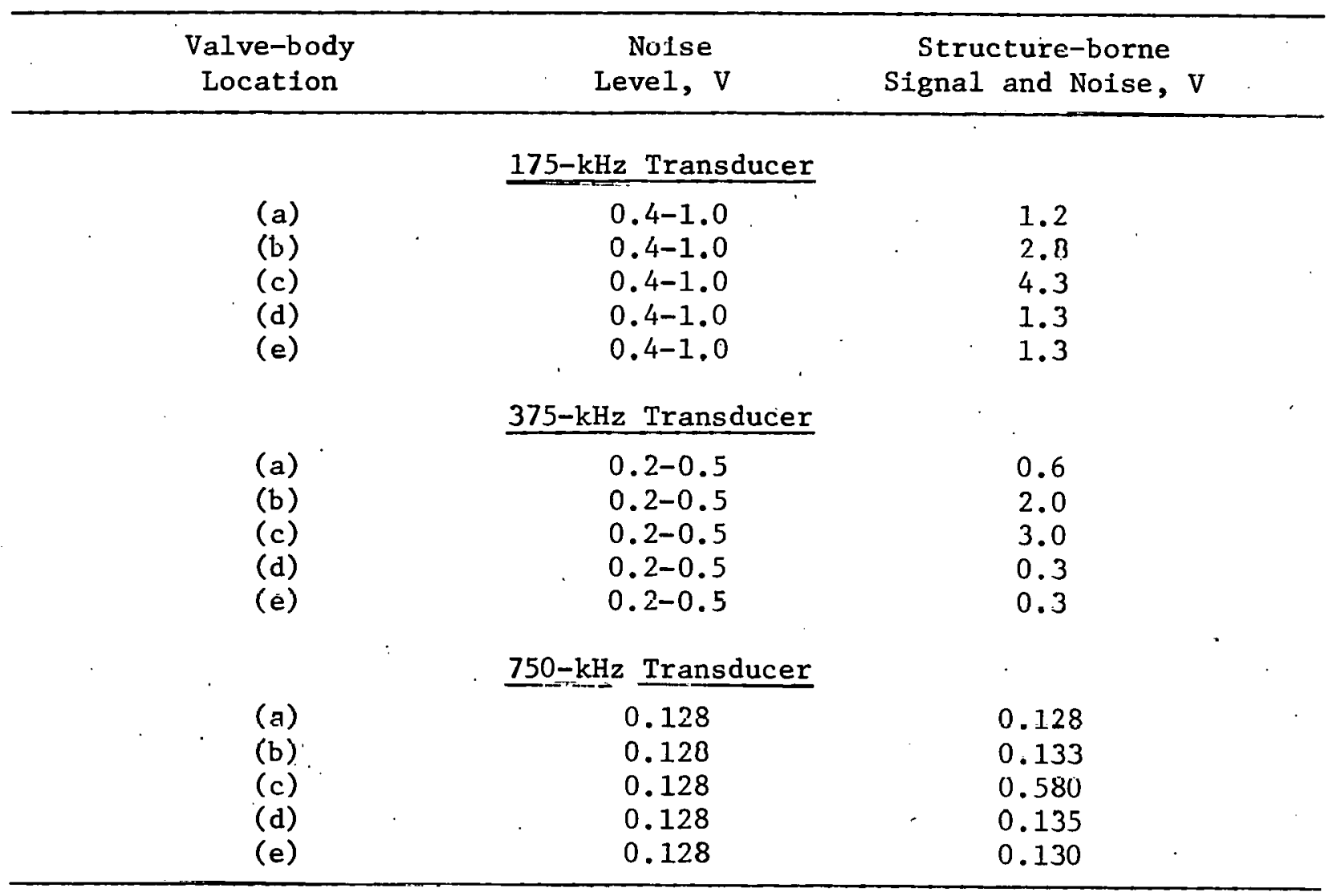


TABLE X. Gas Environment Used for Preliminary Corrosion Experiments at $875^{\circ} \mathrm{C}$

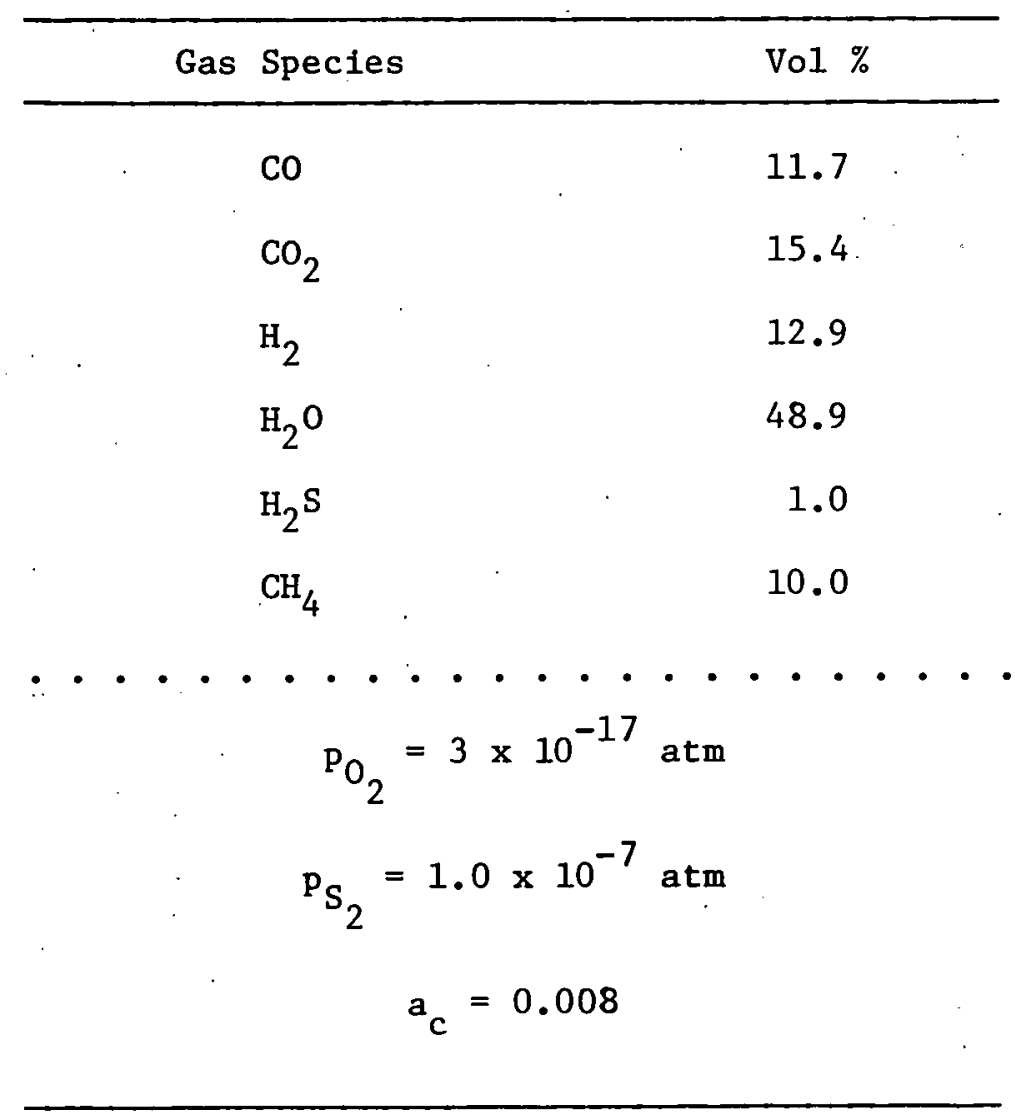


TABLE XI. Themical Composition (wt \%) of Alloss in Corrosion Experiments

\begin{tabular}{|c|c|c|c|c|c|c|c|c|}
\hline A1loy & $\mathrm{Fe}$ & $\mathrm{Cr}$ & Ni & $\mathrm{C}$ & $\mathrm{S}$ & Mn & Si & Other \\
\hline Incoloy $800^{a}$ & 46.0 & 21 & 32.5 & 0.05 & 0.008 & 0.75 & 0.35 & $0.38 \mathrm{Al}, 0.38 \mathrm{Ti}$ \\
\hline Inconel $671^{a}$ & - & 48 & 50 & 0.05 & - & - & - & $0.35 \mathrm{Ti}$ \\
\hline Type $310 \mathrm{ss}^{\mathrm{a}}$ & $\mathrm{Ba} 1^{\mathrm{b}}$ & 25 & 20 & 0.25 & - & 1.5 & 0.4 & - \\
\hline $\begin{array}{l}\text { U. S. Stee1 } \\
\text { Alloya }\end{array}$ & $\mathrm{Bal}^{\mathrm{b}}$ & 18.5 & 17.8 & 0.06 & 0.011 & 1.25 & 2.05 & - \\
\hline Type 304 ss & $\mathrm{Ba} 1^{\mathrm{b}}$ & 19 & 10 & 0.06 & - & 1.5 & 0.4 & - \\
\hline RA 333 & 18 & 25 & 45 & 0.05 & 0.015 & 1.5 & 1.25 & $\begin{array}{c}3.0 \mathrm{~W}, 3.0 \mathrm{Co}, \\
3.0 \mathrm{Mo}\end{array}$ \\
\hline Alloy 406 & $\mathrm{Bal}^{\mathrm{b}}$ & 13.1 & 0.36 & 0.11 & 0.007 & 0.44 & 0.46 & $4.48 \mathrm{~A} 1$ \\
\hline Iron & $\mathrm{Ba} 1^{\mathrm{b}}$ & - & - & 0.012 & 0.025 & 0.017 & - & - \\
\hline
\end{tabular}

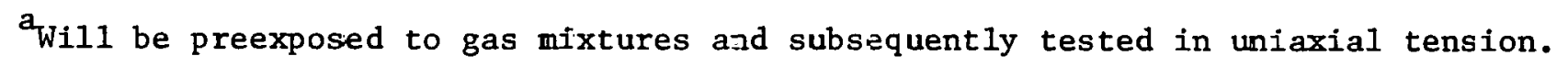

${ }^{\mathrm{b}} \mathrm{Bal}$ indicates balance. 
TABLE XII. Gas Compositions (vc1 \%) Used in the Evaluation of Material Behavior at 750 and $875^{\circ} \mathrm{C}$

\begin{tabular}{|c|c|c|c|c|c|c|c|c|c|}
\hline \multirow{2}{*}{$\begin{array}{c}\text { Gas } \\
\text { Species }\end{array}$} & \multicolumn{4}{|c|}{$750^{\circ} \mathrm{C}$ (No Steam) } & \multicolumn{4}{|c|}{$875^{\circ} \mathrm{C}$ (No Steam) } & \multirow{2}{*}{$\begin{array}{c}875^{\circ} \mathrm{C} \\
\text { with. steam }\end{array}$} \\
\hline & 1 & 2 & 3 & 4 & 1 & 2 & 3 & 4 & \\
\hline $\mathrm{CO}_{2}$ & 56.8 & 30.9 & 10.3 & 2.0 & 32.8 & 17.2 & 11.8 & 3.1 & 8.1 \\
\hline - $\mathrm{CH}_{4}$ & 9.5 & 5.2 & 1.7 & 0.33 & 5.5 & 2.9 & 2.0 & 0.51 & 2.9 \\
\hline $\mathrm{H}_{2} \mathrm{~S}$ & 0.09 & 0.81 & 1.40 & 1.64 & 0.77 & 1.21 & 1.36 & 1.60 & 1.5 \\
\hline $\mathrm{H}_{2} \mathrm{O}$ & - & - & - & - & - & - & - & - & 8.6 \\
\hline $\mathrm{p}_{\mathrm{O}_{2}}$ (atm) & $1.0 \times 10^{-20}$ & $2.4 \times 10^{-21}$ & $4.1 \times 10^{-22}$ & $4.2 \times 10^{-23}$ & $1.9 \times 10^{-18}$ & $5.5 \times 10^{-19}$ & $2.4 \times 10^{-19}$ & 1. $7 \times 10^{-20}$ & $5.4 \times 10^{-19}$ \\
\hline$a_{c}$ & 0.25 & 0.348 & 0.348 & 0.20 & 0.056 & 0.070 & 0.076 & 0.082 & 0.070 \\
\hline$\because$ & . & & $\cdot$ & & & & & & 1 \\
\hline . & & & & & & & . & & \\
\hline
\end{tabular}




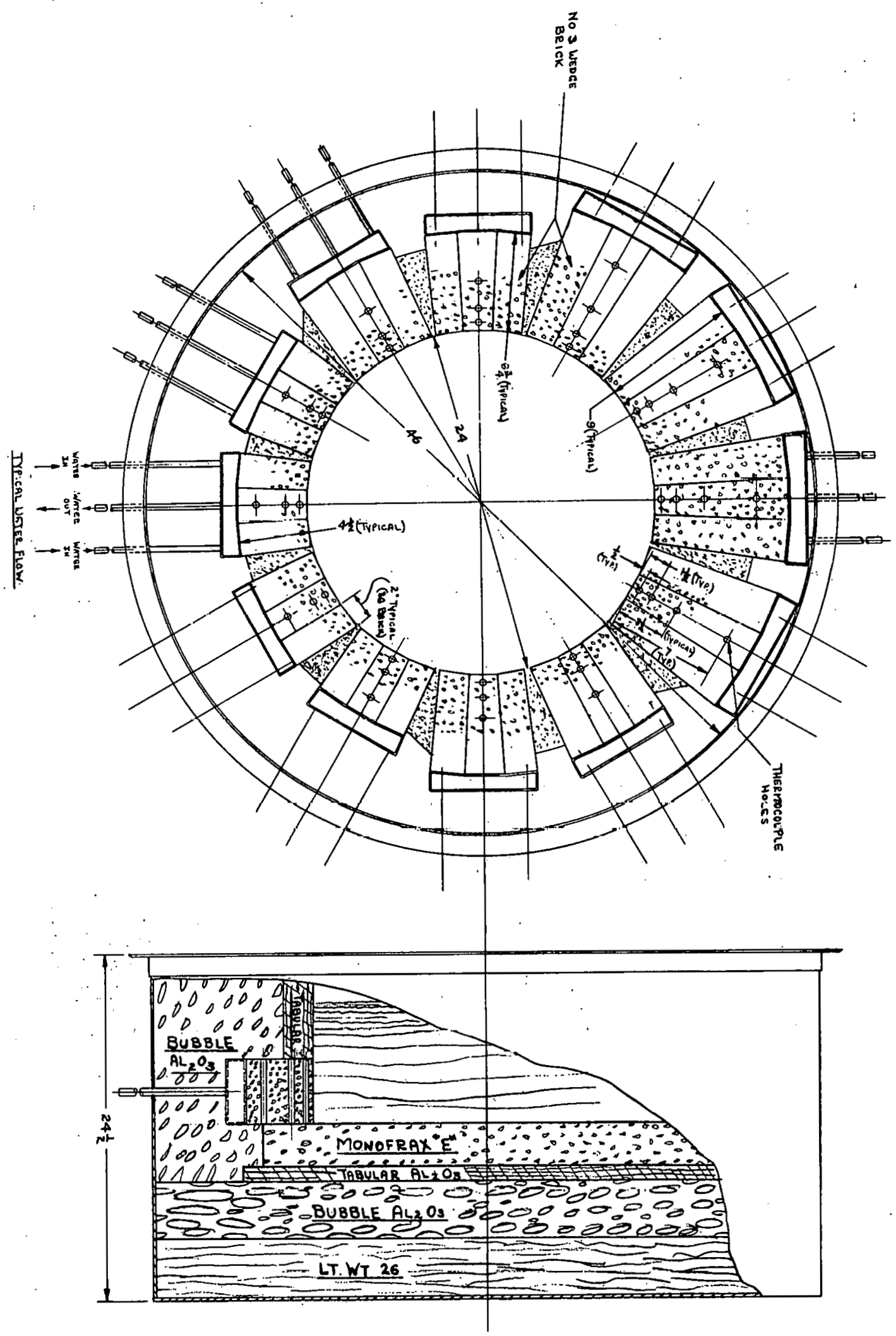

Fig. 1. Top and Side Views of the New Bottom Section of the slag-corrosion Furnace. Dimensions are in inches. ANL Neg. No. 306-77-47. 


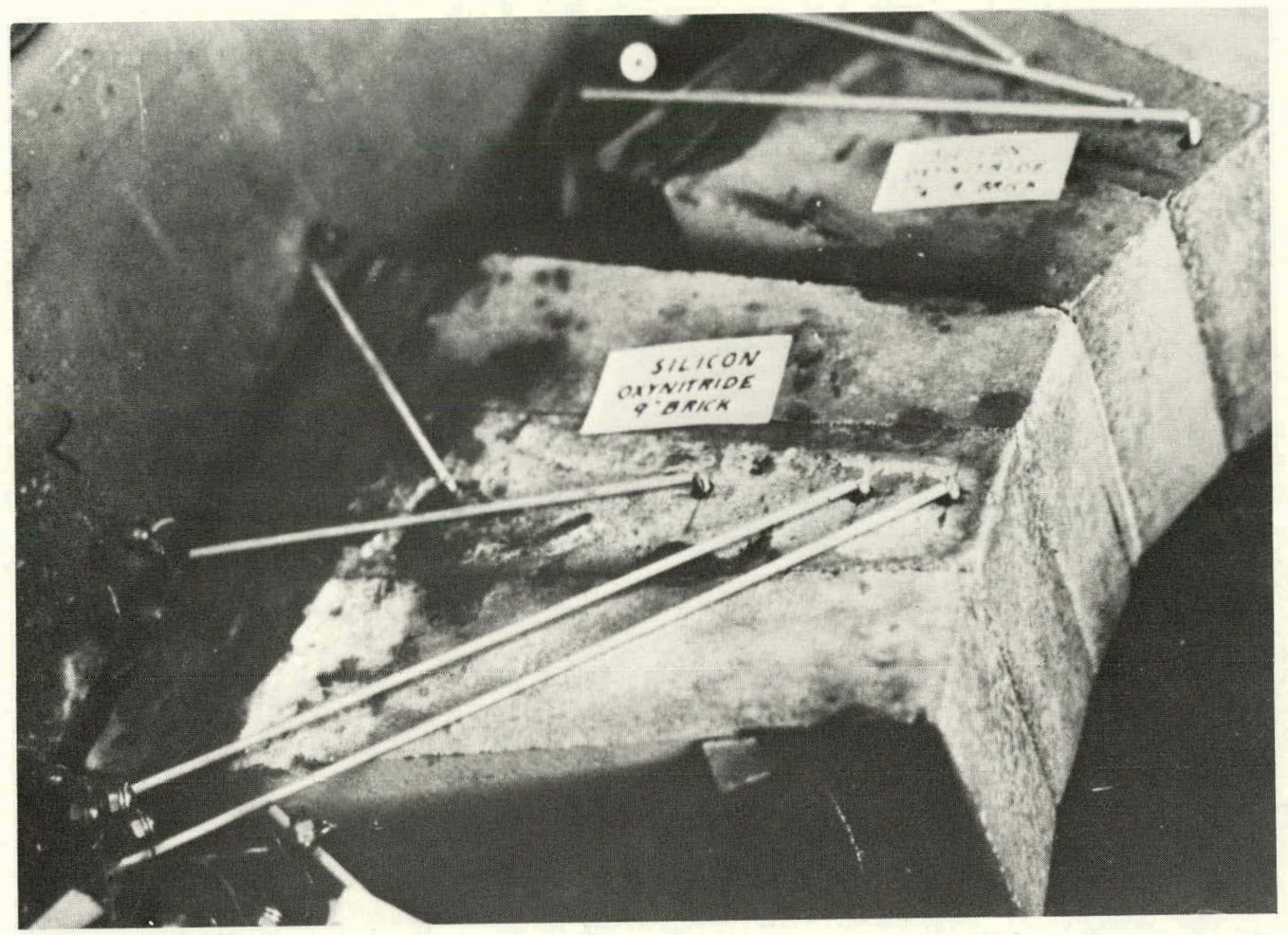

Fig. 2. Thermocouple Positions in a Full Length (228.6 mm) Brick. Neg. No. MSD-64010. 


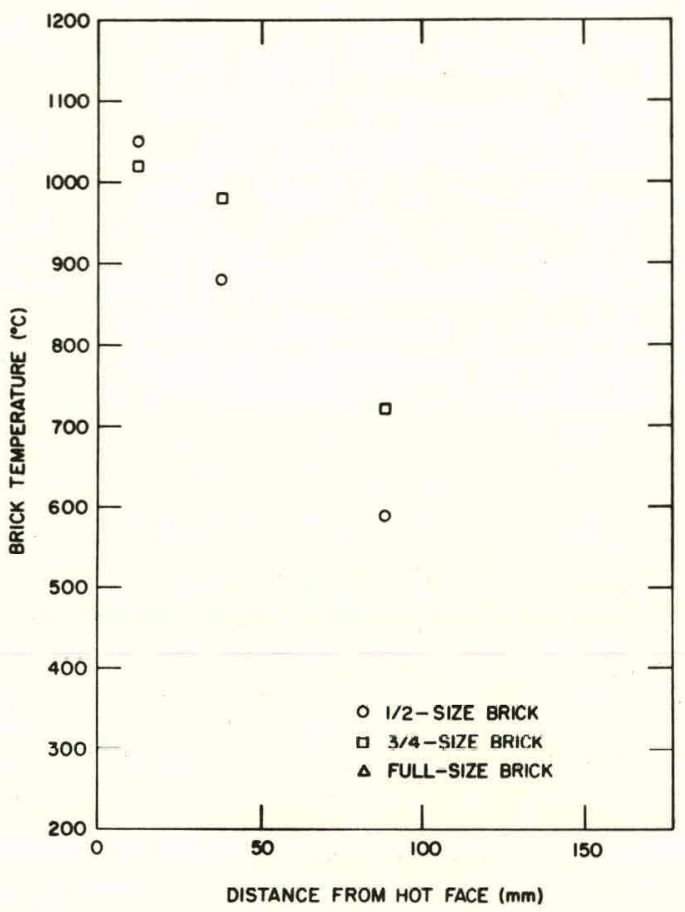

(a)

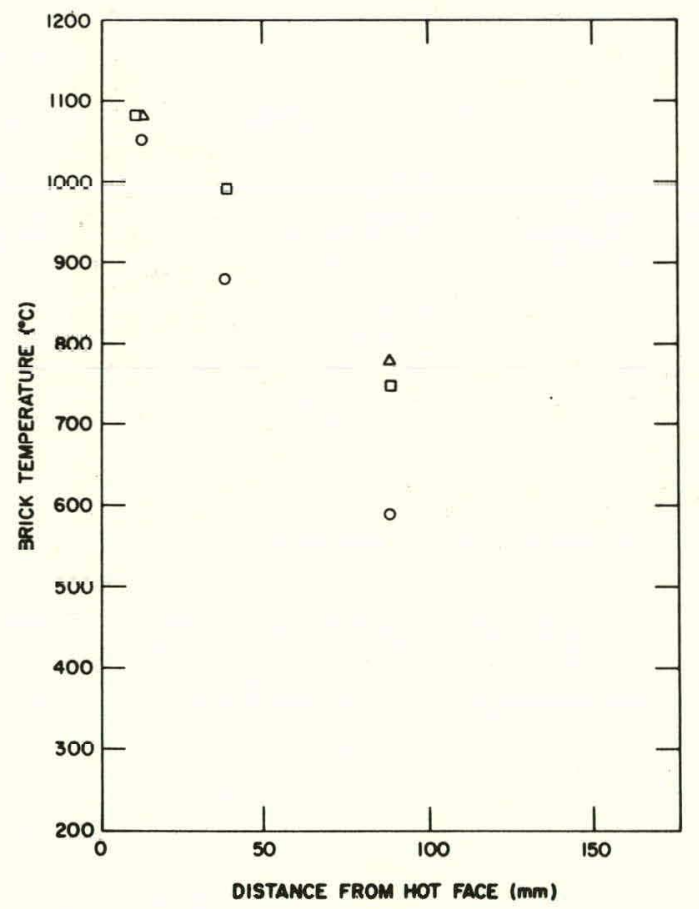

(c)

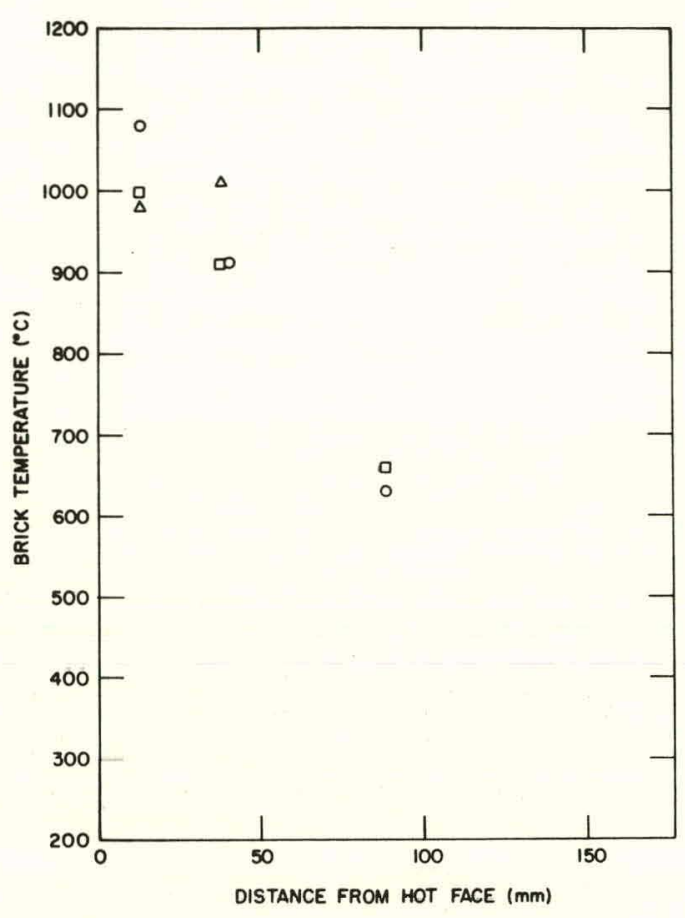

(b)

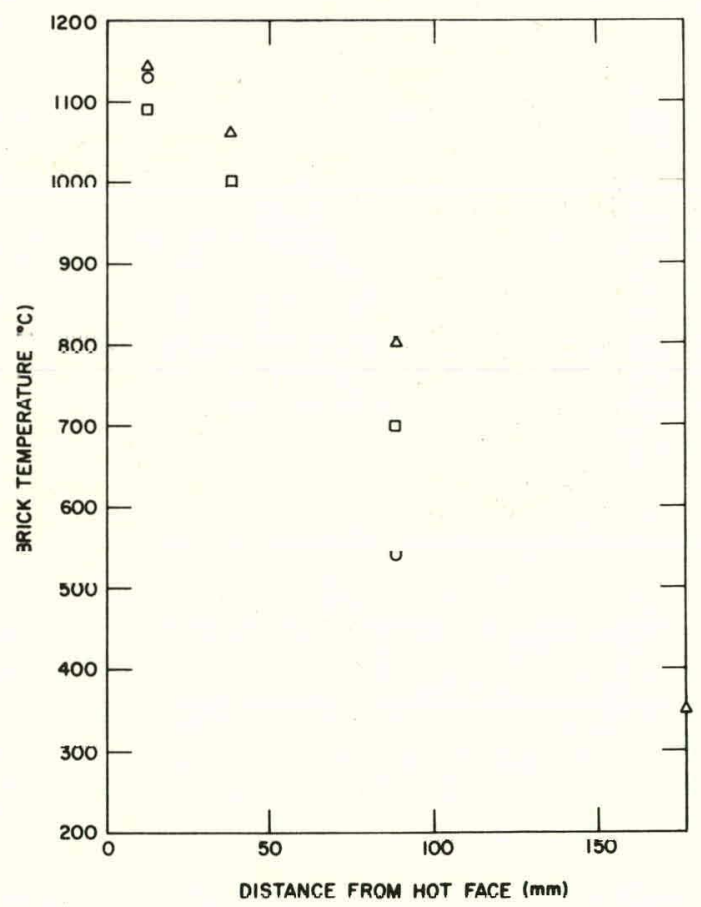

(d)

Fig. 3. Temperatures in Bricks at Beginning of Test at Four Locations in Fu11length Bricks and at Three Locations in 3/4- and 1/2-1ength Bricks. (Lack of data points indicates thermocouple failed.) (a) Nitride-bonded silicon carbide, (b) silicate-bonded silicon carbide, (c) oxynitride-bonded silicon carbide, and (d) silicon oxynitride. ANL Neg. No. 306-77-277. 


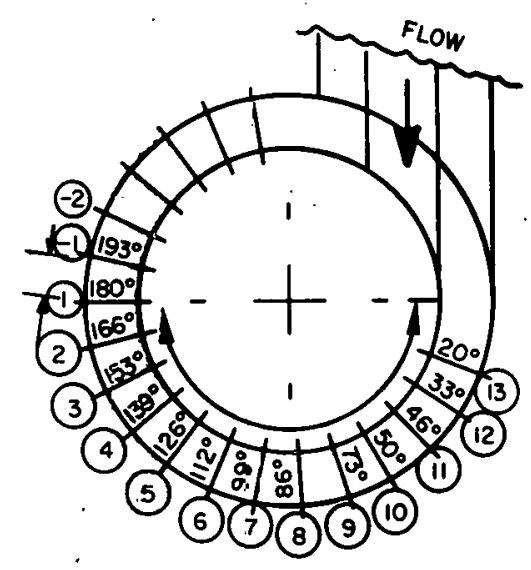

(a)

$\underset{w}{w}$

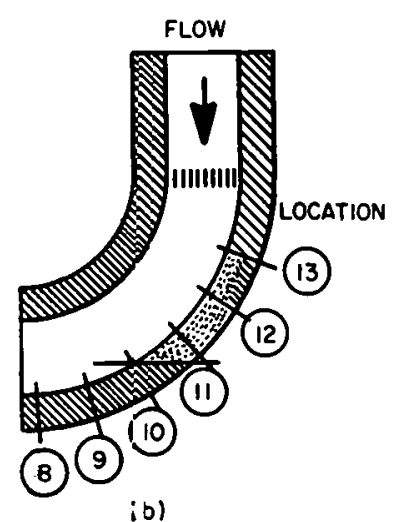

Fig. 4. (a) Azimuthal Distribution of Measurements Location along the Inlet Centerline of the HYGAS Cyclone and (b) Assumed Erosion Pattern Based on Elbow Studies. ANL Neg. No. 306-77-177.

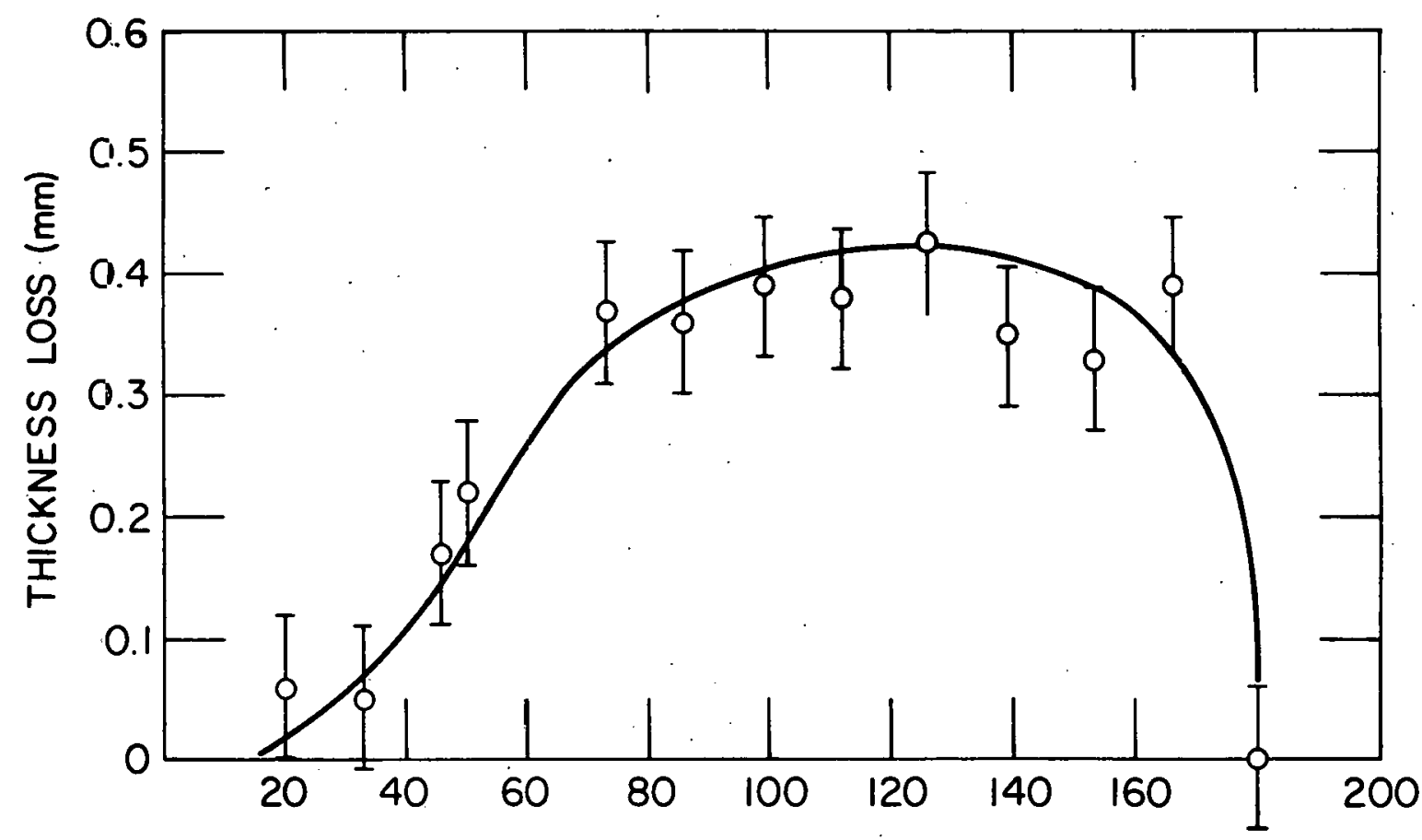

AZIMUTHAL POSITION

Fig. 5. Azimutha1 Distribution of Wear along the Inlet Centerline of the HYGAS Cyclone. ANL Neg. No. 306-77-178. 


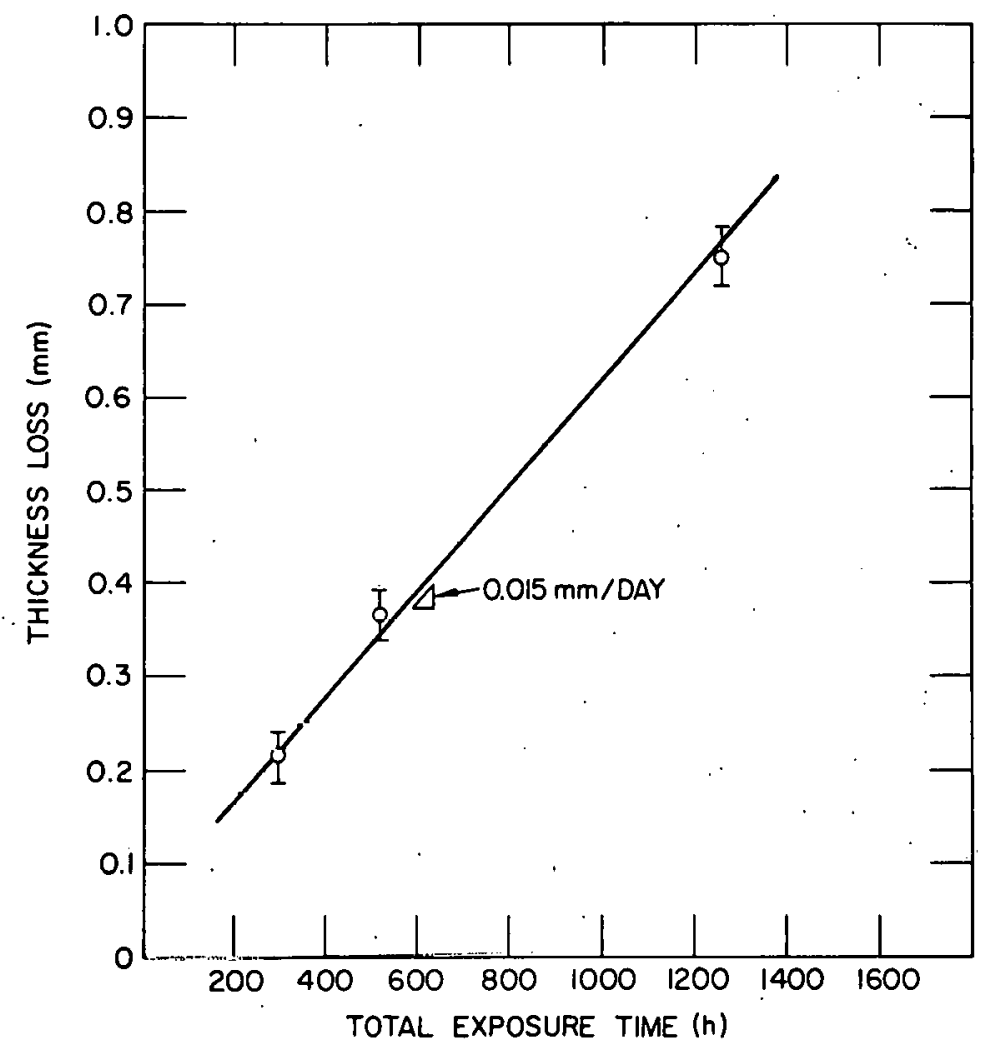

Fig, 6. Average Wear Rate along the Inlet Centerline of the HYGAS Cyclone as a Function of the Number of Hours of Operation. ANL Neg. No. 306-77-172.

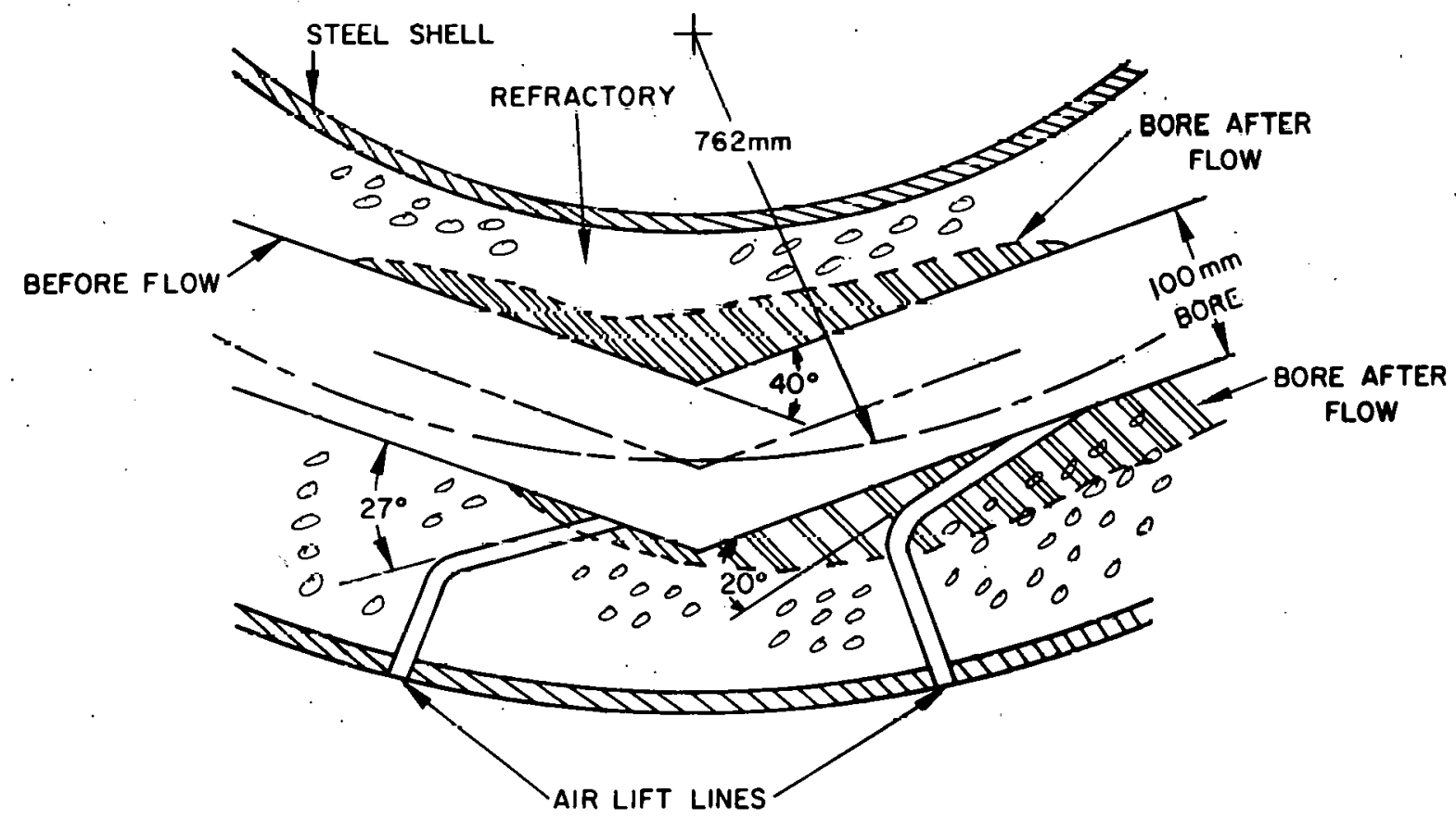

Fig. 7. Erosive Wear of Refractory-lined Transfer Line After 200-h Exposure. ANL Neg. No. 306-77-168. 


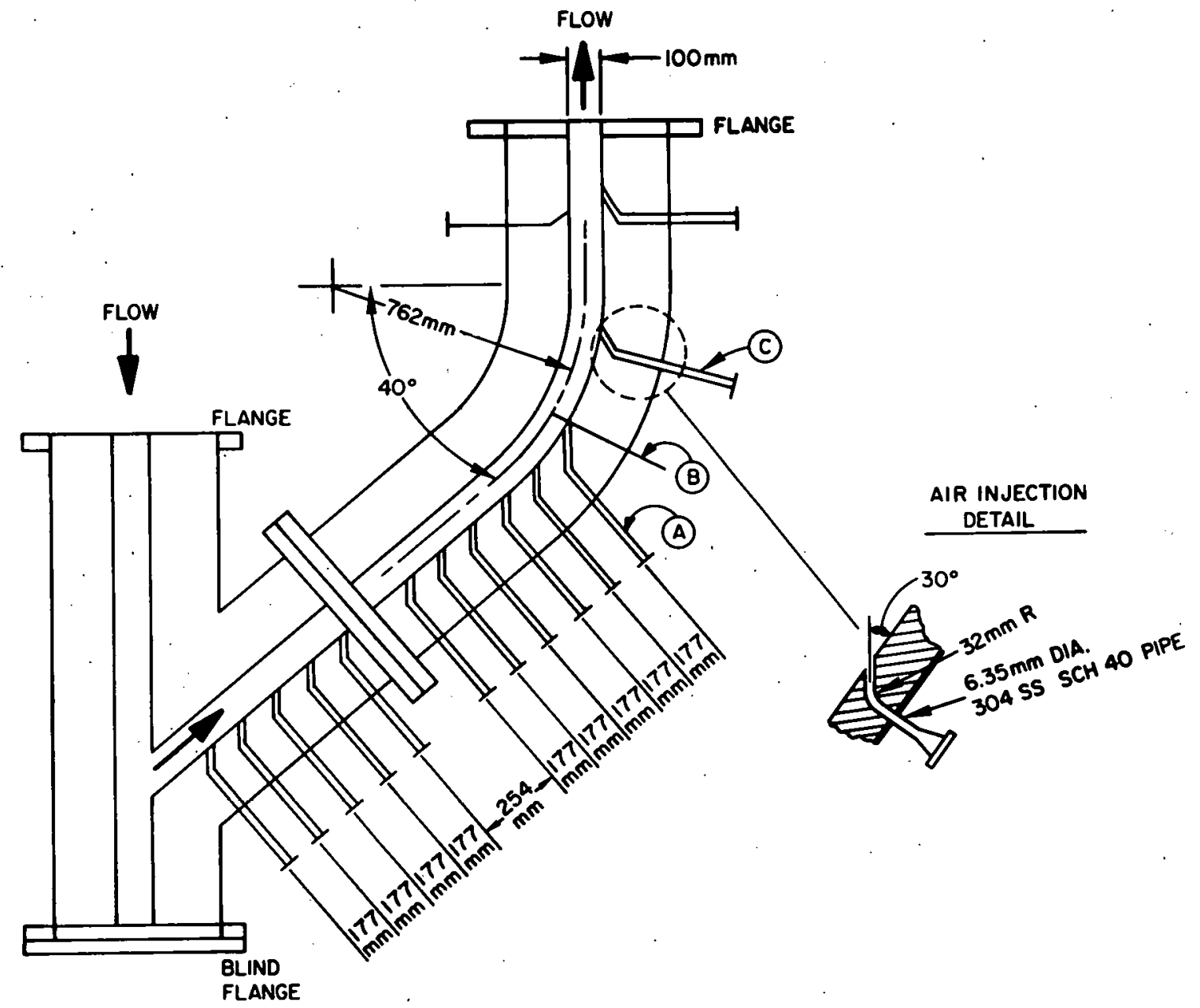

Fig. 8. Schematic of the Ash 502 Direction Change Transfer Lines. ANL Neg. No. 306-77-182. 


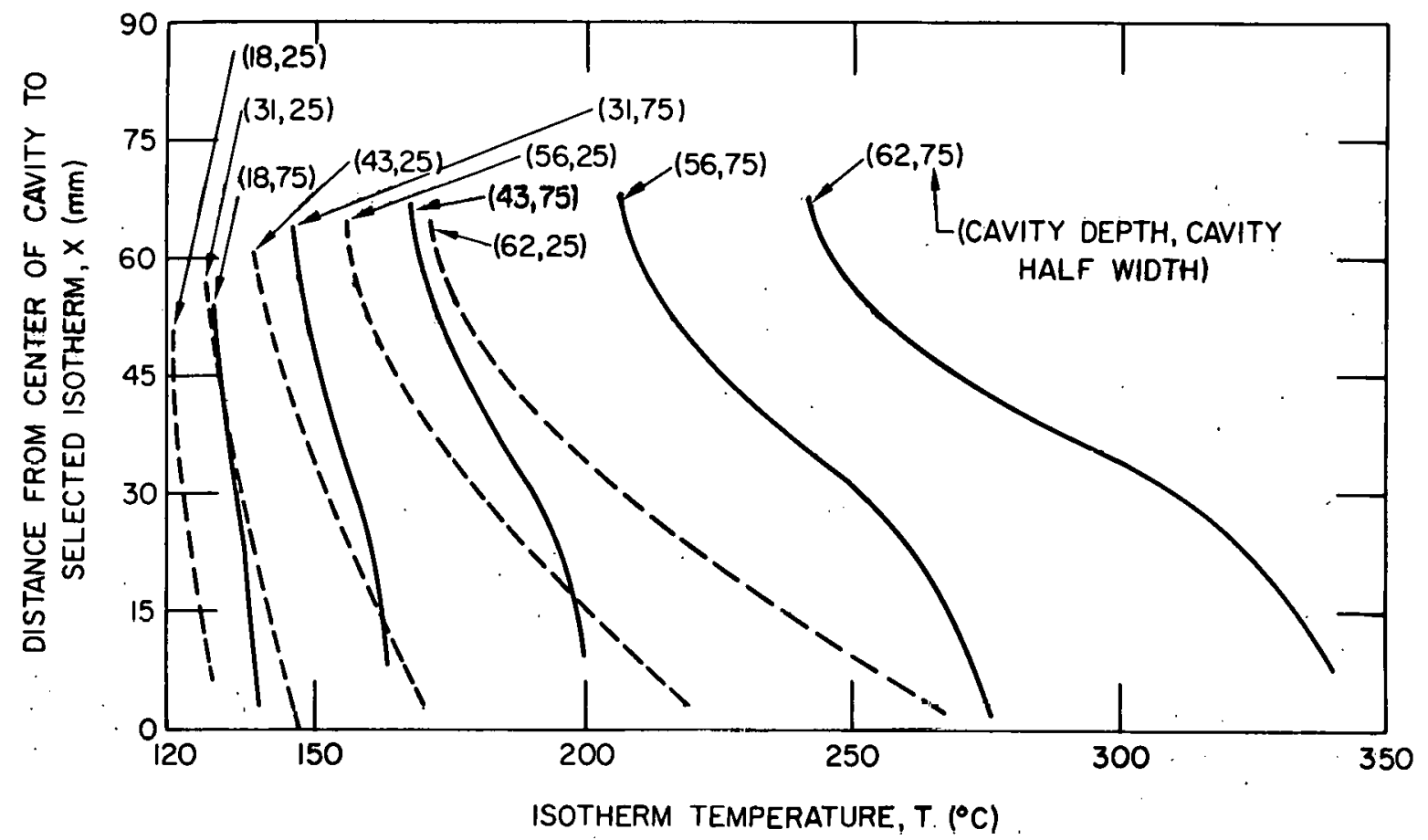

Fig. 9. Isothermal Distance from Center Line of a Synthesized Cavity in a 76-mm-thick Refractory Bnnter to a $6.5=\mathrm{mm}=$ thick Stcel Plate. Daslied and solid lines indicate cavity half widths of 25 and $75 \mathrm{~mm}$, respectively. ANL Neg. No. 306-77-173.
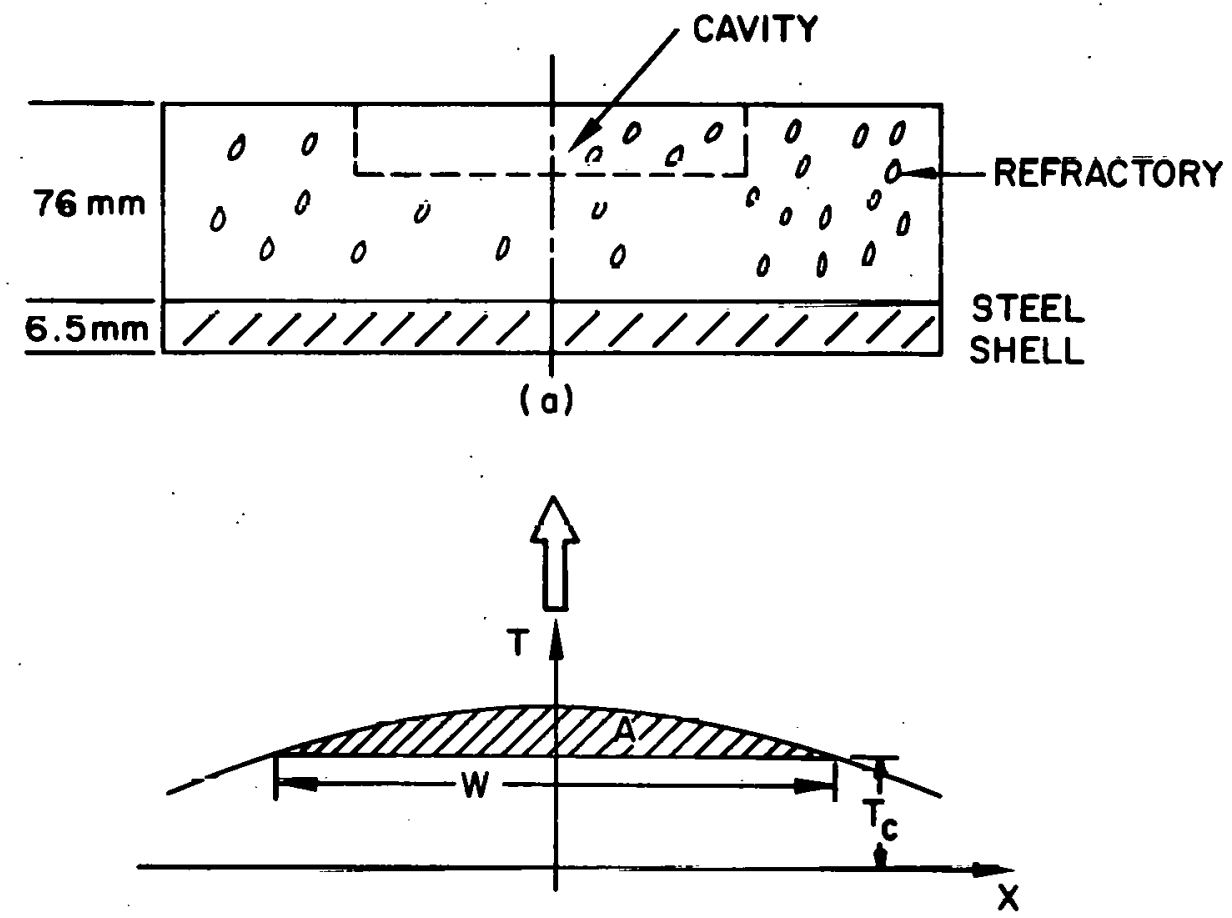

(b)

Fig. 10. Schematic of (a) Refractory-steel Lamination with Rectangular Cavity Defect and (b) Thermal Profile Observed in a Single Line Scan across the Cavity Defect. ANL Neg. No. 306-77-179. 


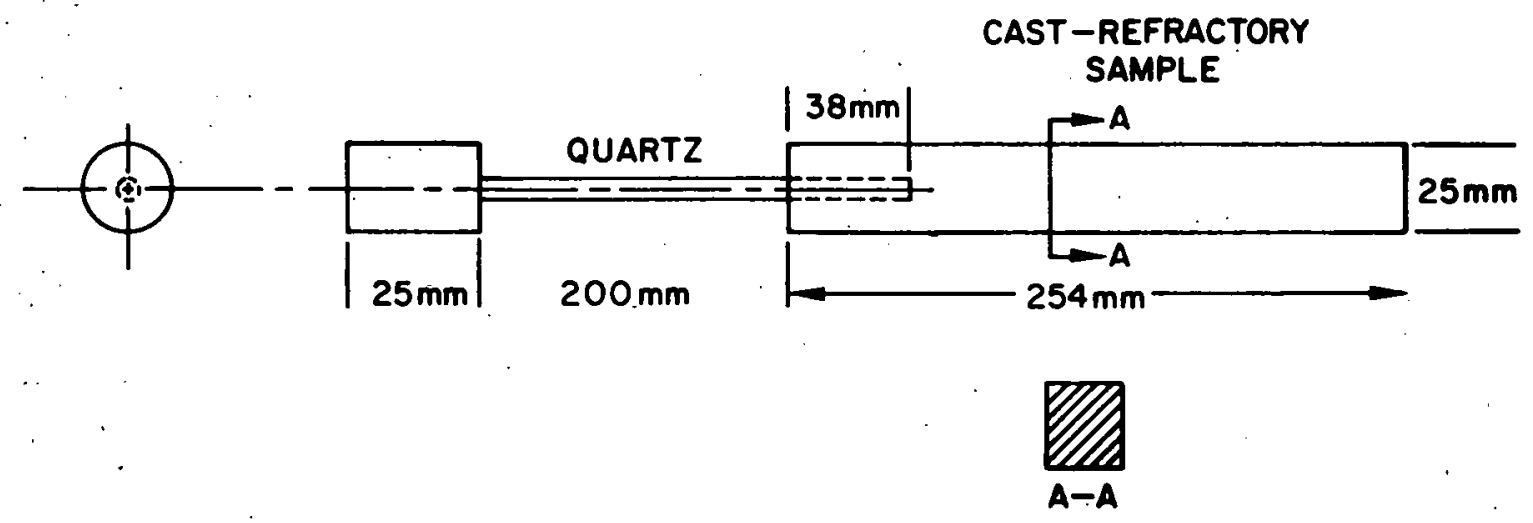

Fig. 11. Schematic of Sample and Embedded Acoustic Waveguide. ANL Neg. No. 306-77-169.

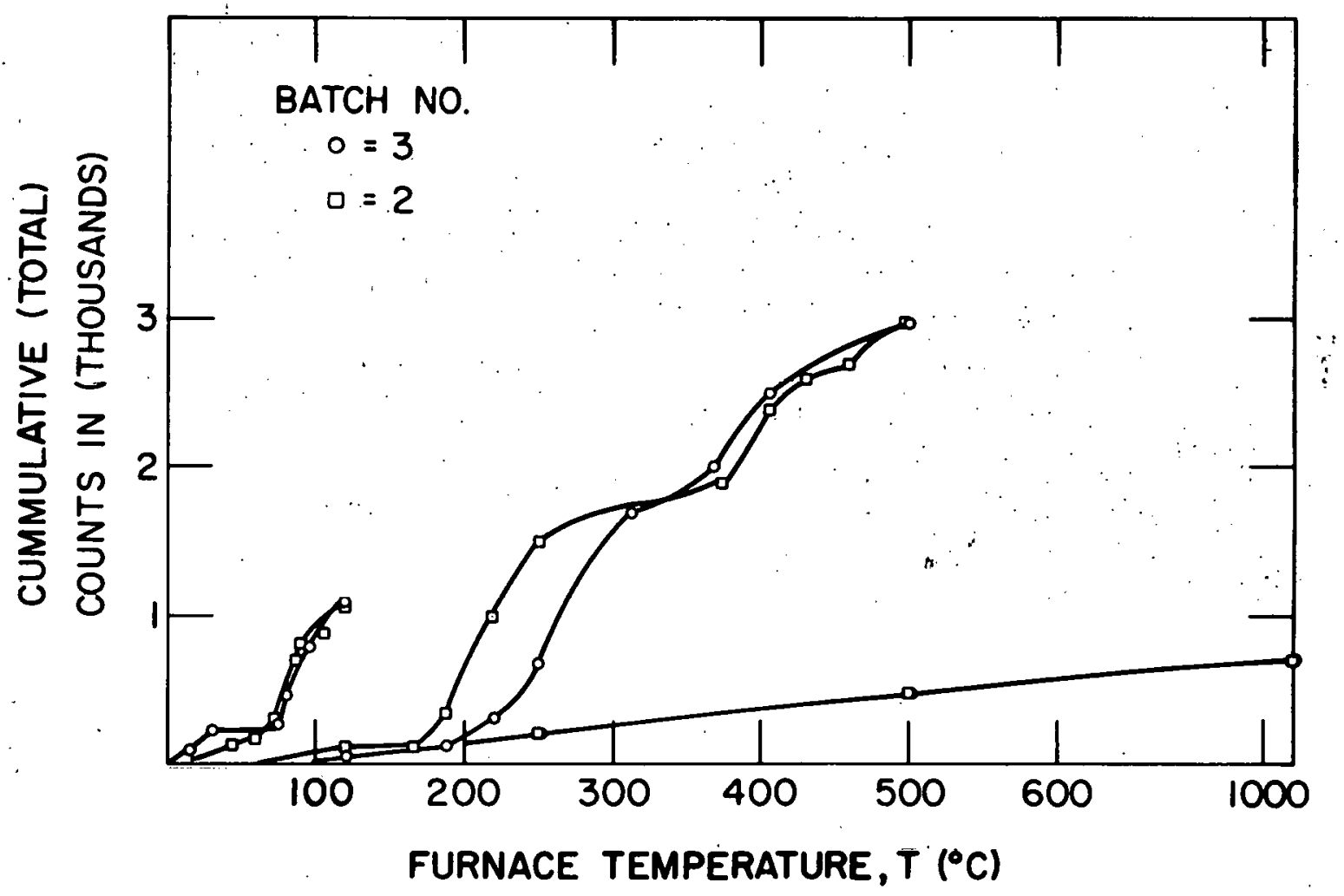

F1g. 12. Total Acoustic-emission Counts as a Function of Temperature for Three Heating Cycles on the Same Sample. ANL Neg. No. 306-77-181. 


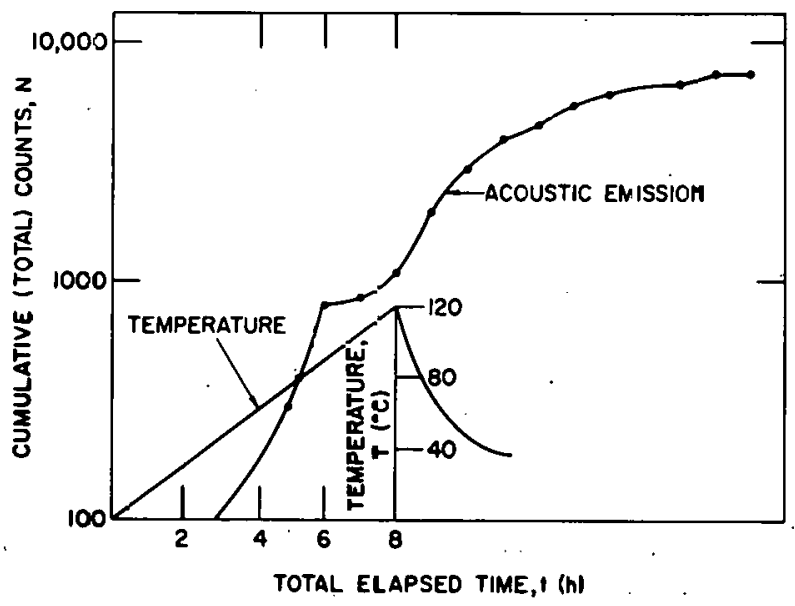

(a)

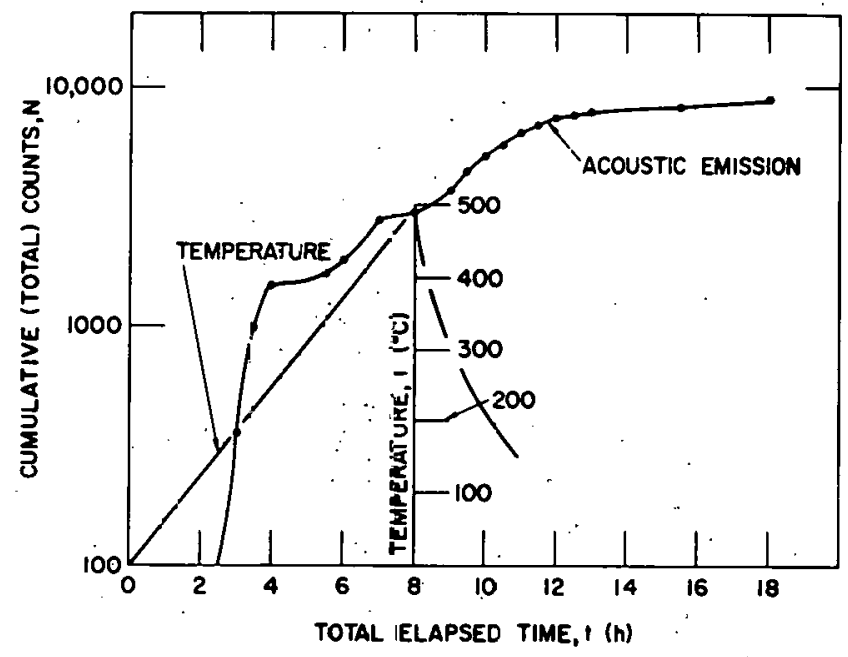

(b)

t

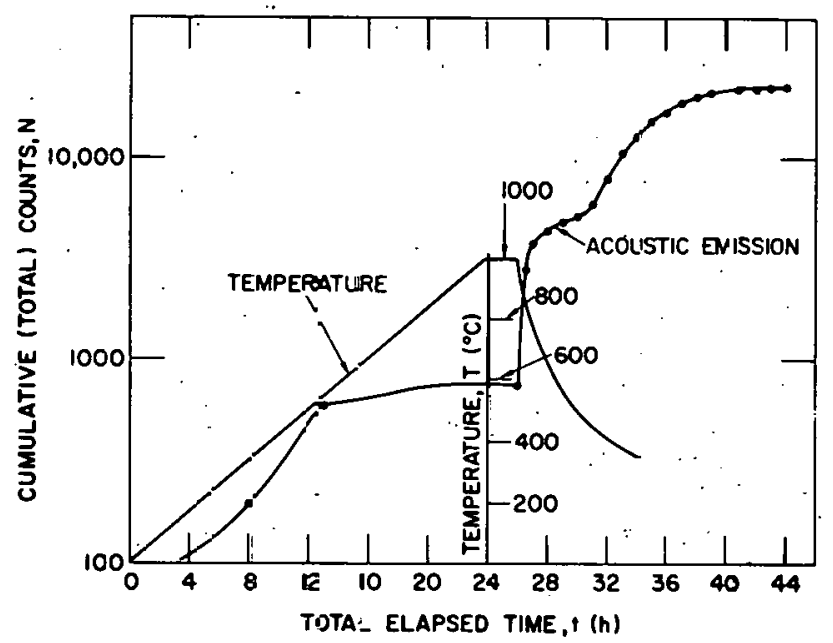

(c)

Fig. 13. Total Acoustic-emission Counts as a Function of Time for (a) the $120^{\circ} \mathrm{C}$

Linear Heating Ramp, (b) the $500^{\circ} \mathrm{C}$ Linear Heating Ramp, and (c) the $1000^{\circ} \mathrm{C}$ Linear Heating Ramp, all with Furnace Cooling. ANs Neg. No. 306-77-276. 


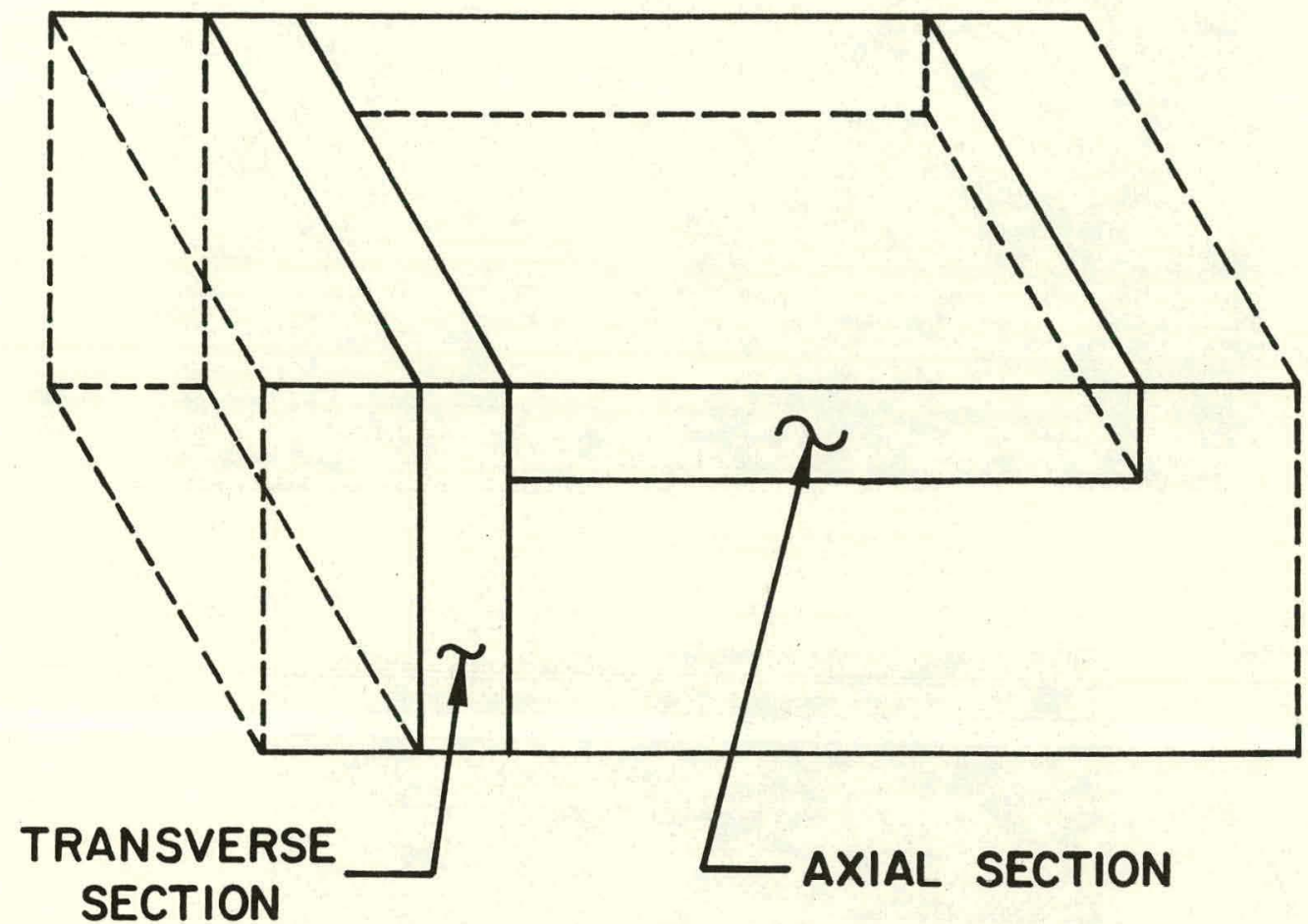

Fig. 14. Schematic Showing Metallographic Sample Locations. ANL Neg. No. 306-77-170. 


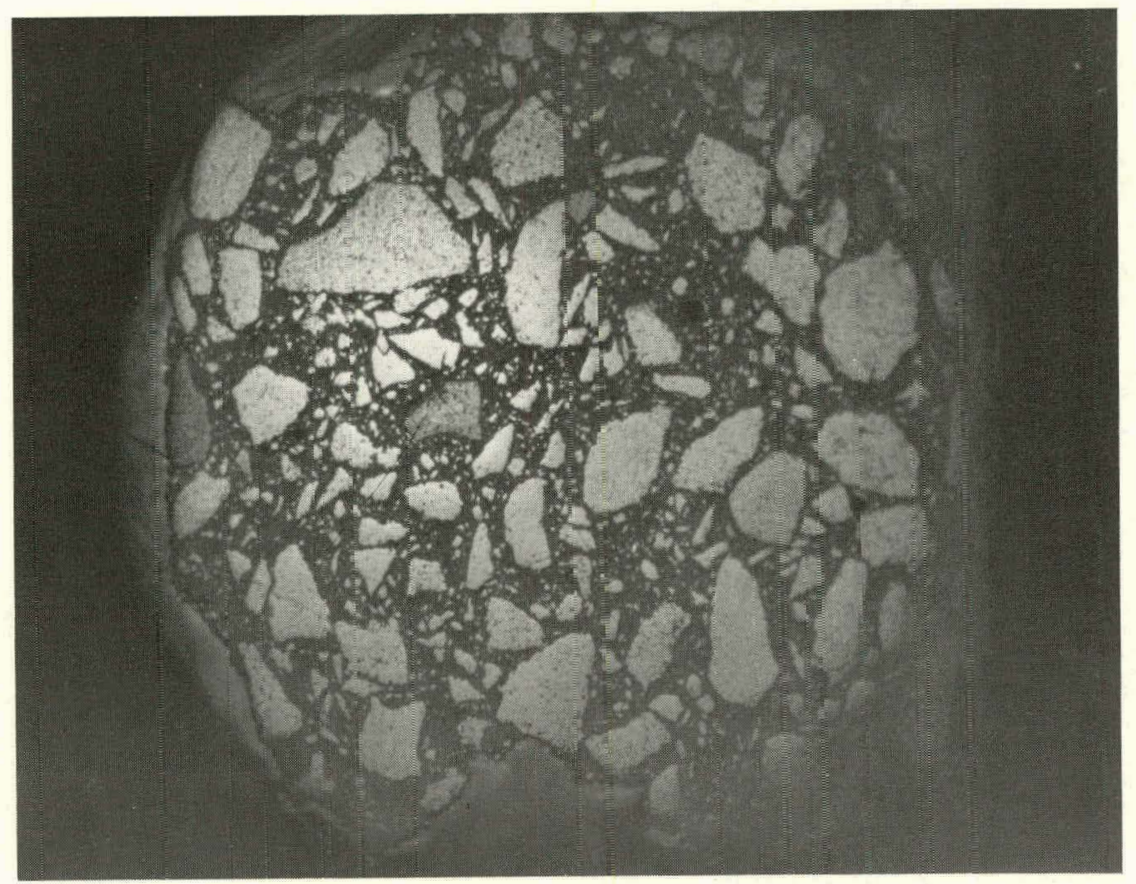

Fig. 15. Transverse Metallographic Sample. ANL Neg. No. 306-77-187.

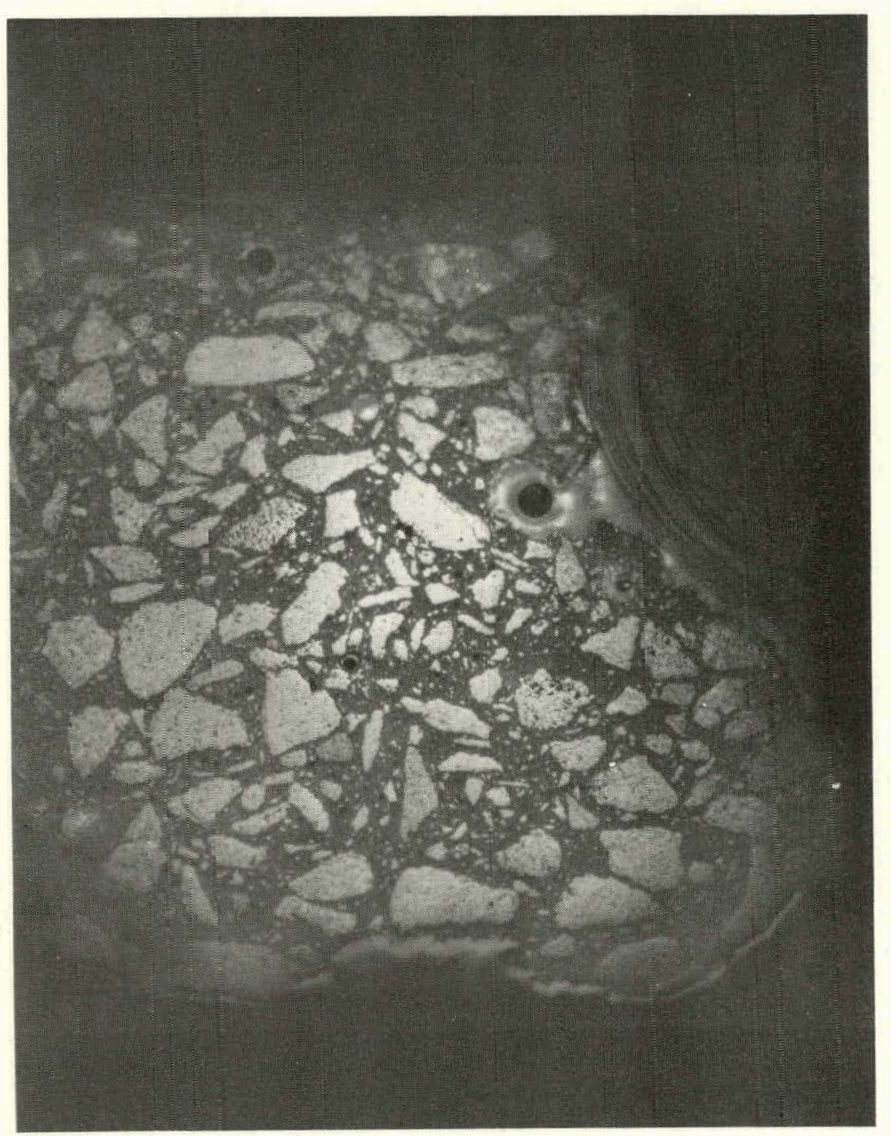

Fig. 16. Axial Metallographic Sample. ANL Neg. No. 306-77-186. 


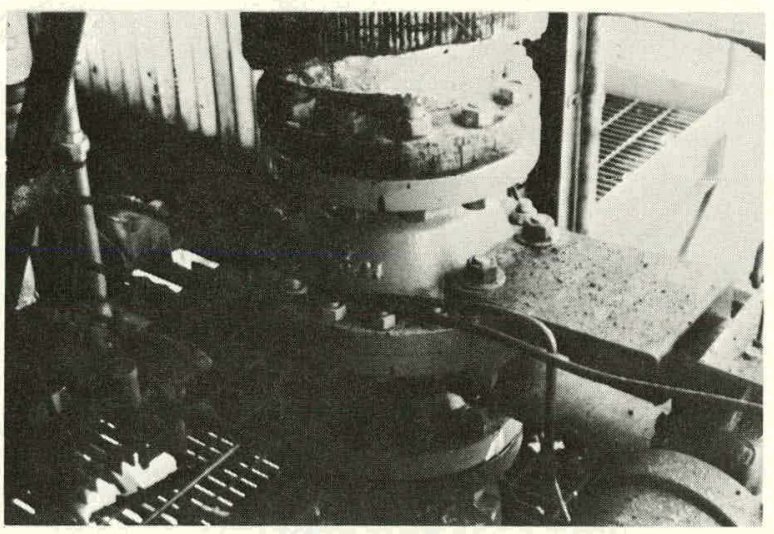

(a)

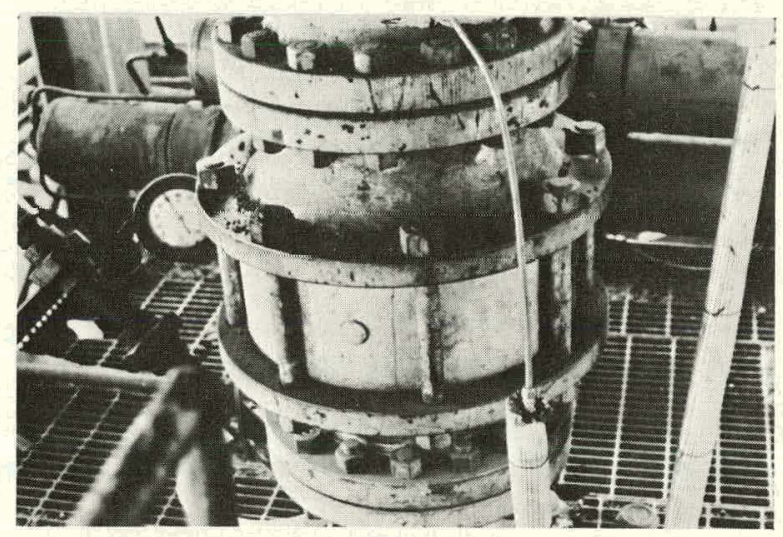

(b)

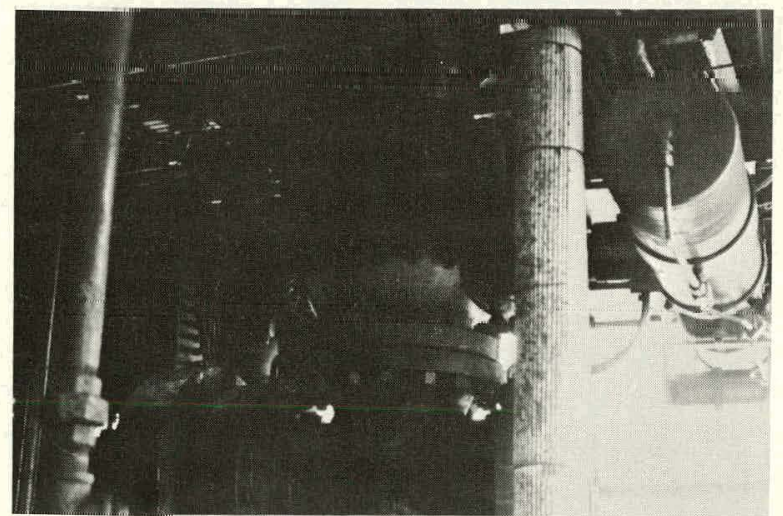

(c)

Fig. 17. Valves at MERC Low-Btu Gasifier.

(a) Top cyclone lockhopper valve,

(b) top ash lockhopper valve, and

(c) north bottom coal-feed 1ockhopper

valve. ANL Neg. No. 306-77-269. 


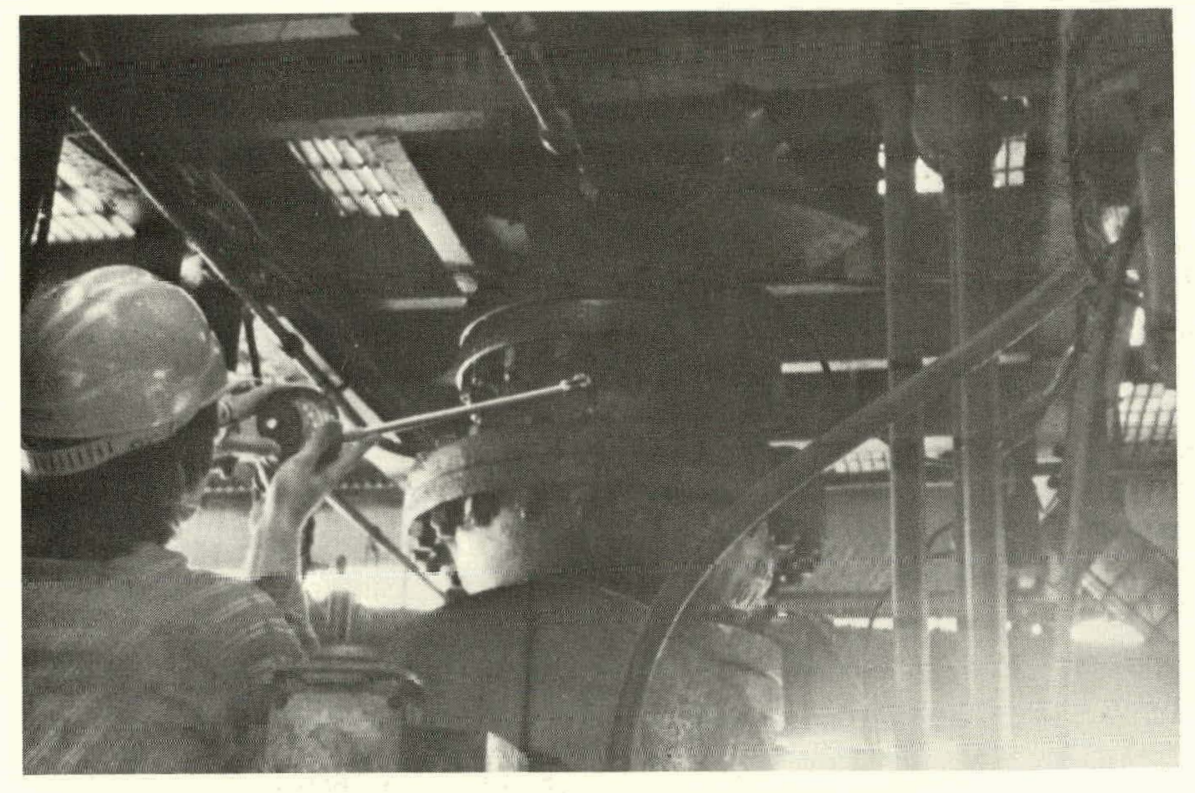

Fig. 18. Measurement of Reference Temperatures Using a Contact Pyrometer. ANL Neg. No. 306-77-185. 


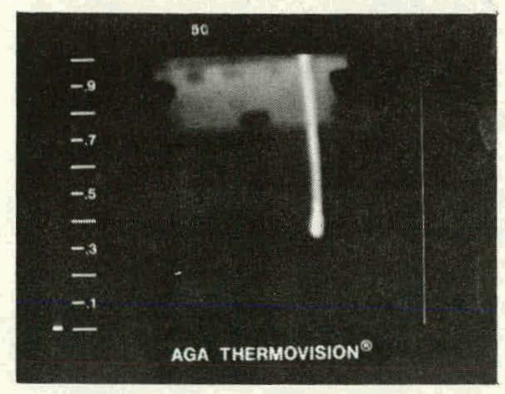

(a)

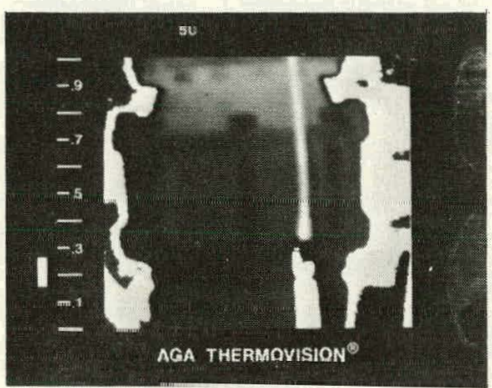

(b)

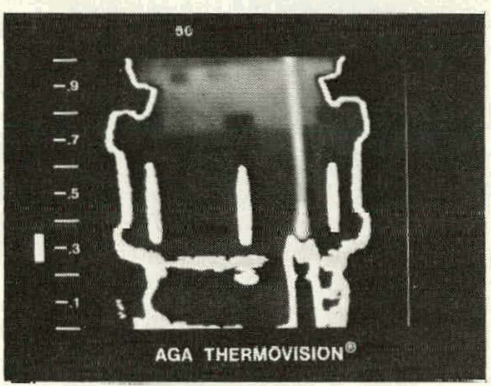

(c)

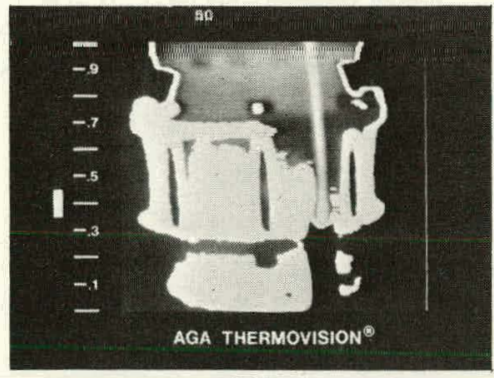

(d)

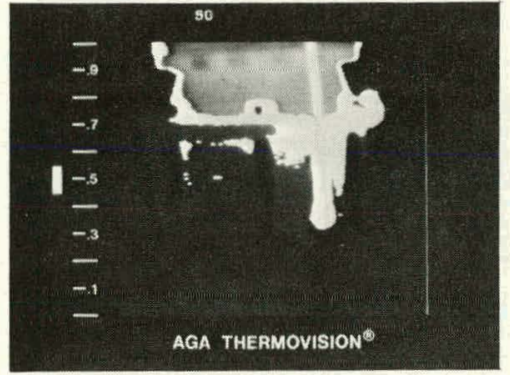

(e)

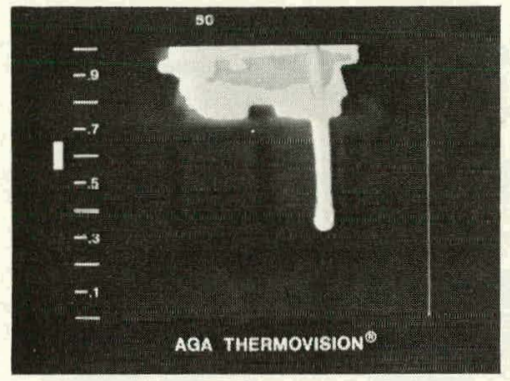

(f)

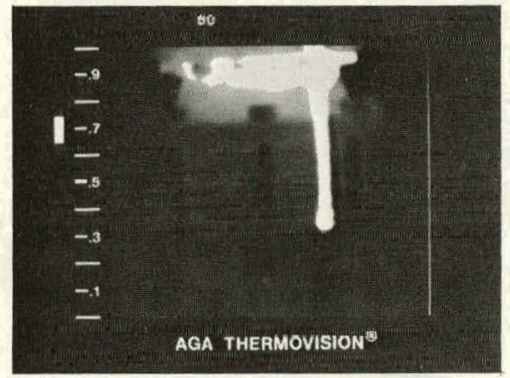

(g)

Fig. 19. Thermal Profile Sequence of the Top Ash Lockhopper Valve (Thermovision Range $=50$ ). (a) Thermal picture,

(b) $\mathrm{T}=53^{\circ} \mathrm{C}$ isothermal area, (c) $\mathrm{T}=55^{\circ} \mathrm{C}$ isothermal area, (d) $\mathrm{T}=57^{\circ} \mathrm{C}$ isothermal area, (e) $\mathrm{T}=59^{\circ} \mathrm{C}$ isothermal area, (f) $\mathrm{T}=62^{\circ} \mathrm{C}$ isothermal area, and $(\mathrm{g}) \mathrm{T}=64^{\circ} \mathrm{C}$ Isothermal area. ANL Neg. No. 306-77-270. 


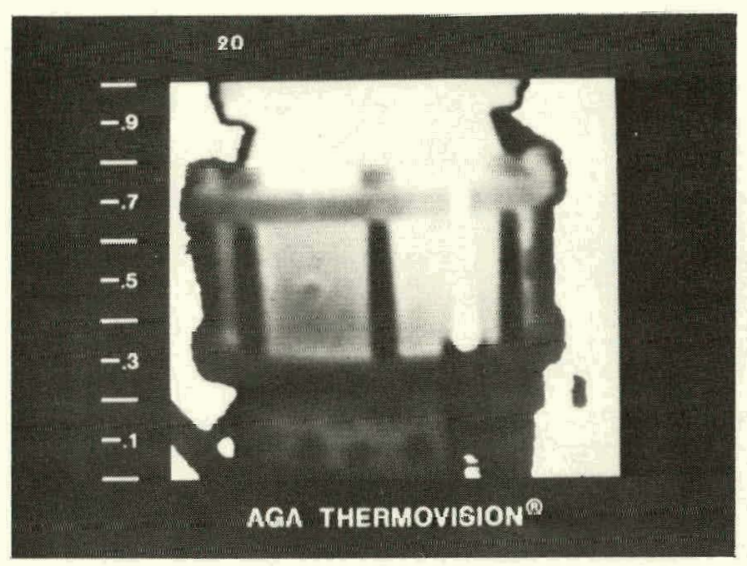

(a)

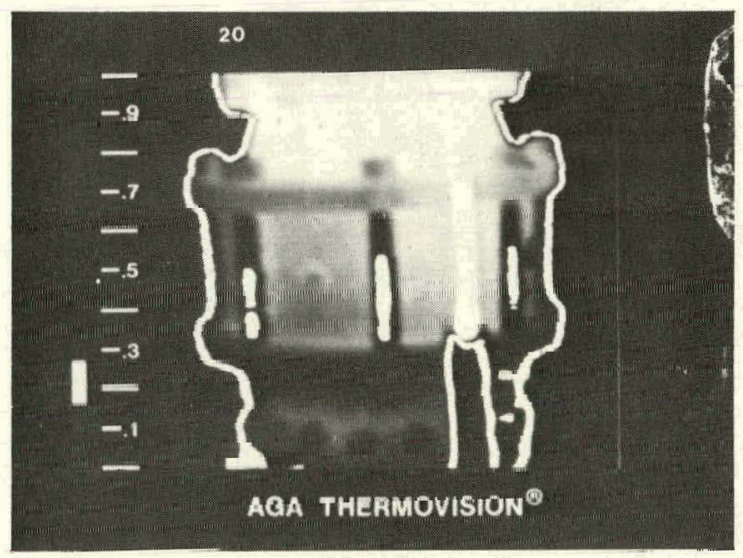

(c)

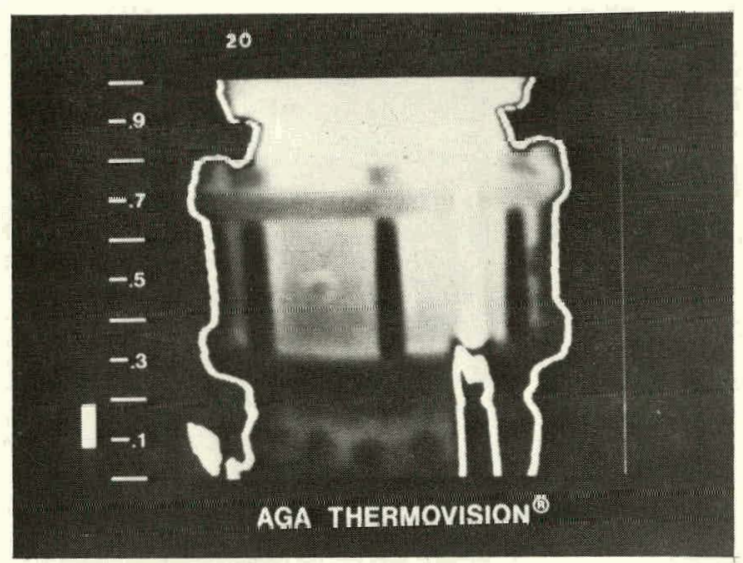

(b)

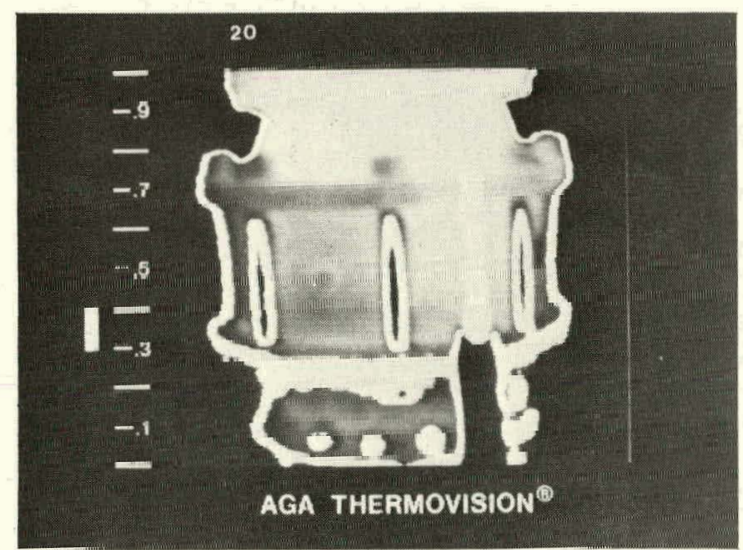

(d)

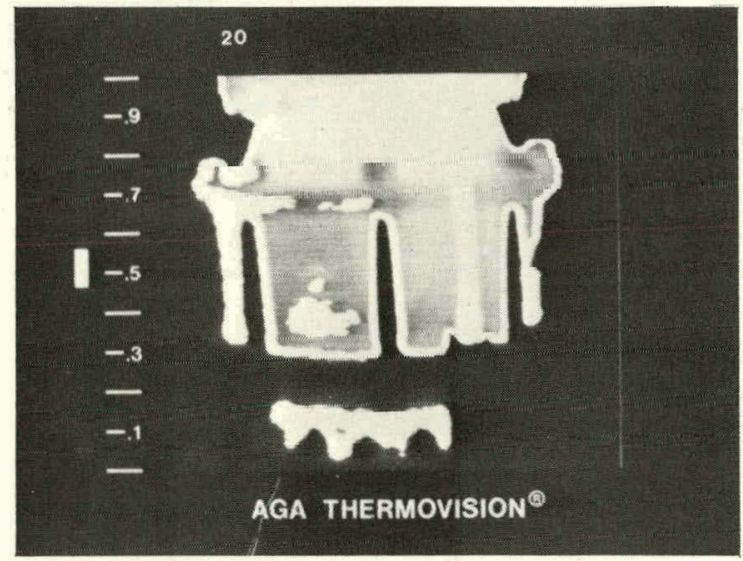

(e)

Fig. 20. Thermal Profile Sequence of the Top Ash Lockhopper Valve (Thermovision Range $=20$ ). (a) Thermal picture, (b) $\mathrm{T}=54^{\circ} \mathrm{C}$ isothermal area, (c) $\mathrm{T}=55^{\circ} \mathrm{C}$ isothermal area, (d) $\mathrm{T}=56^{\circ} \mathrm{C}$ isothermal area, and (e) $\mathrm{T}=57^{\circ} \mathrm{C}$ isothermal area. ANL Neg. No. 306-77-272. 


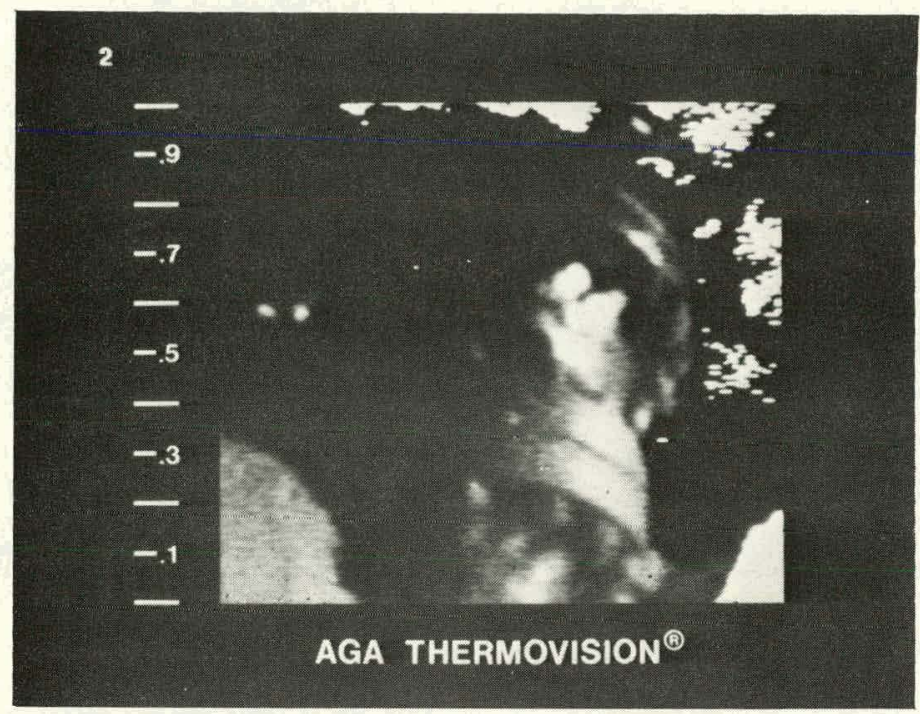

(a)

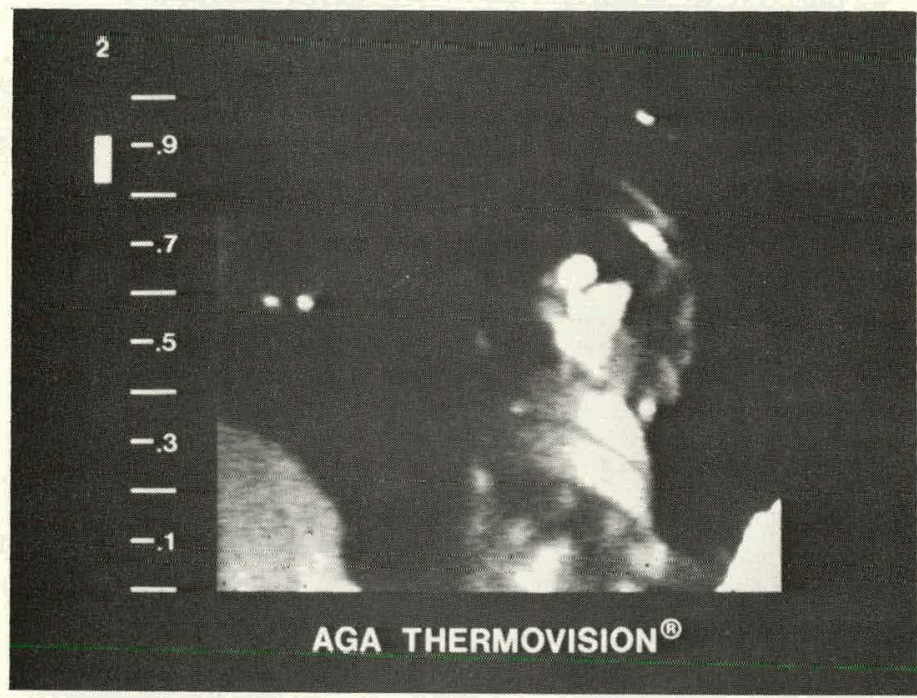

(b)

Fig. 21. Thermal Profile Sequence of the North Bottom Coal-feed Lockhopper Valve. (a) Thermal picture and (b) $\mathrm{T}=37^{\circ} \mathrm{C}$ "hot spot." ANL Neg. No. 306-77-268. 


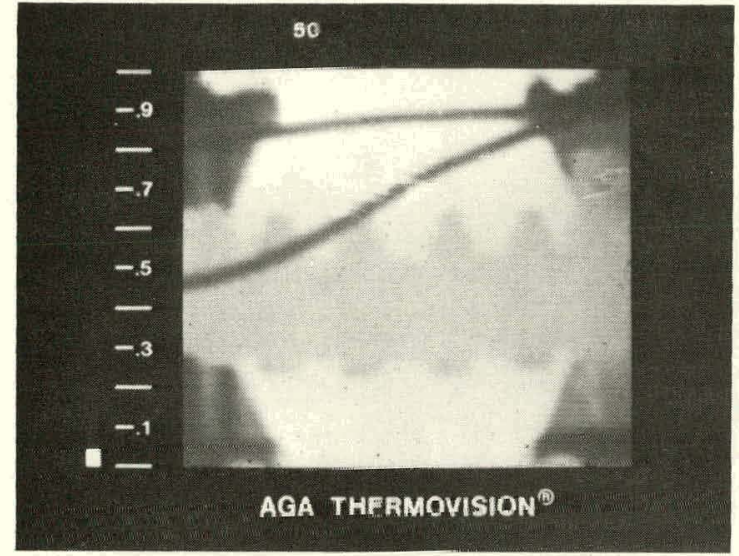

(a)

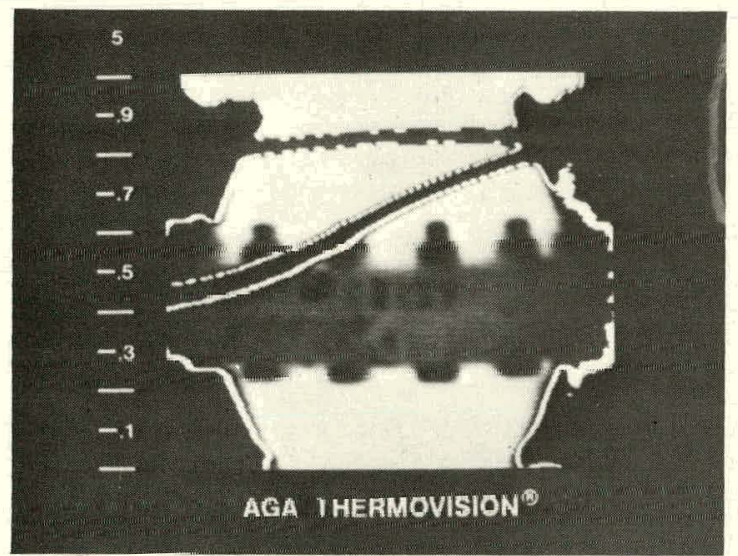

(c)

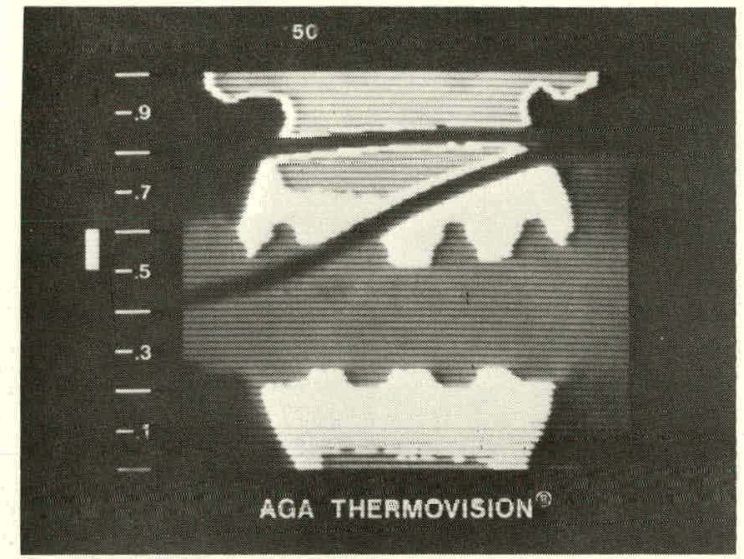

(b)

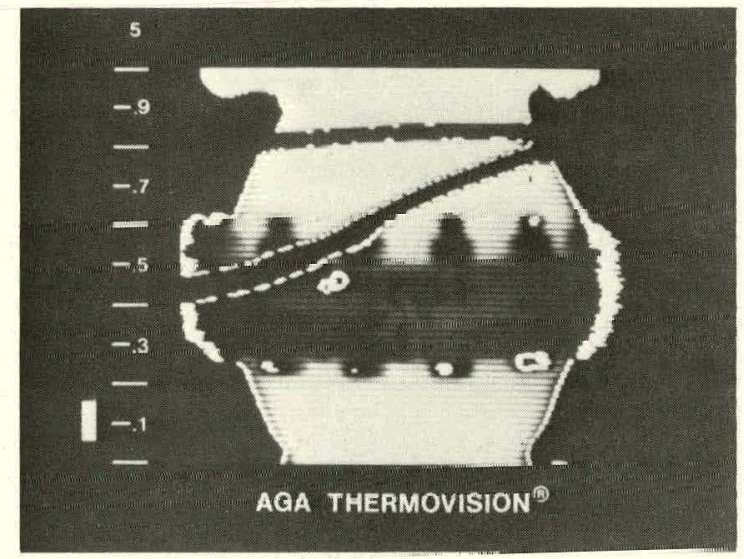

(d)

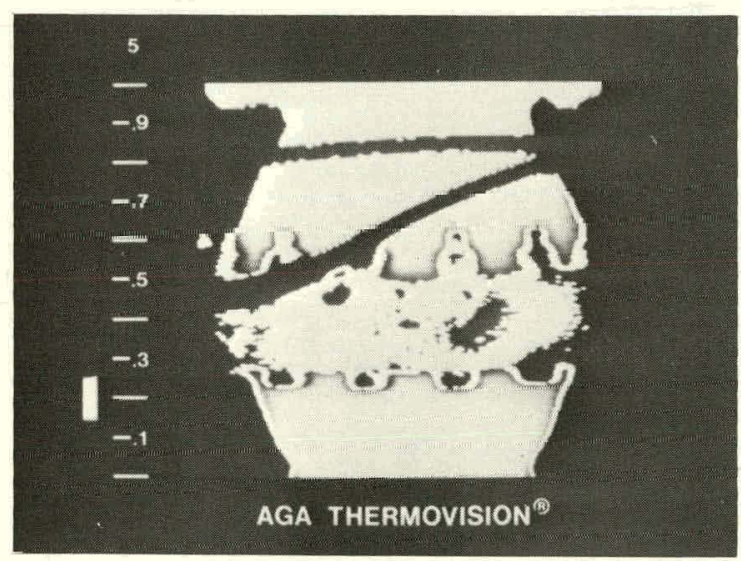

(e)

Fig. 22. Thermal Profile Sequence of Top Cyclone Lockhopper Valve. (a) Thermal picture (thermovision range $=50$ ), (b) $\mathrm{T}=60^{\circ} \mathrm{C}$ isothermal area, (c) thermal picture (thermovision range $=5$ ), (d) $\mathrm{T} \simeq 58.5^{\circ} \mathrm{C}$ isothermal area, and (e) $\mathrm{T}=59^{\circ} \mathrm{C}$ isothermal area. ANL Neg. No. 306-77-267. 


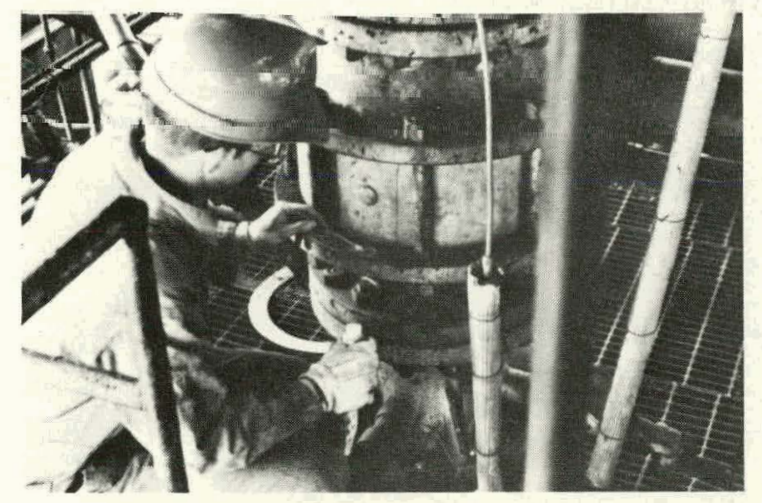

(a)

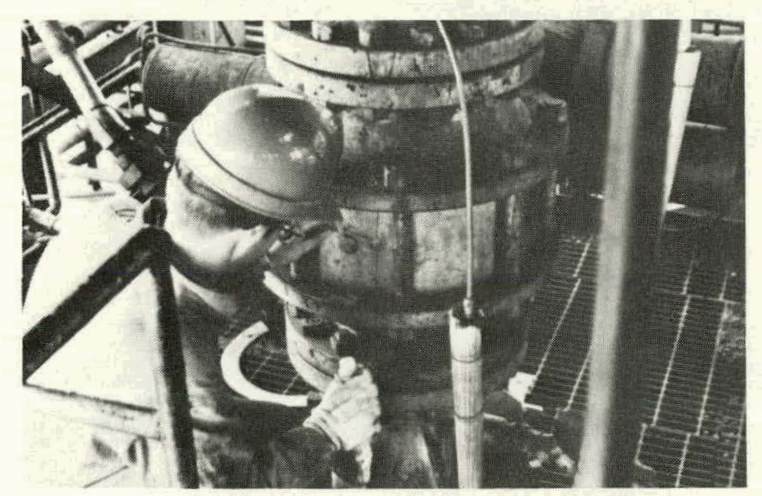

(b)

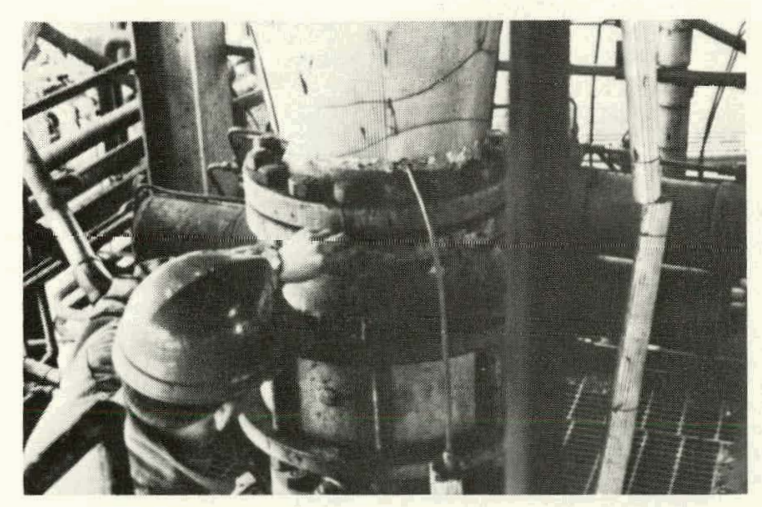

(c)

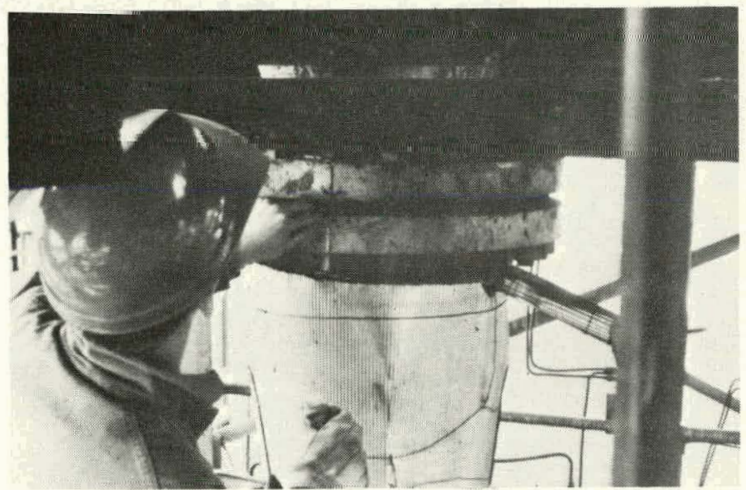

(d)

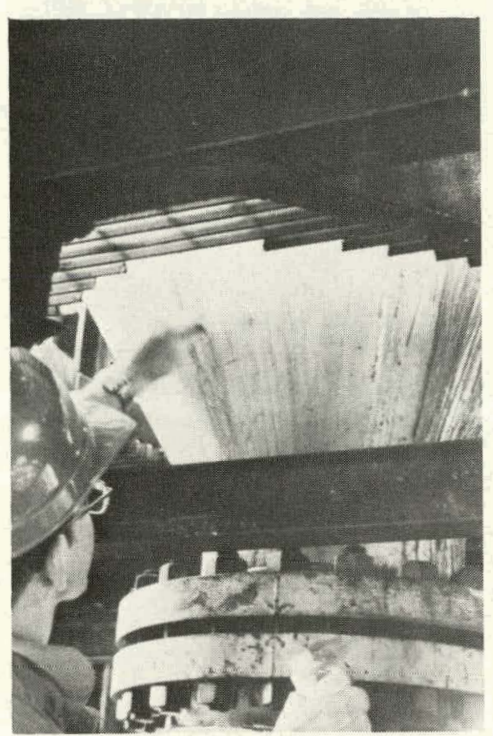

(e)

Fig. 23. Acoustic-emission Measurement Locations on the MERC Top Cyclone Lockhopper Valve. ANL Neg. No. 306-77-265. 


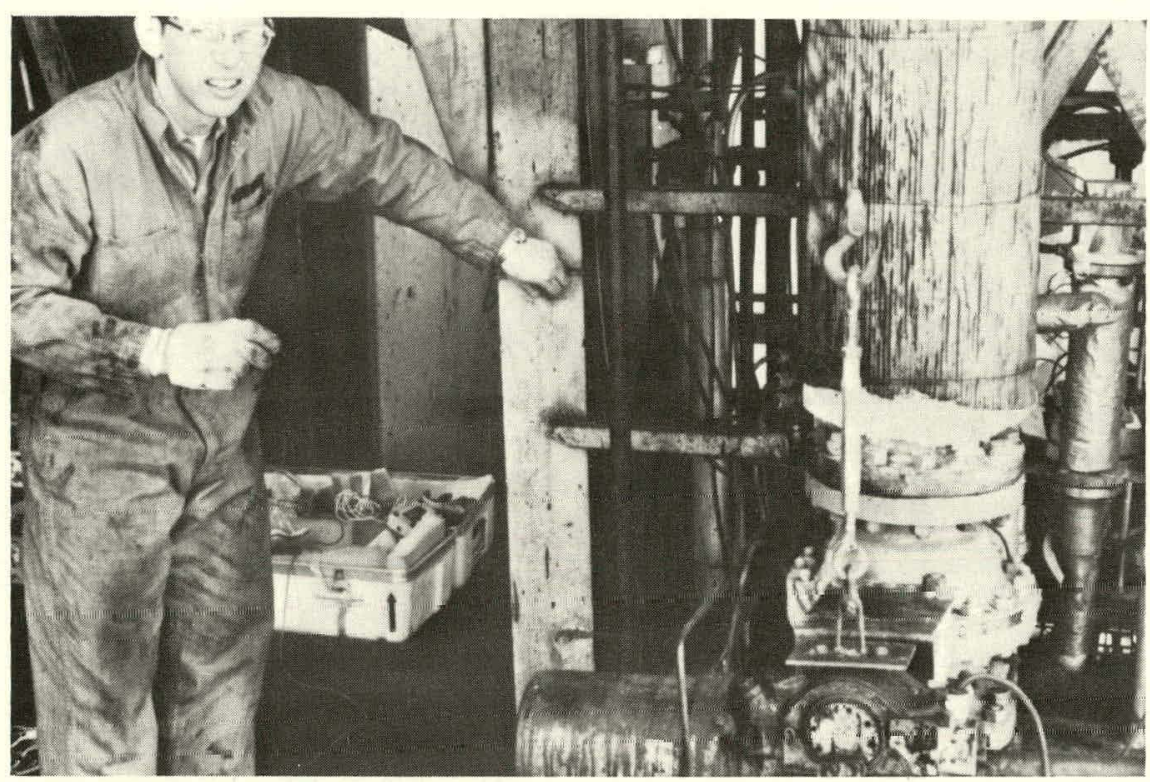

(a)

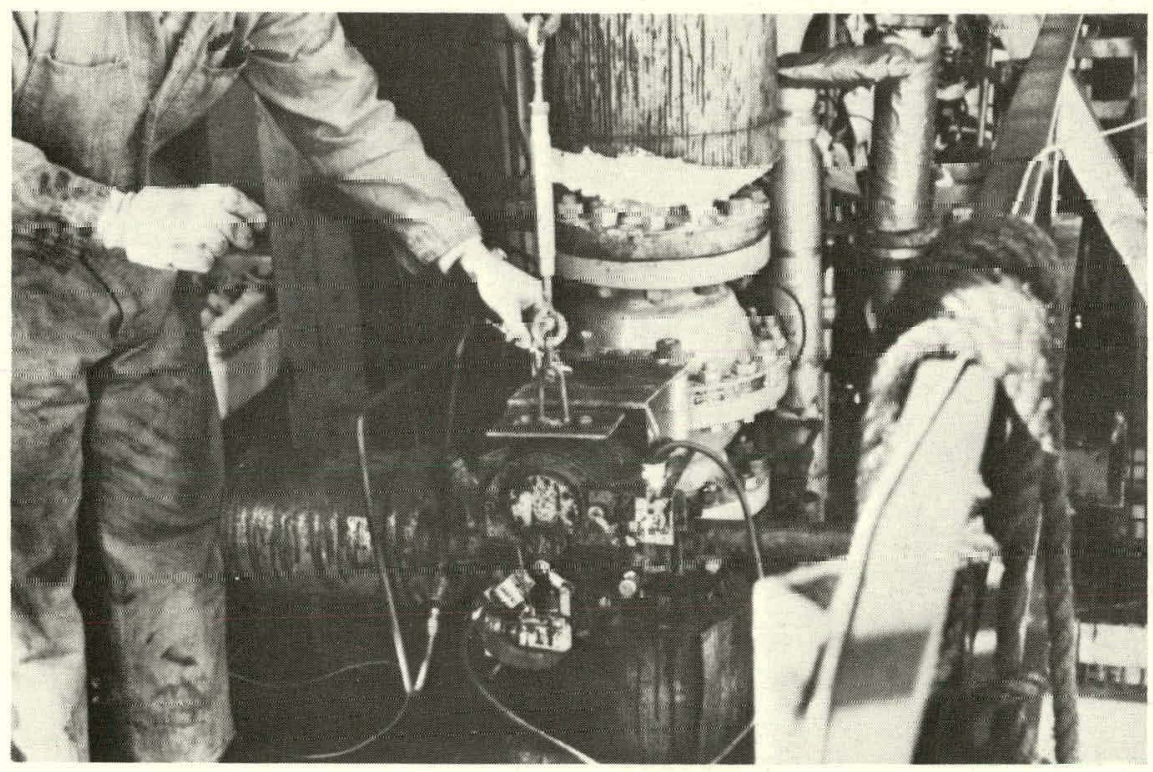

(b)

Fig. 24. Acoustic-emission Measurement Locations on Structure Near Cyclone Lockhopper Valve. ANL Neg. No. 306-77275 . 


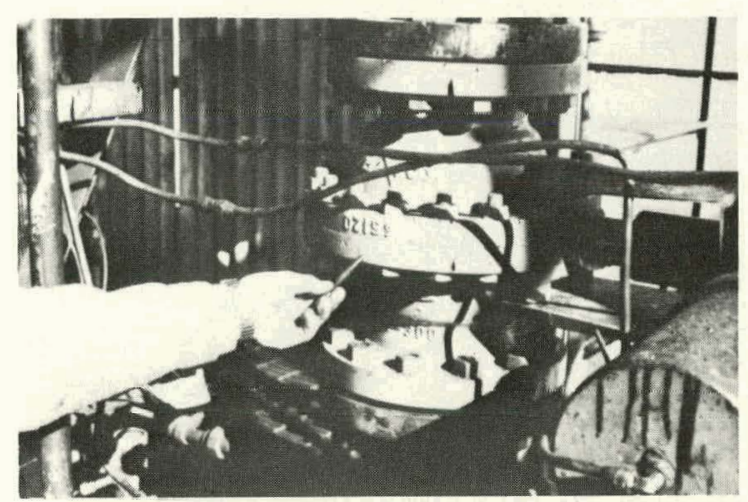

(a)

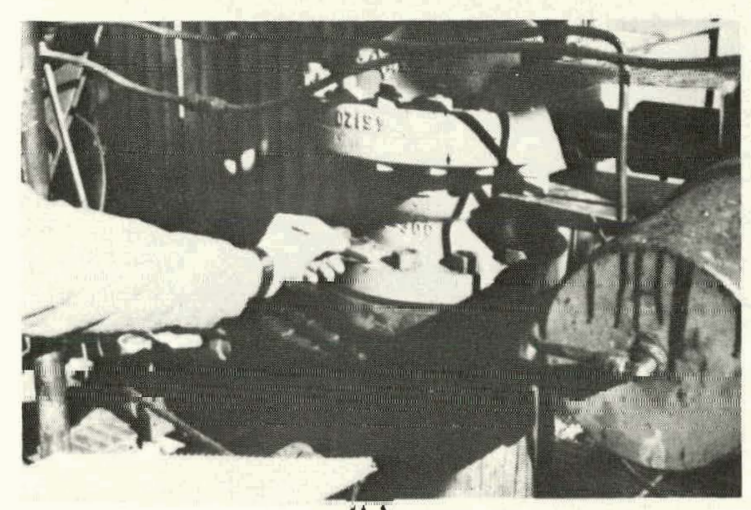

(b)

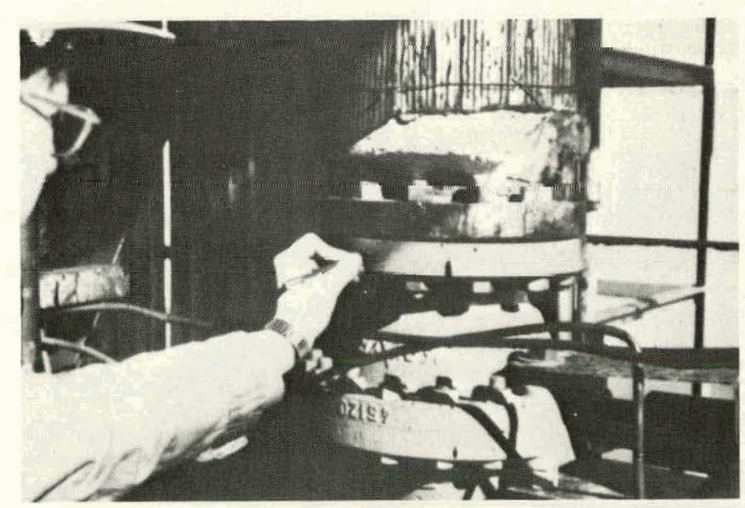

(c)

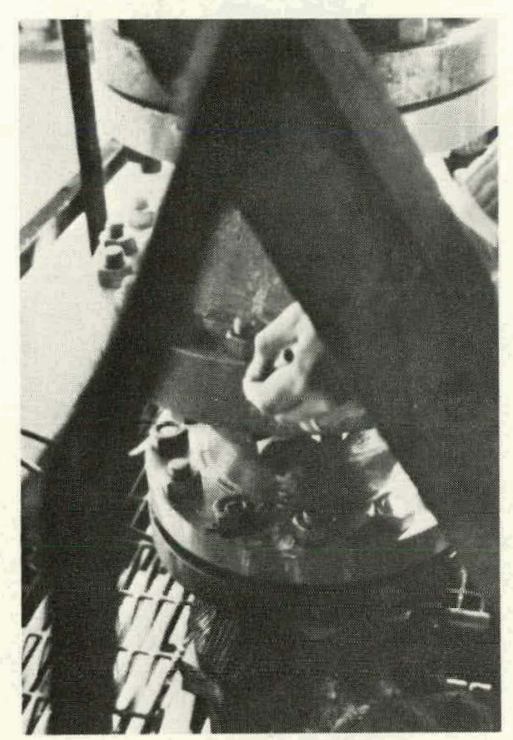

(d)

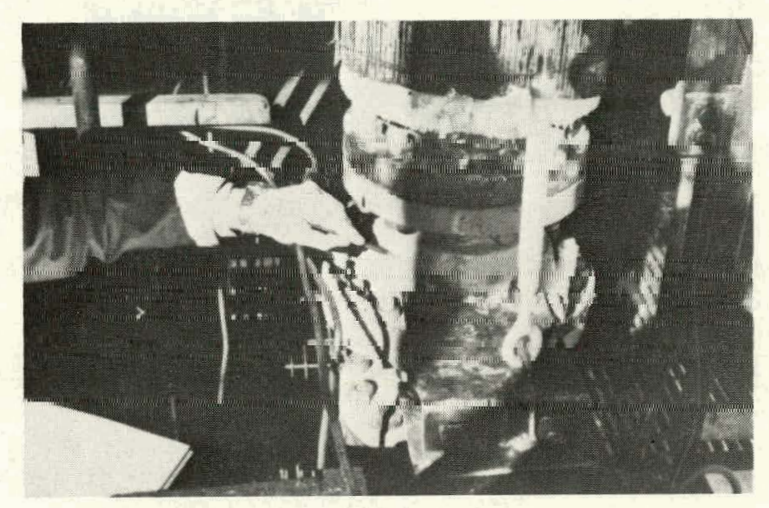

(e)

Fig. 25. Acoustic-emission Measurement Locations on the MERC Top Ash Lockhopper Valve. ANL Neg. No. 306-77-274. 


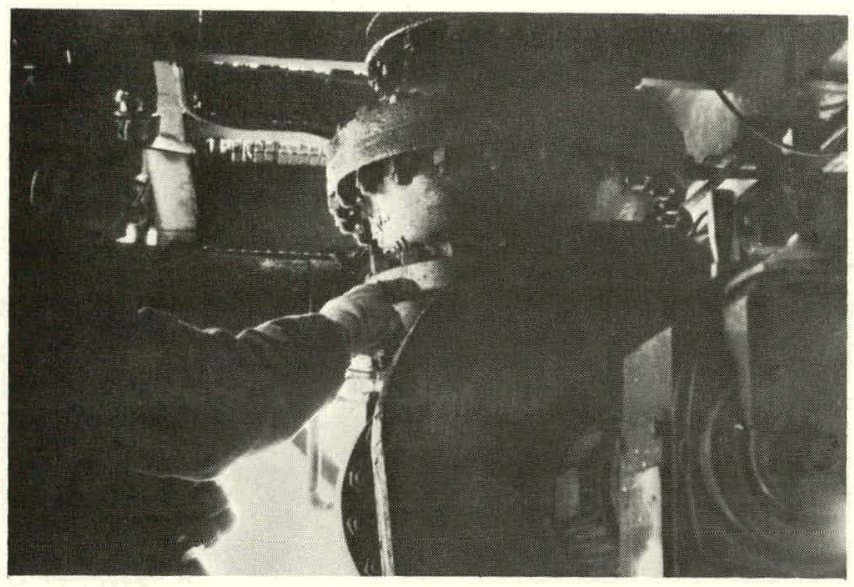

(a)

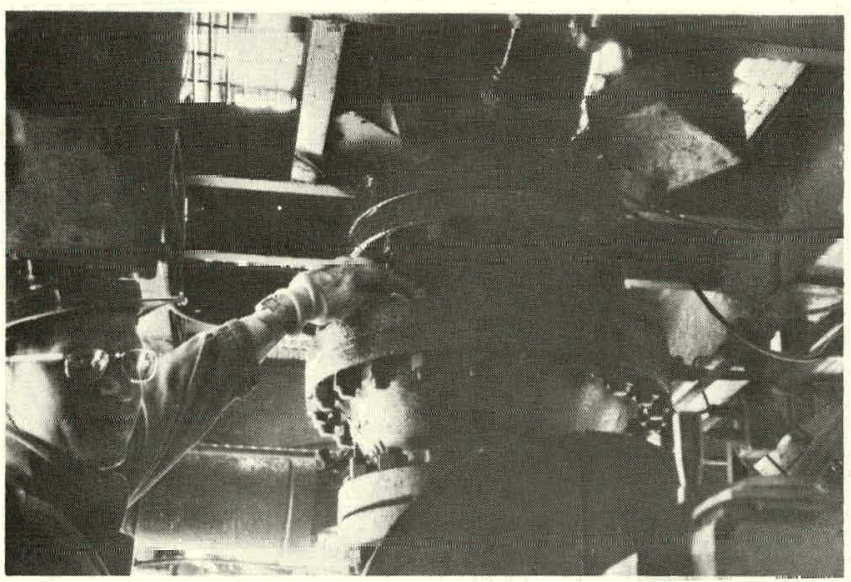

(b)

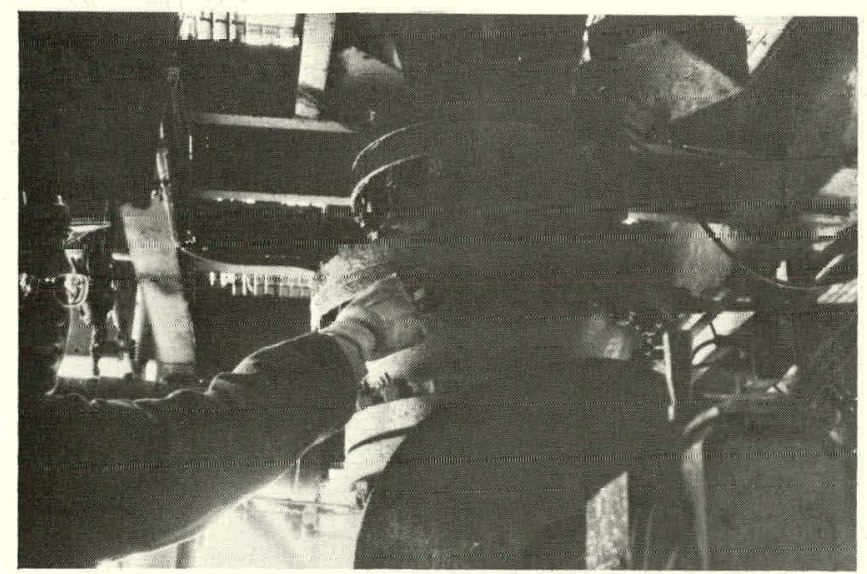

(c)

Fig. 26. Acoustic-emission Measurement Locations for the MERC North Bottom Coal-feed Lockhopper Valve. ANL Neg. No. 306-77-271. 


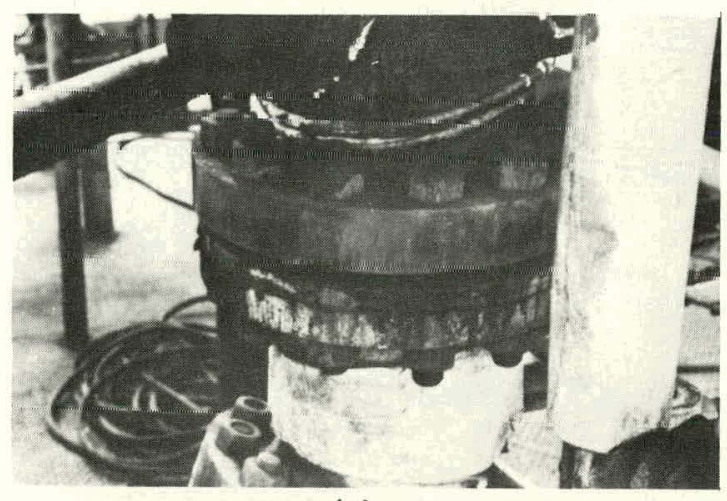

(a)

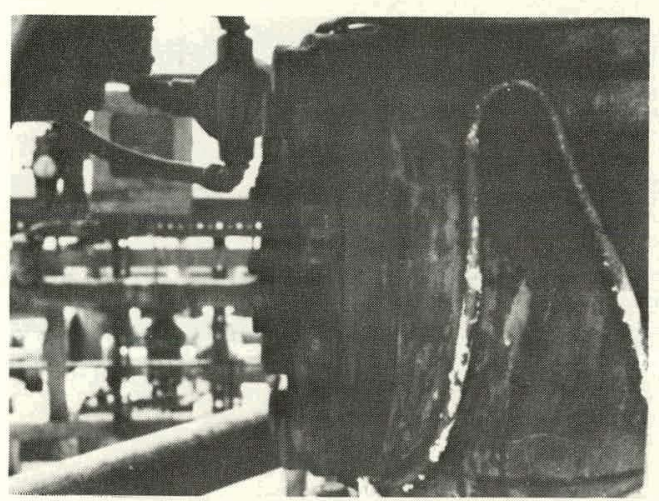

(b)

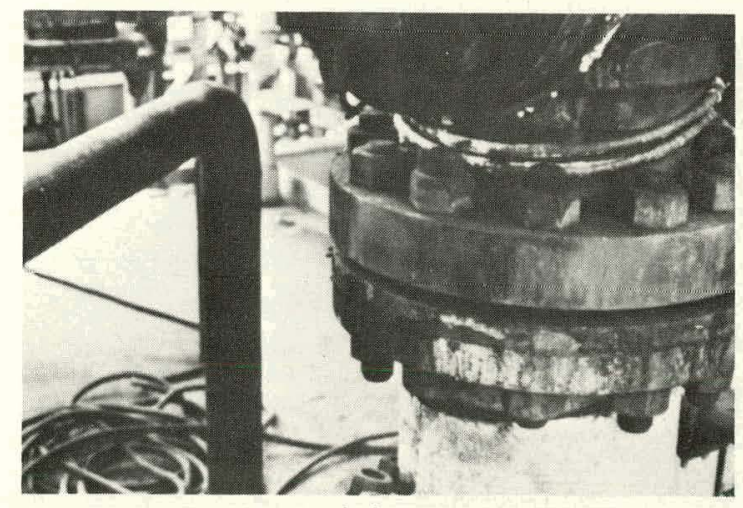

(c)

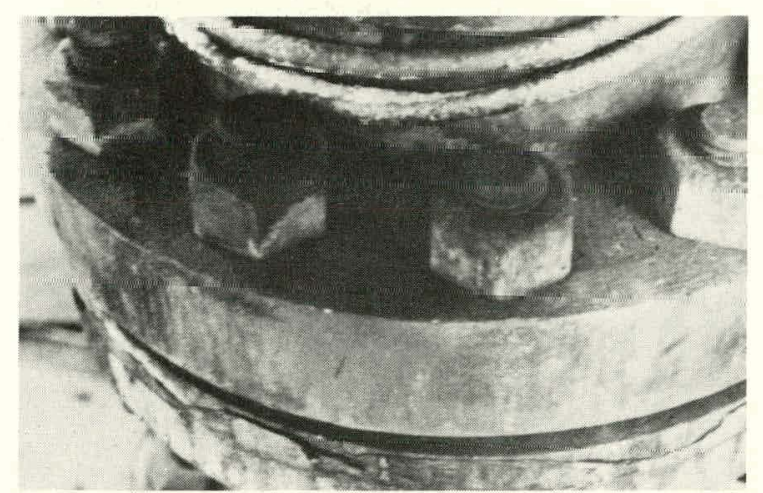

(d)

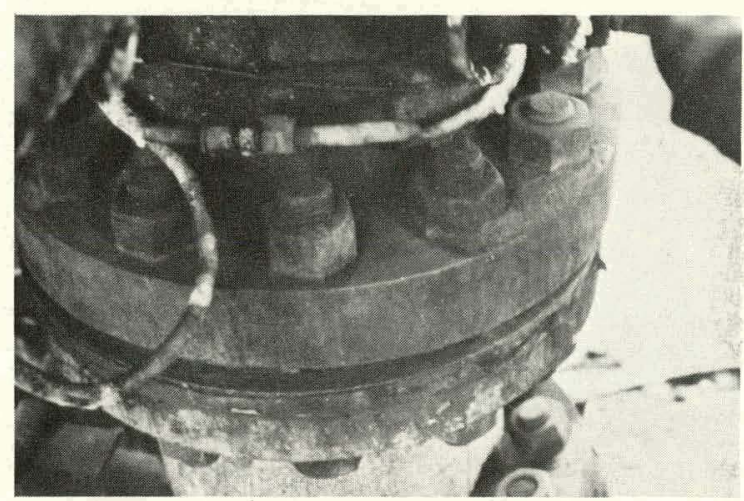

(e)

Fig. 27. Acoustic-emission Measurement Locations for the Synthane North Lower Petrocarb Feed Valves. ANL Neg. No. 306-77-266. 


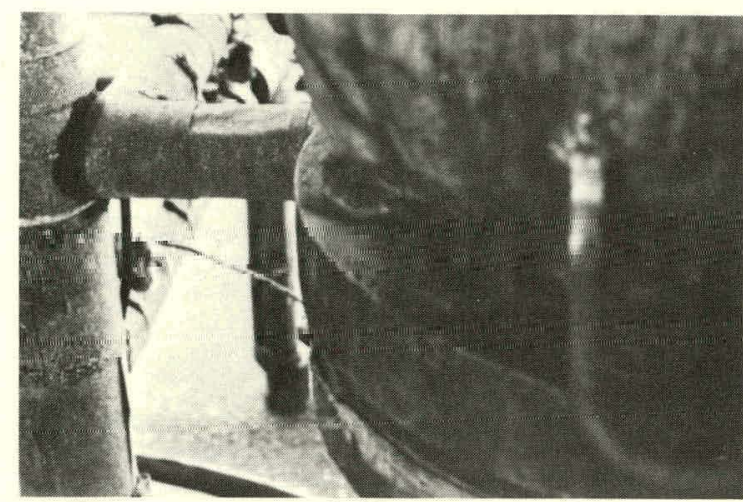

(n)

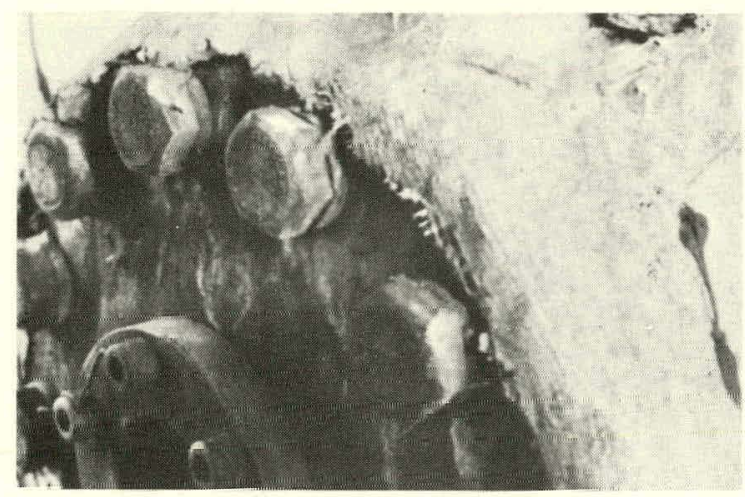

(b)

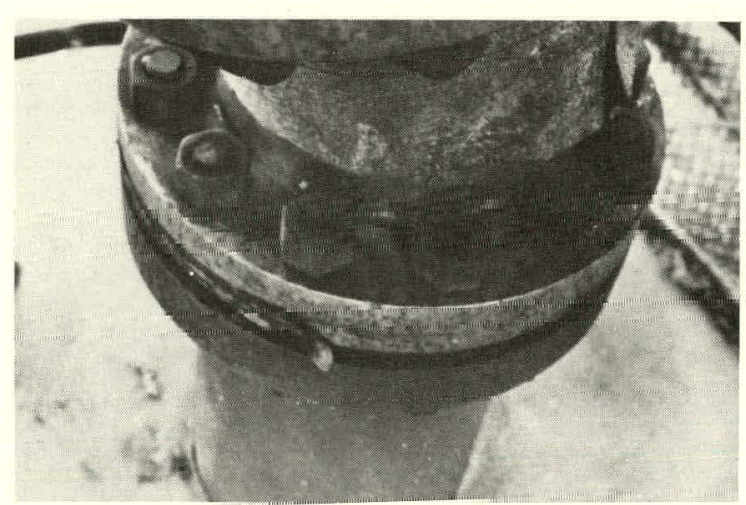

(c)

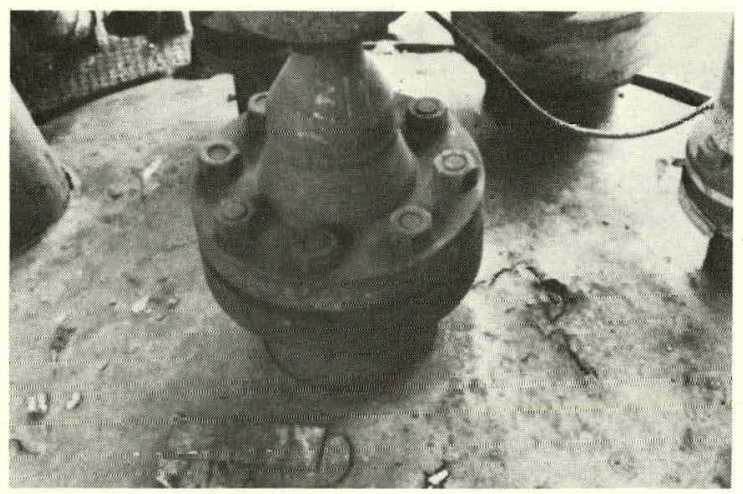

(d)

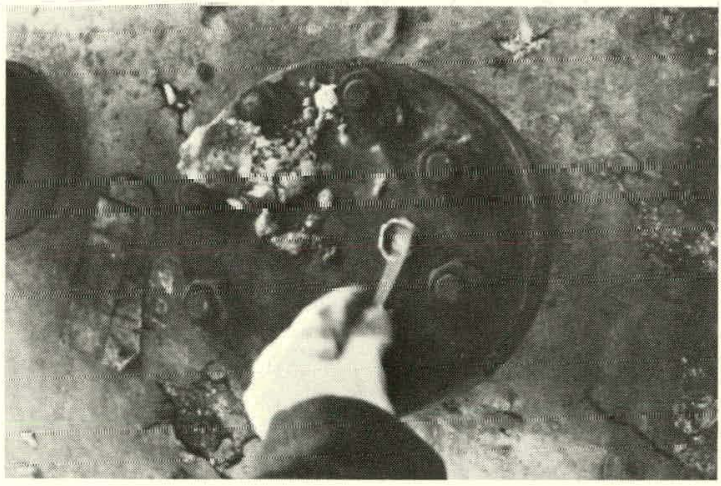

(e)

Fig. 28. Acoustic-emission Measurement Locations for the Synthane South Lower Petrocarb Feed Va1ves and Ncarby Struclure. ANL Neg. No. 306-77-273. 

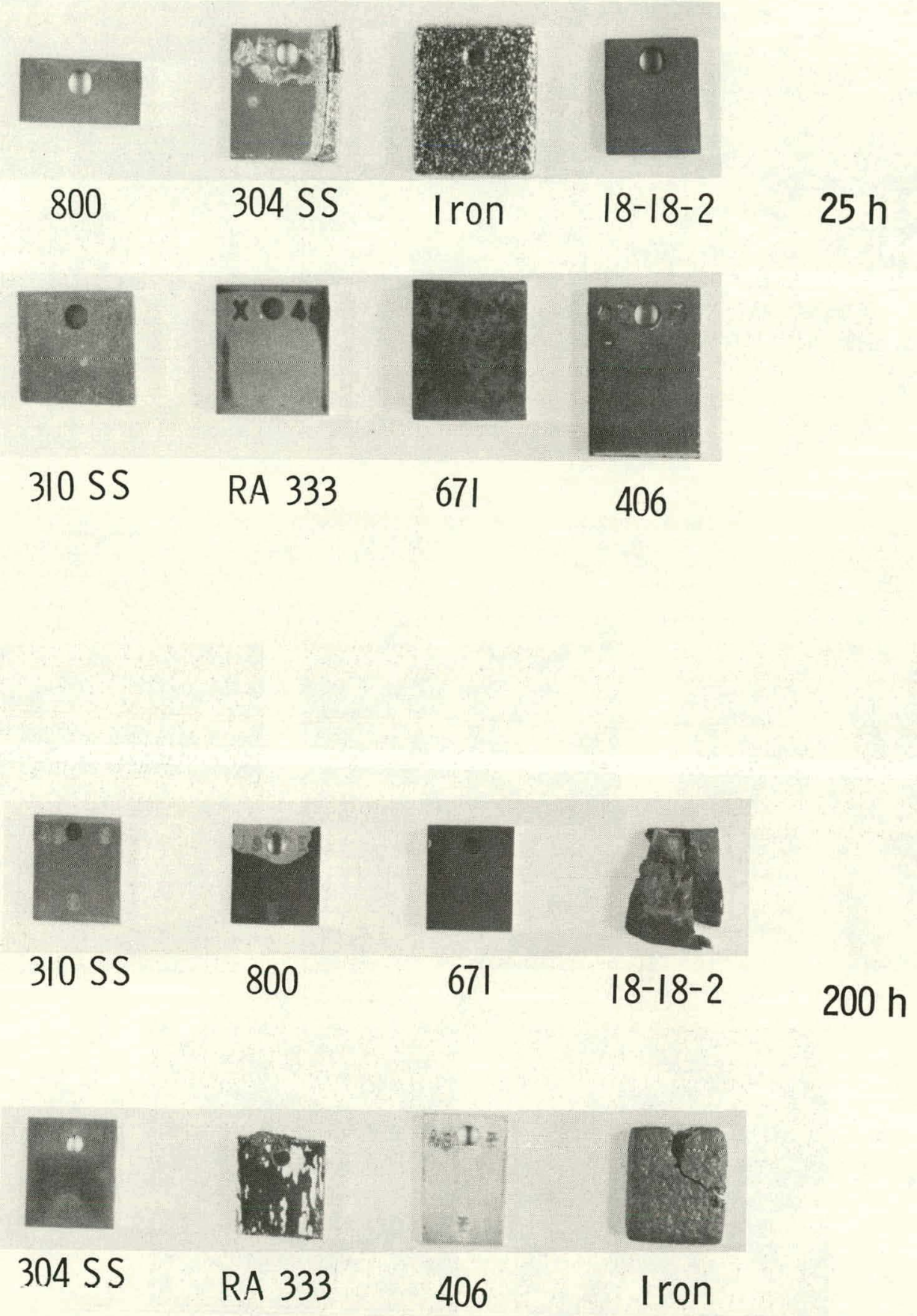

Fig. 29. Macruscopic Photographs of Specimens That Have Been Exposed to Multicomponent Gas Environment at $875^{\circ} \mathrm{C}$ for $25 \mathrm{~h}$ (Top) and $200 \mathrm{~h}$ (Bottom). 

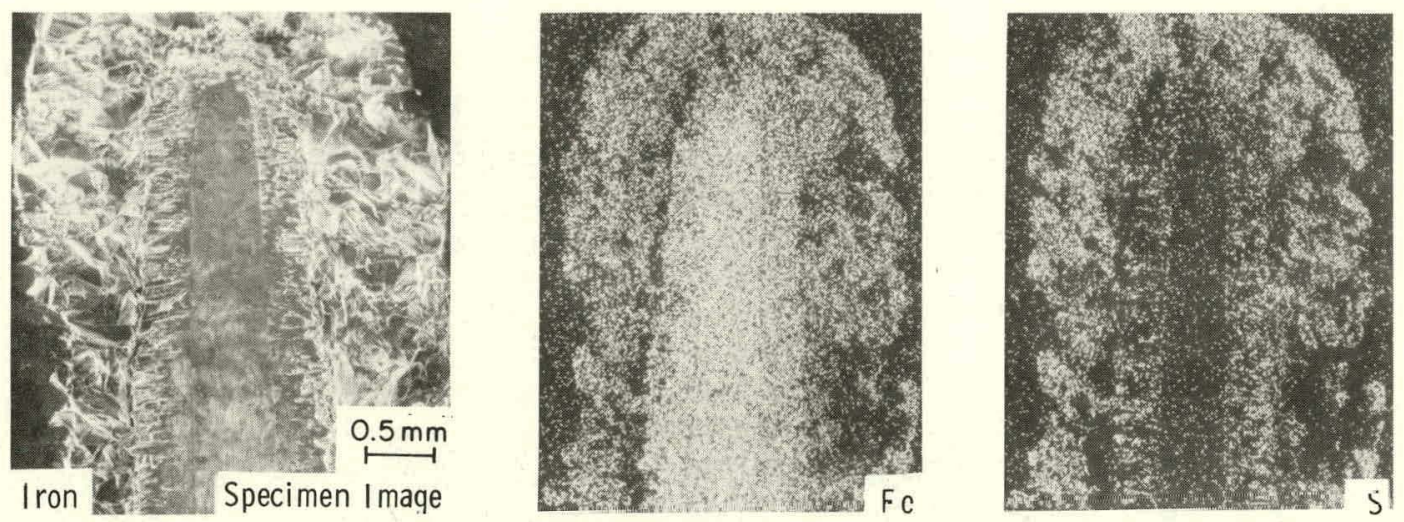

Fig. 30. X-ray Specimen Image and the $\mathrm{Fe}$ and $\mathrm{S}$ Distributions for an Iron Specimen Exposed to a Compler Gas Mixture al $875^{\circ} \mathrm{C}$ for $25 \mathrm{~h}$.
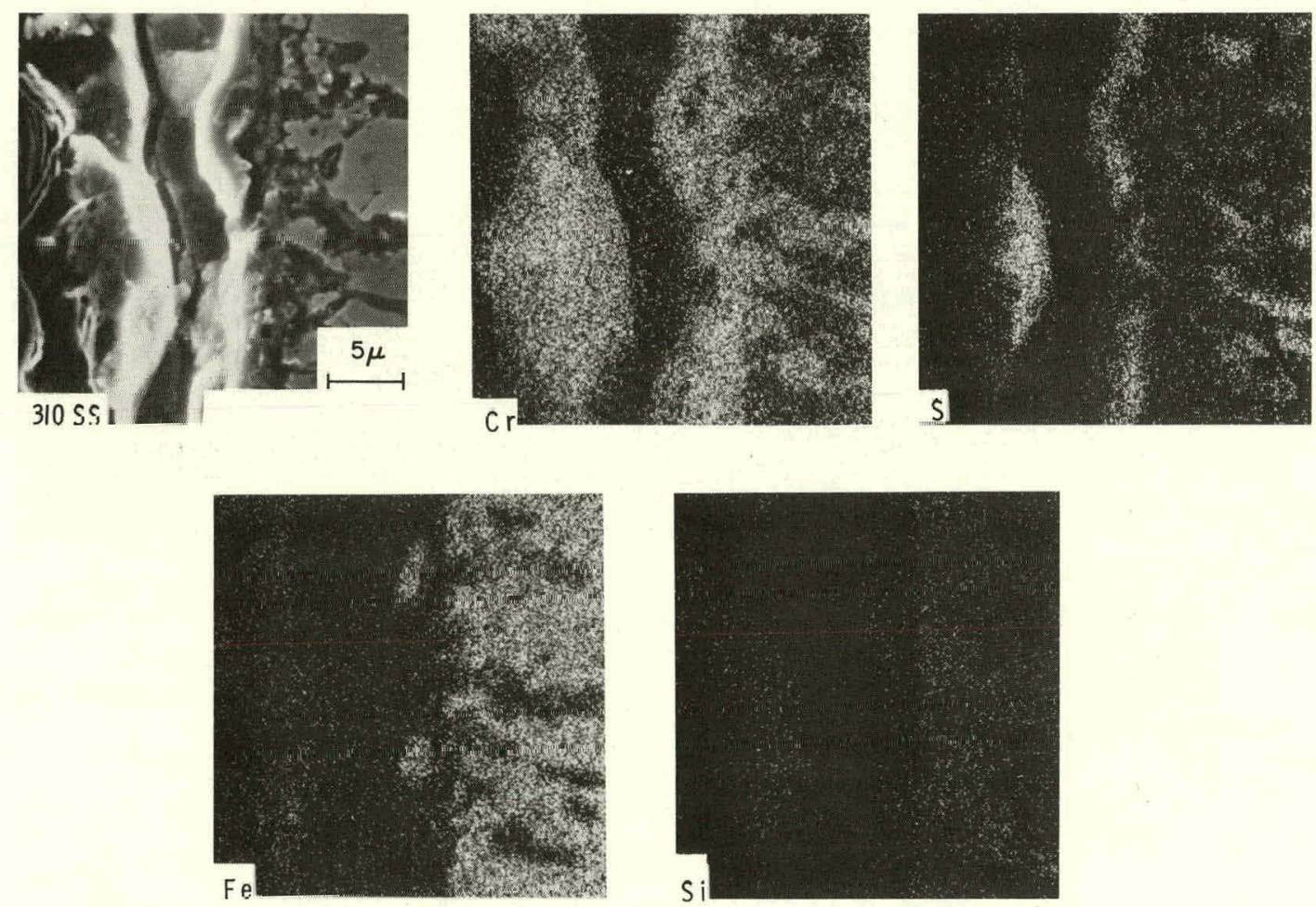

Fig. 31. X-ray Specimen Image and $\mathrm{Cr}, \mathrm{S}, \mathrm{Fe}$, and Si Distrihutions in Type 310 Stainless Steel Exposed to the Gas Mixture Listed in Table $\mathrm{X}$ for $25 \mathrm{~h}$ at $875^{\circ} \mathrm{C}$. In the distribution photographs, the light region indicates a high concentration of the respective elements. 


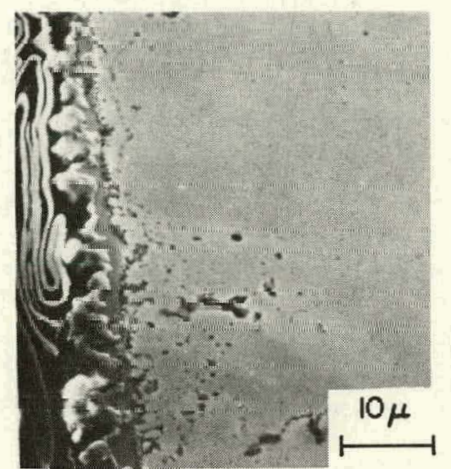

Incoloy 800 Specimen Image

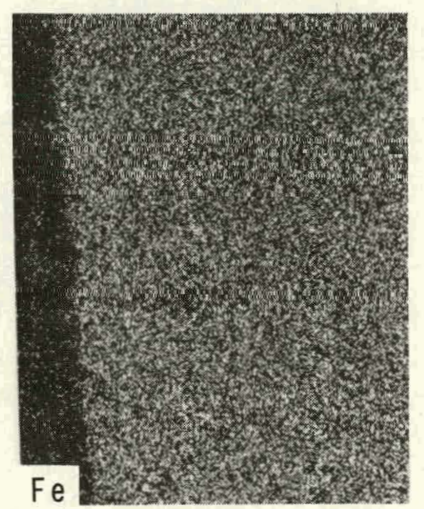

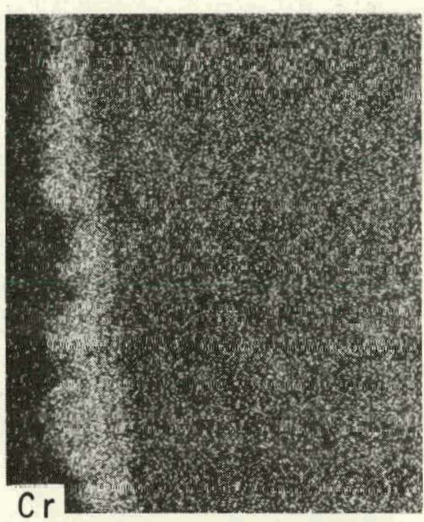
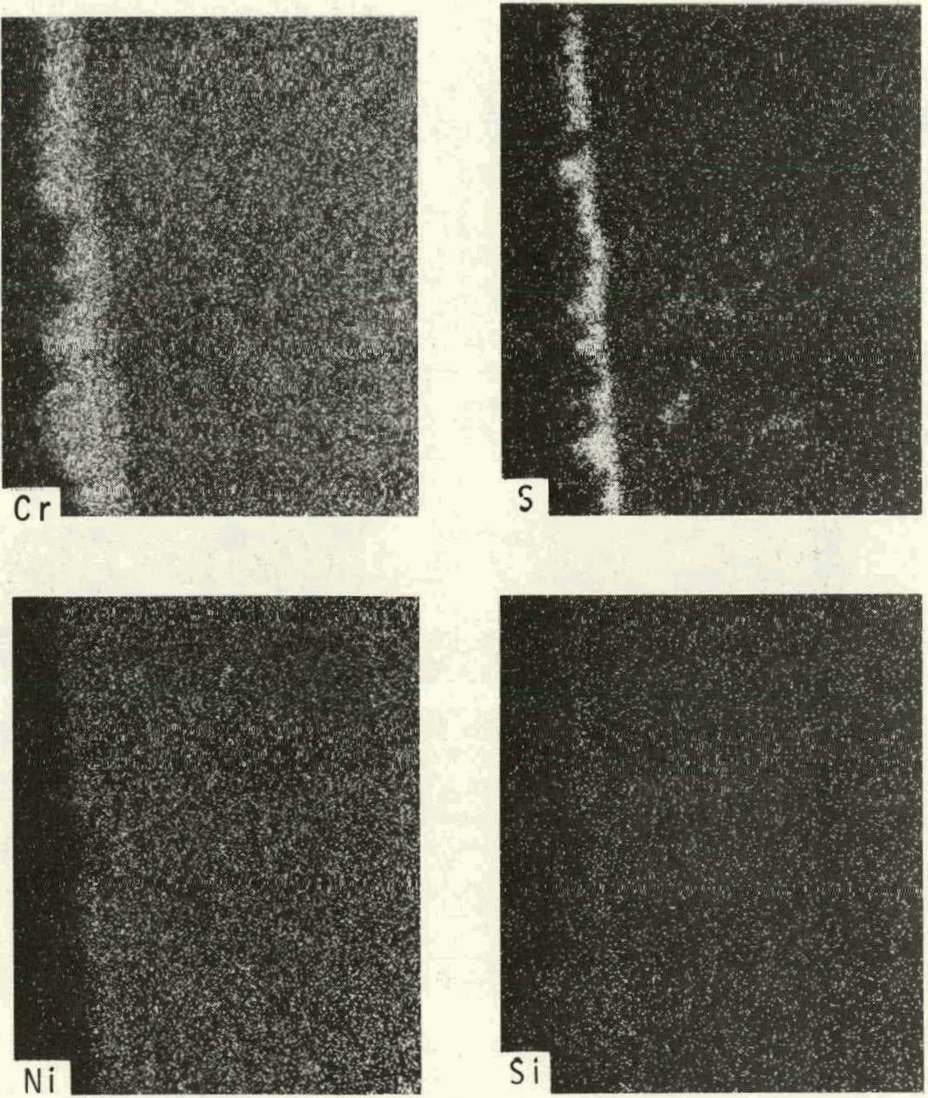

Fig. 32. X-ray Specimen Image and $\mathrm{Cr}, \mathrm{S}, \mathrm{Fe}, \mathrm{Ni}$, and $\mathrm{Si}$ Distributions in Incoloy 800 Exposed to the Gas Mixture Listed in Table X for $25 \mathrm{~h}$ at $875^{\circ} \mathrm{C}$. In the distribution photographs, the light region indicates a high concentration of the respective elements. 

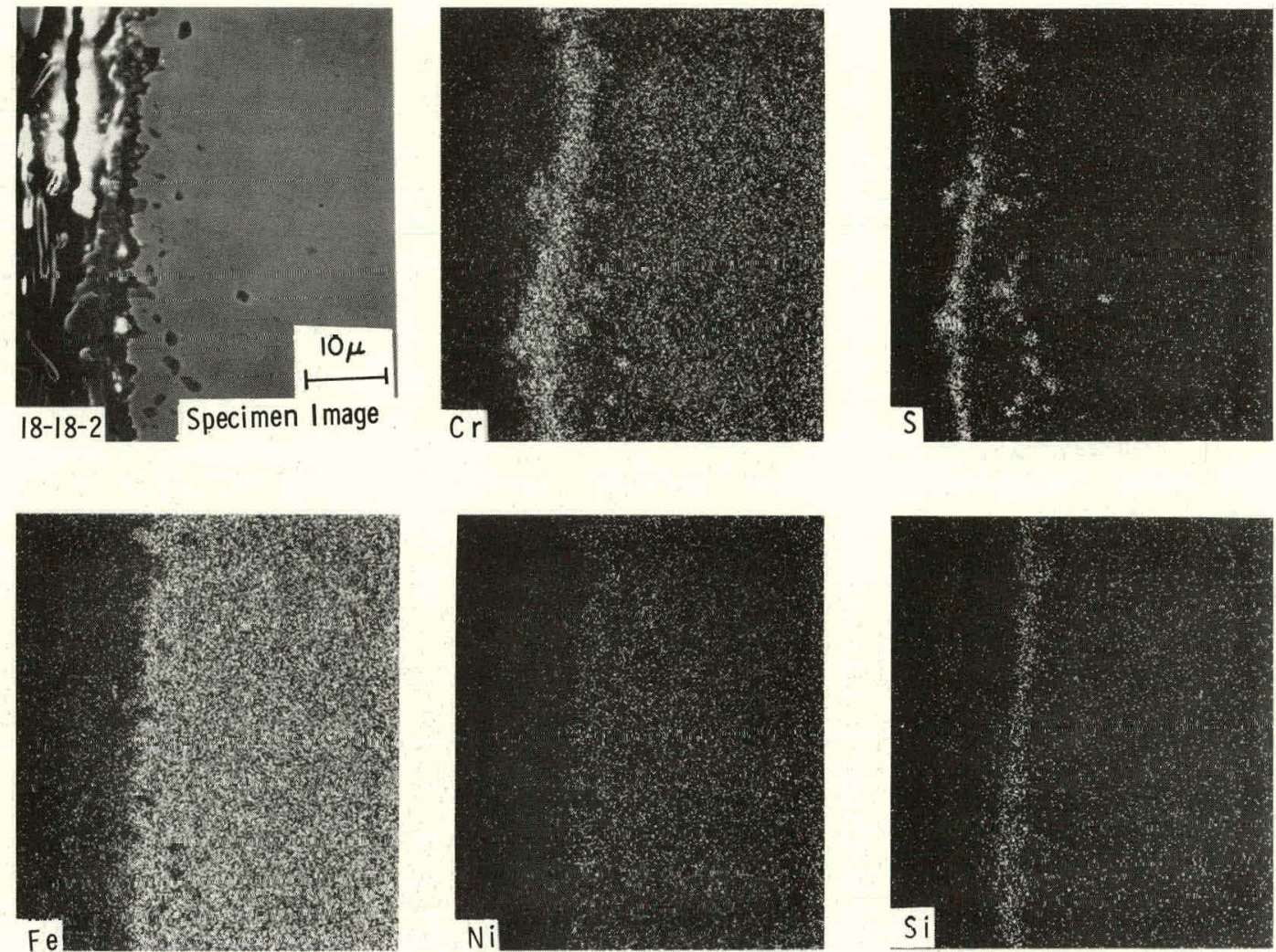

Fig. 33. X-ray Specimen Image and $\mathrm{Cr}, \mathrm{S}, \mathrm{Fe}, \mathrm{Ni}$, and $\mathrm{Si}$ Distributions in U. S. Steel Alloy 18-18-2 Exposed to the Gas Mixture Listed in Table $\mathrm{X}$ for $2.5 \mathrm{~h}$ at $875^{\circ} \mathrm{C}$. In the distribuliun phutographs, the light region indicates a high concentration of the respective elements. 

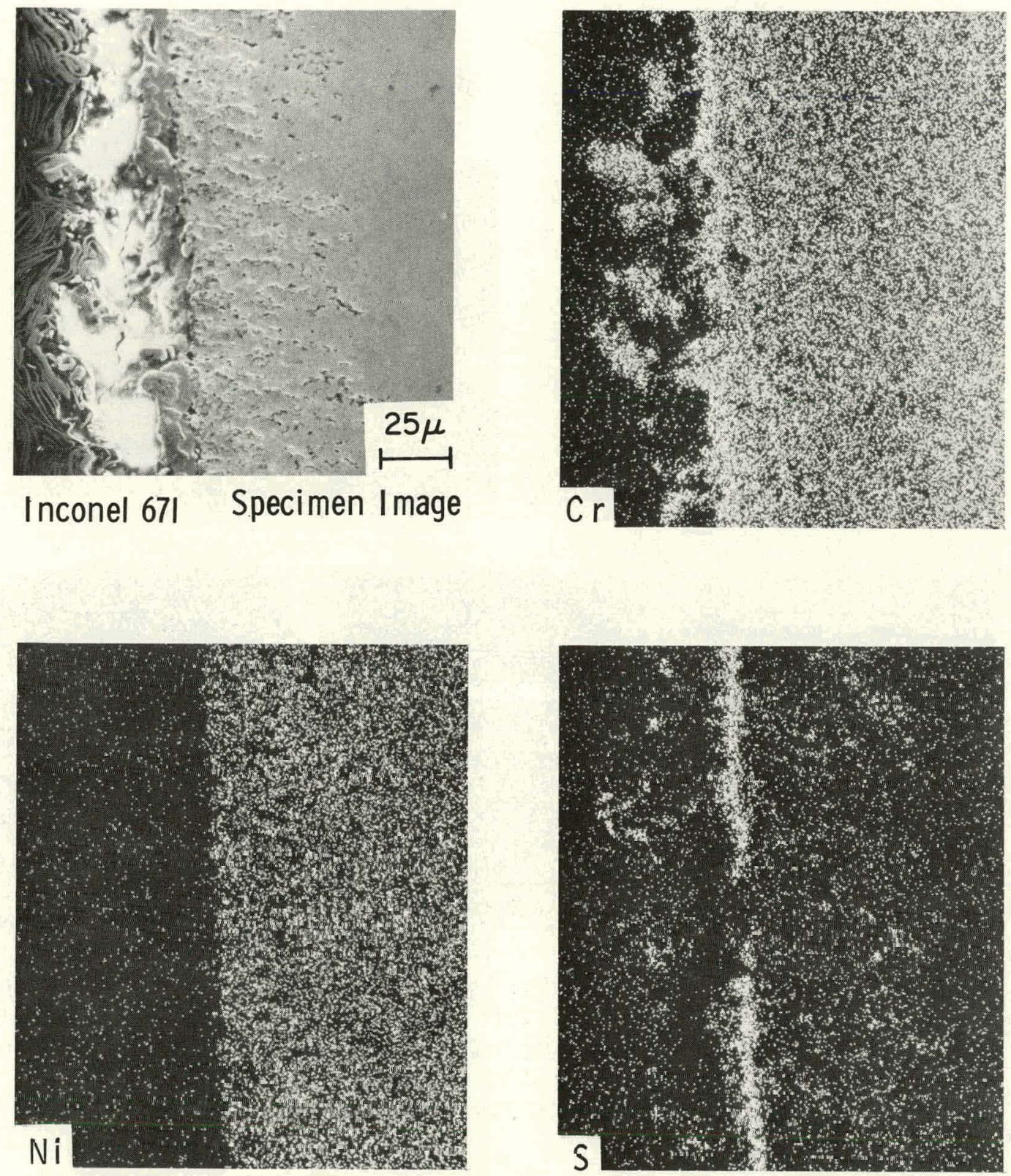

Fig. 34. X-ray Specimen Image and $\mathrm{Cr}$, Ni, and $\mathrm{S}$ Distributions in Incone1 671 Exposed to the Gas Mixture Listed in Table X for $25 \mathrm{~h}$ at $875^{\circ} \mathrm{C}$. In the distribution photographs, the light region indicates a high concentration of the respective elements. 

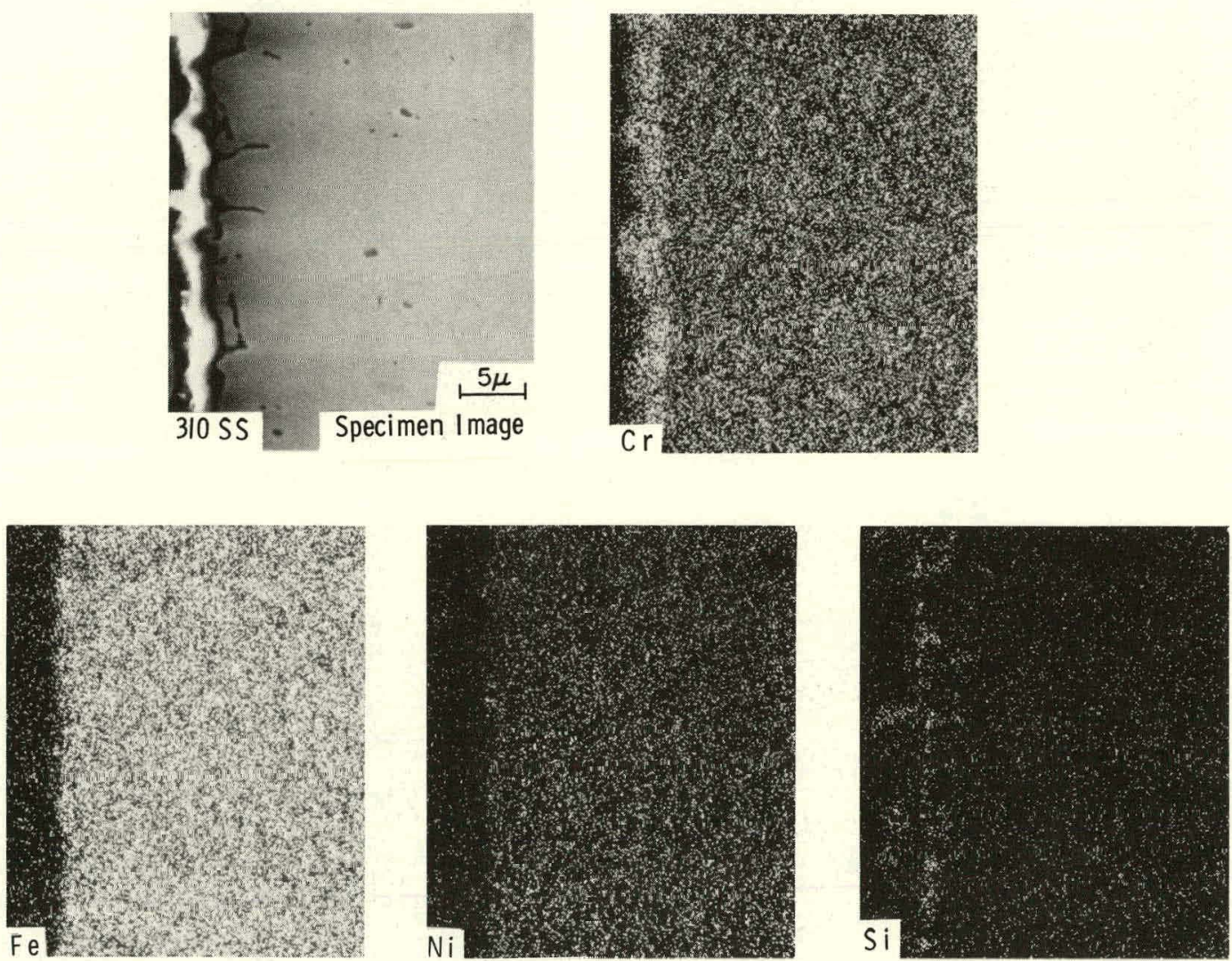

Fig. 35. X-ray Specimen Image and $\mathrm{Cr}, \mathrm{Fe}, \mathrm{Ni}$, and $\mathrm{Si}$ Distributions in Type 310 Stainless Steel Exposed to the Gas Mixture I,isted in Table $X$ for $200 \mathrm{~h}$ at $875^{\circ} \mathrm{C}$. Sulfur was absent in this specimen. In the distribution photographs, the light region indicates a high concentration of the respective elements. 

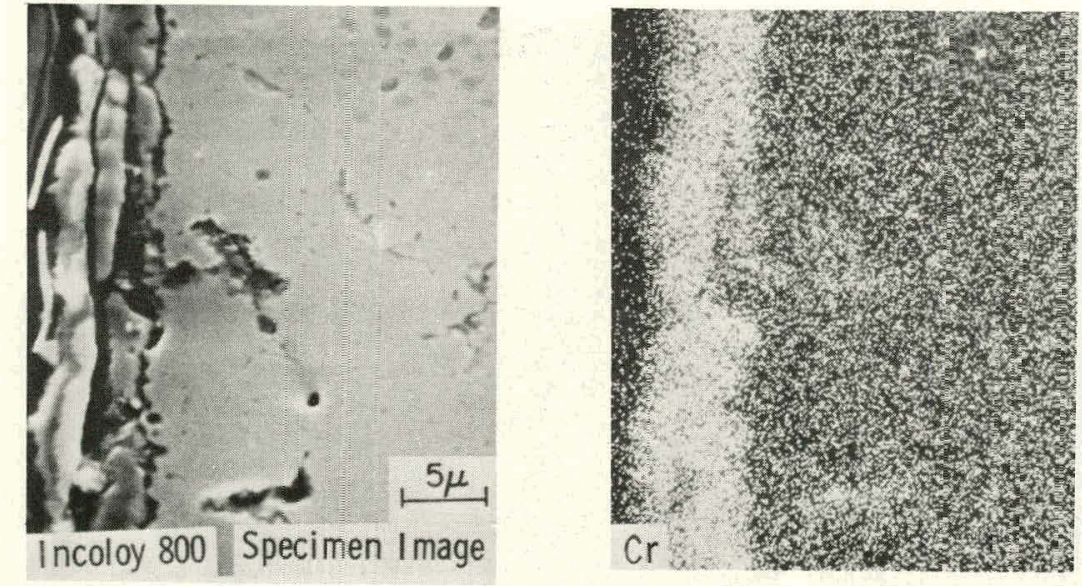

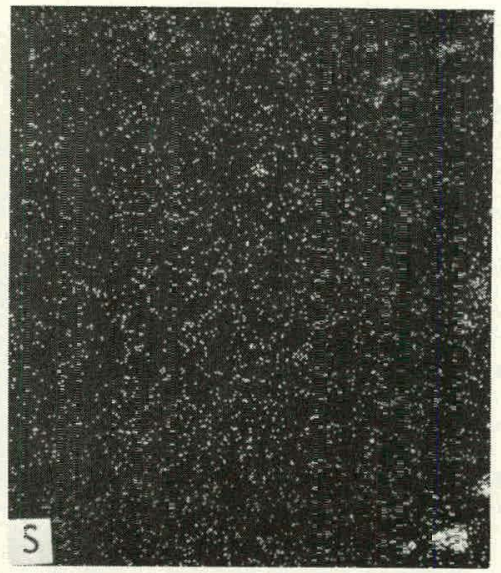

$\stackrel{2}{\circ}$
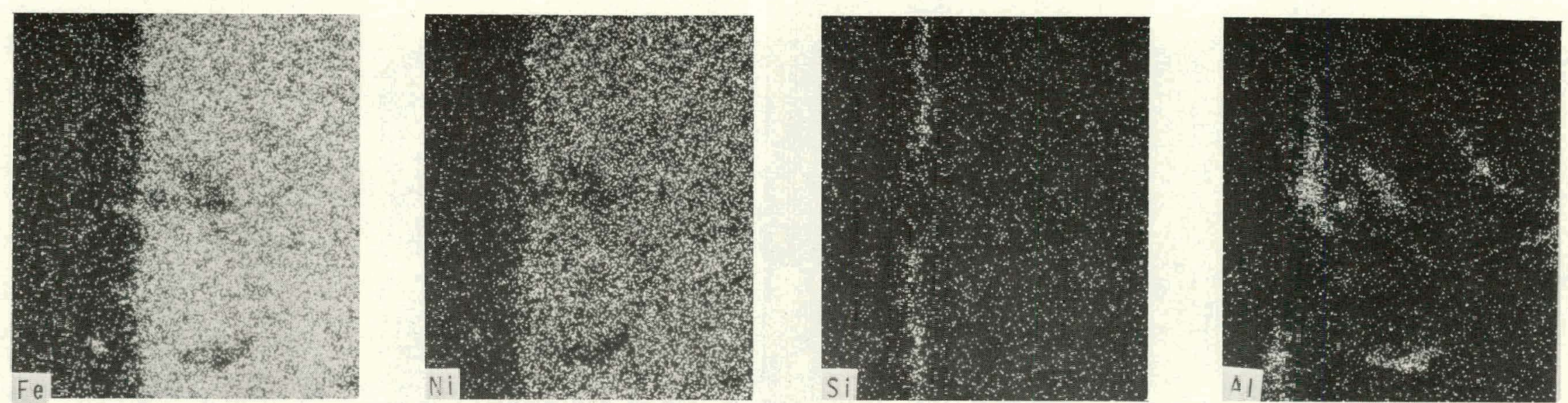

Fig. 36. X-ray Specimen Image and $\mathrm{Cr}, \mathrm{S}, \mathrm{Fe}, \mathrm{Ni}, \mathrm{Si}$, and $\mathrm{Al}$ Distributions in Incolcy 8010 Expcsed to the Gas Mixture Listed in Table $X$ for $200 \mathrm{~h}$ at $875^{\circ} \mathrm{C}$. In the distribution photographs, the light region indicates a high concentration of the respective elements. 

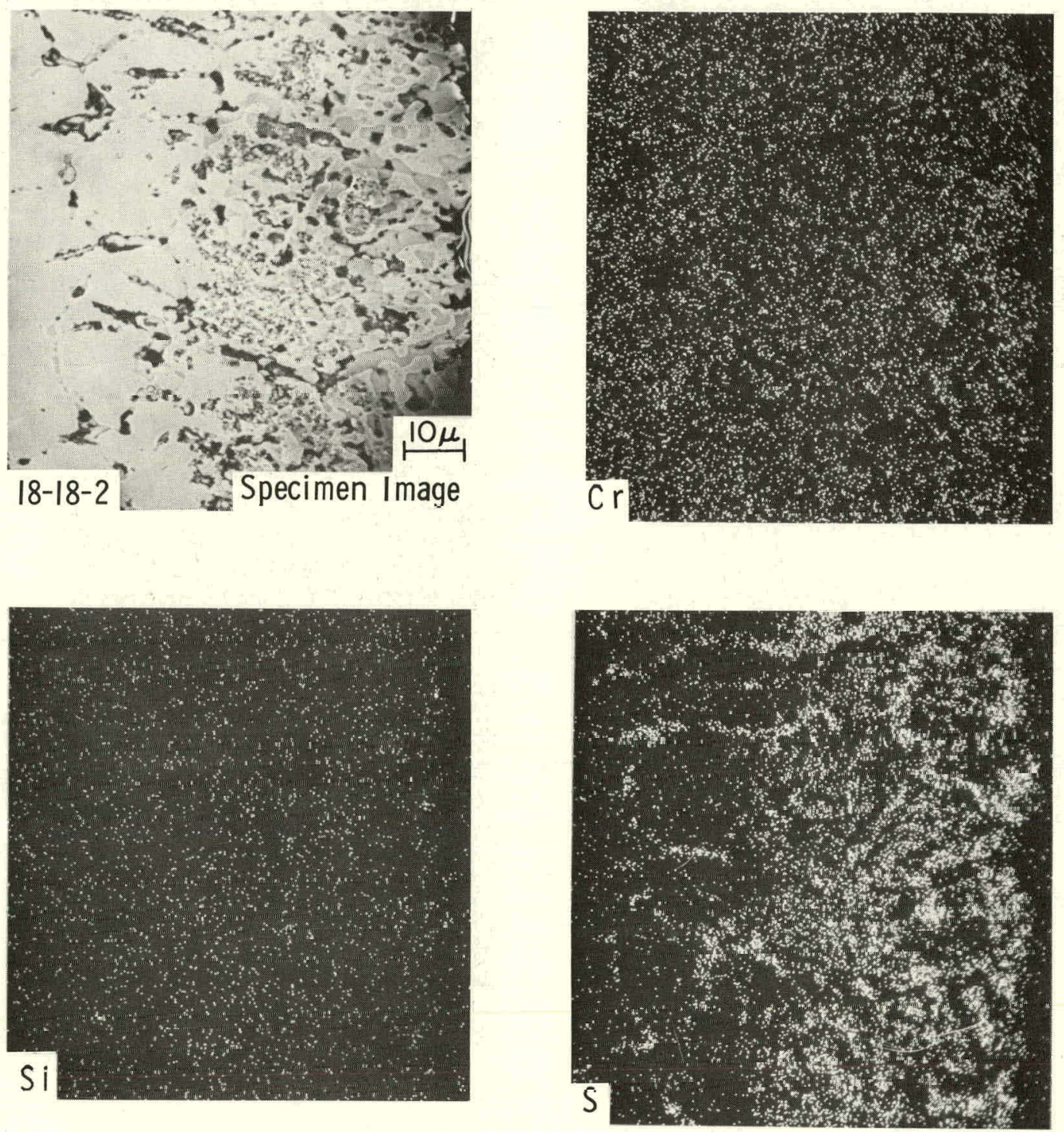

Fig. 37. X-ray Specimen Image and $\mathrm{Cr}, \mathrm{Si}$, and $\mathrm{S}$ Distributions in the Alloy Regions of U. S. Stee1 A11 oy 18-18-2 Exposed to the Gas Mixture Listed in Table $\mathrm{X}$ for $200 \mathrm{~h}$ at $875^{\circ} \mathrm{C}$. In the distribution photographs, the light region indicates a high concentration of the respective elements. 


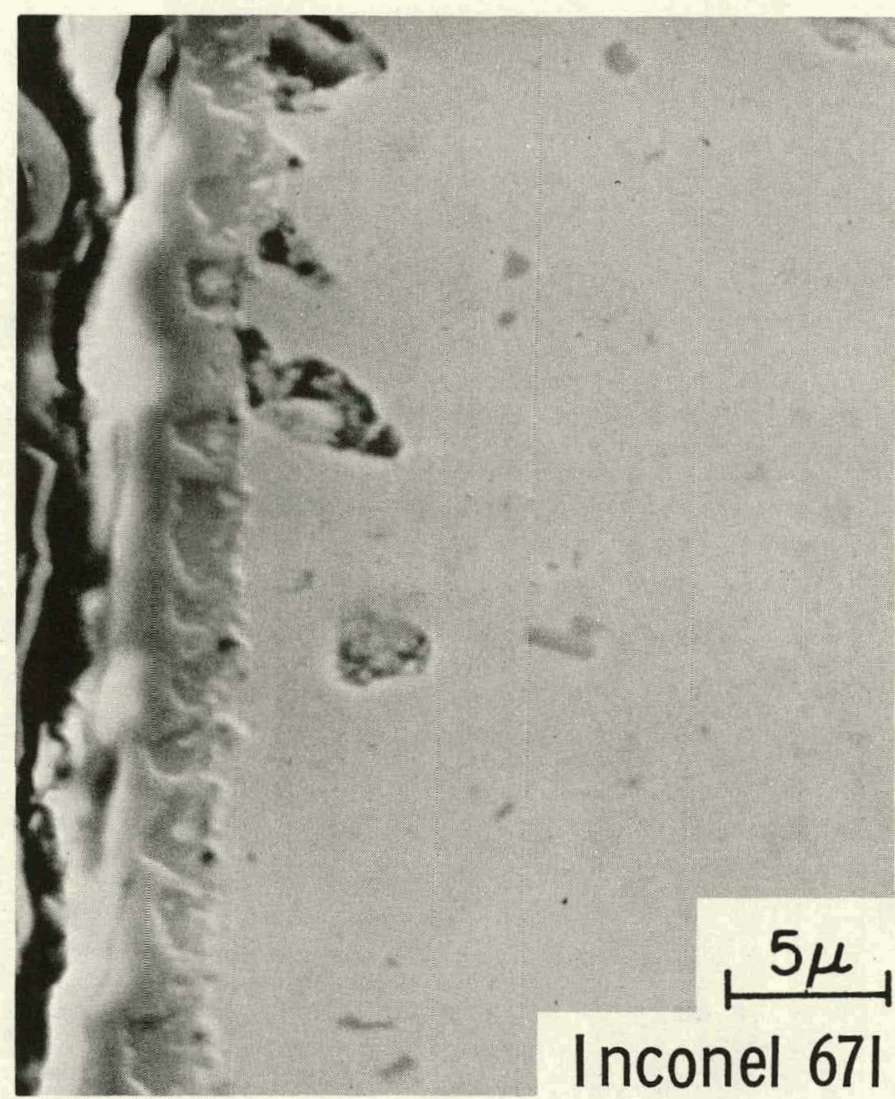

Fig. 38. SEM Photograph of Inconel 671 Specimen Exposed to the Gas Mixture Listed in Table X for $2 \mathrm{CO} \mathrm{h}$ at $875^{\circ} \mathrm{C}$. The scale is predominantly $\mathrm{Cr}$-rich oxide, and no $\mathrm{S}$ was detected.

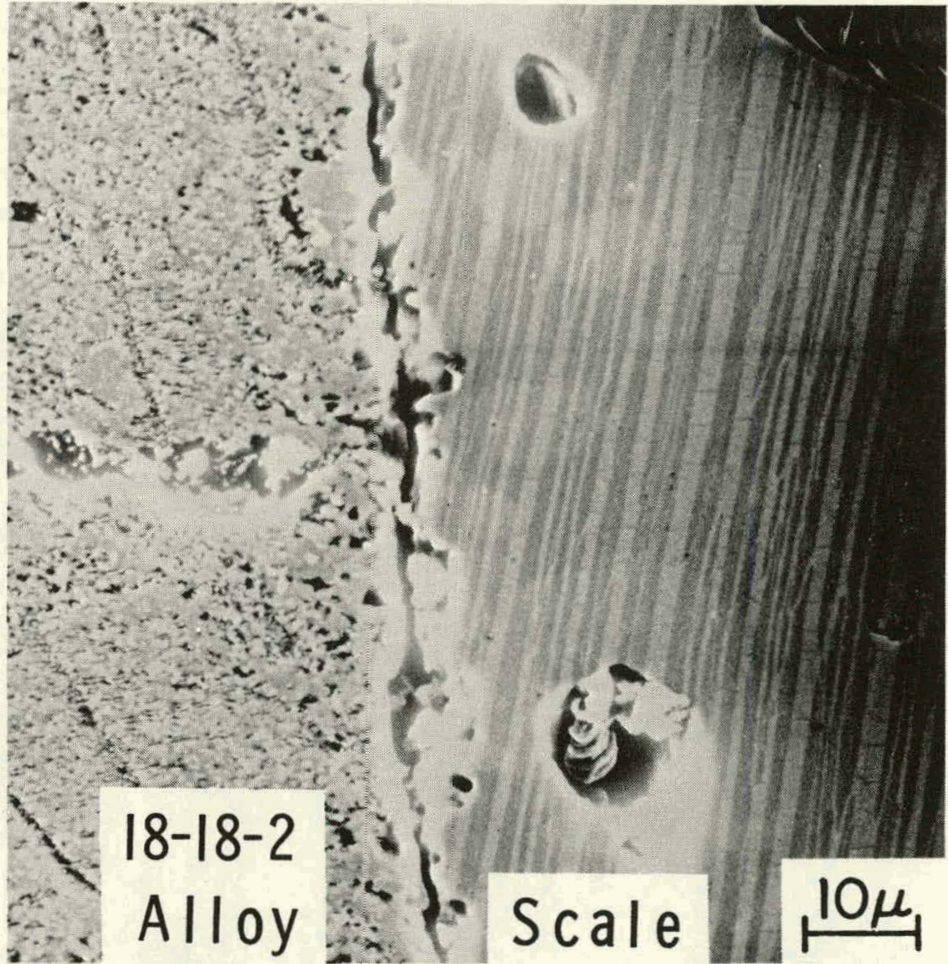

Fig. 39. SEM Photograph of Scale/Alloy Interface Regions of U. S. Steel Alloy 18-18-2 Exposed to the Gas Mixture Listed in Table X for $200 \mathrm{~h}$ at $875^{\circ} \mathrm{C}$. The striated region of the scale consisted of $\mathrm{Cr}$ sulfide and $\mathrm{Fe}$ sulfide. 


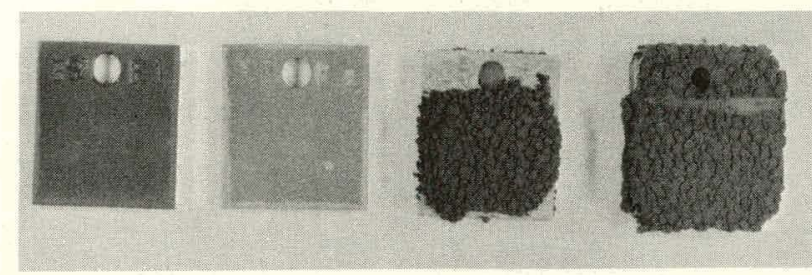

800

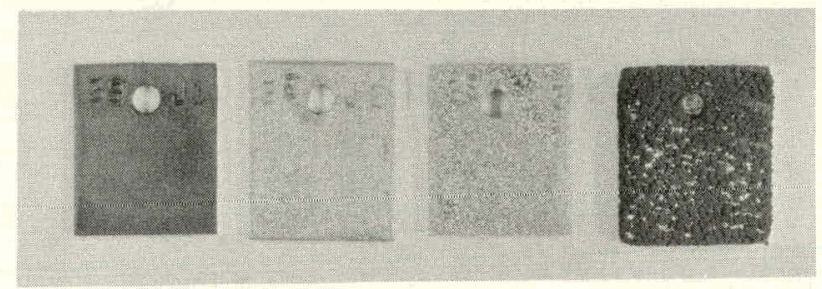

304 SS

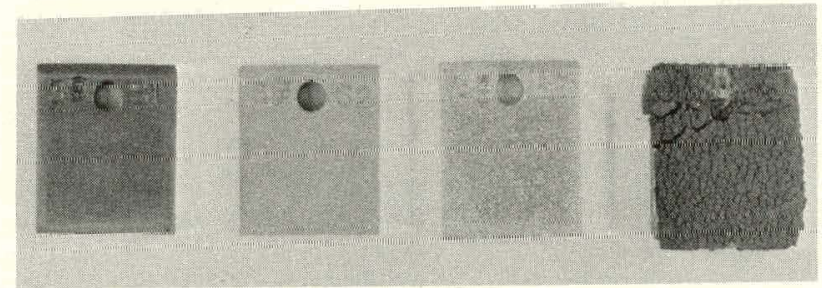

$310 \mathrm{SS}$
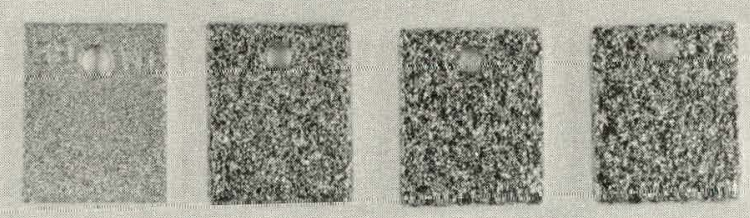

Iron

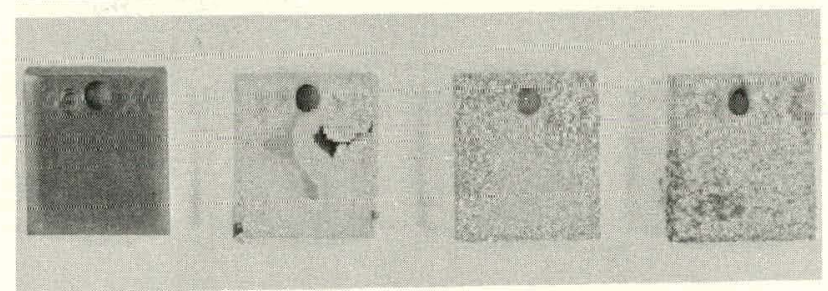

RA 333

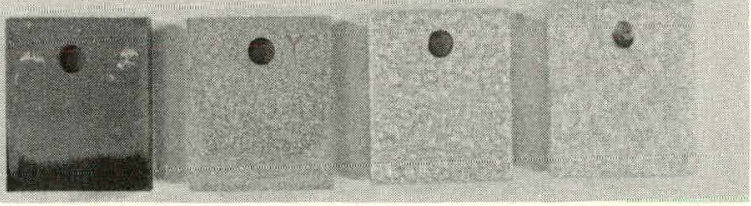

671

$750 \mathrm{C} 25 \mathrm{~h}$

Fig. 40. Macroscopic Photographs of Different A1loy Specimens after $25-\mathrm{h}$ Exposure at $750^{\circ} \mathrm{C}$ to the Gas Mixtures Listed in Table XII. The oxygen partial pressures for these specimens from left to right are $1.0 \times 10^{-20}, 2.4 \times 10^{-21}, 4.1 \times 10^{-22}$, and $4.2 \times 10^{-23}$ atm. 

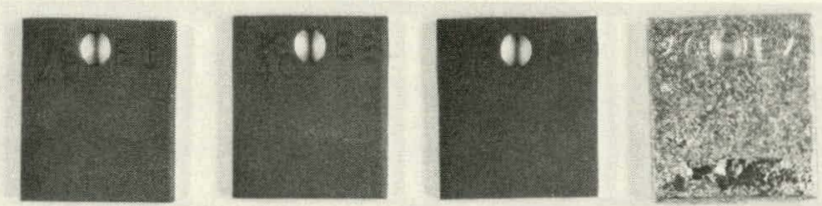

800
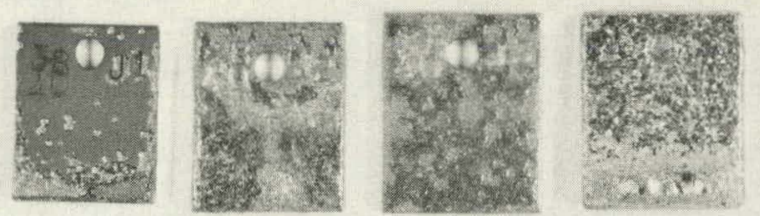

304 SS
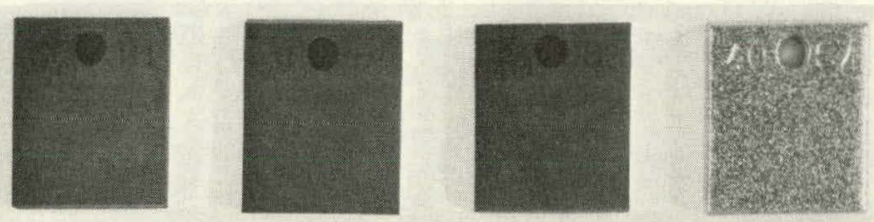

310 SS
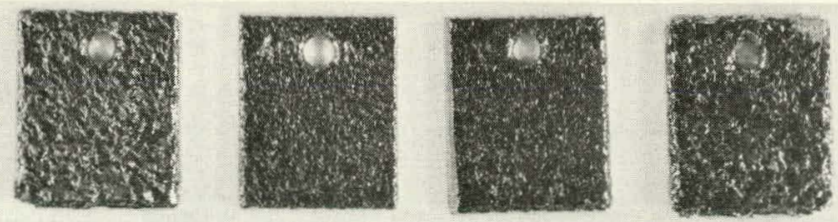

Iron
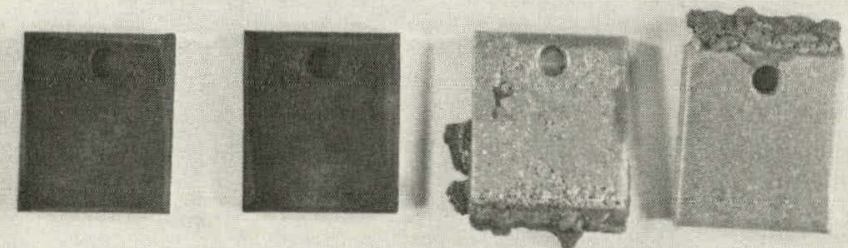

RA 333
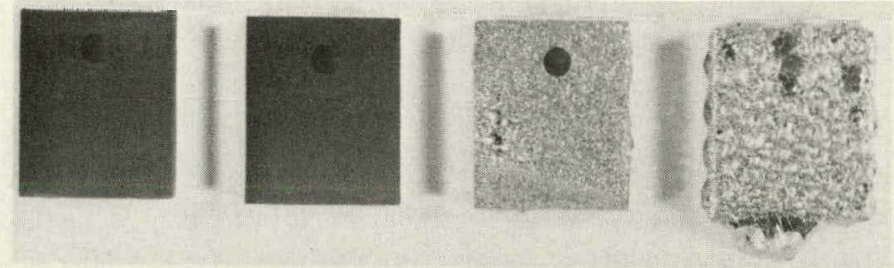

671

$875 \mathrm{C} 25 \mathrm{~h}$

Fig. 41. Macroscopic Photographs of Different Alluy Specimens after $25-\mathrm{h}$ Exposure at $875^{\circ} \mathrm{C}$ to the Gas Mixtures Listed in Table XII. The oxygen partial pressures for these specimens from left to right are $1.9 \times 10^{-18}, 5.5 \times 10^{-19}, 2.4 \times 10^{-19}$, and $1.7 \times 10^{-20} \mathrm{~atm}$. 

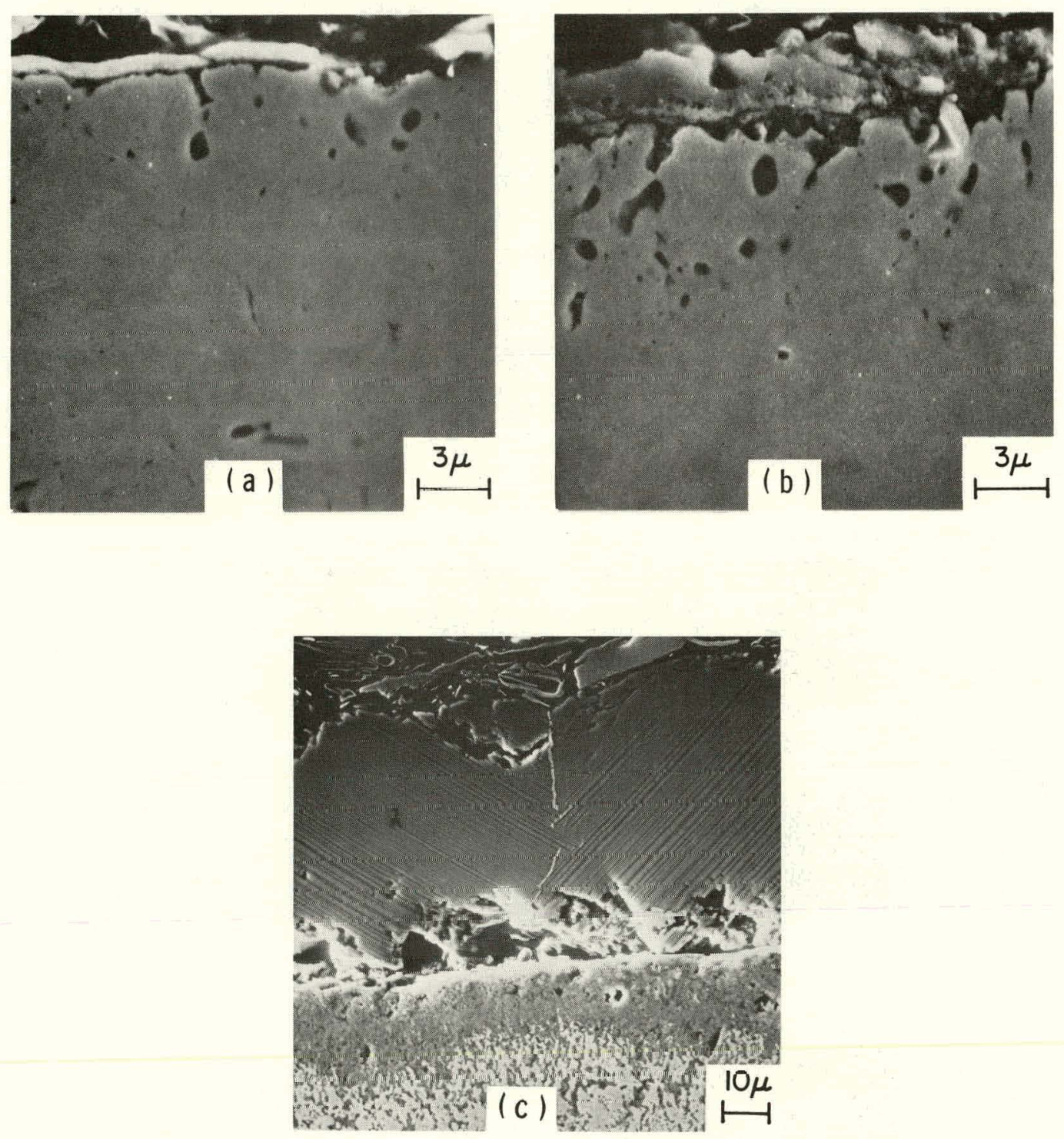

Fig. 42. SEM Photographs of Type 310 Stainless Steel Specimens after $25-\mathrm{h}$ Exposure at $750^{\circ} \mathrm{C}$ to the Gas Mixtures Listed in Table XII. The oxygen partial pressures in (a), (b), and (c) were $1.0 \times 10^{-20}, 2.4 \times 10^{-21}$, and $4.1 \times 10^{-22}$ atm, respectively. 

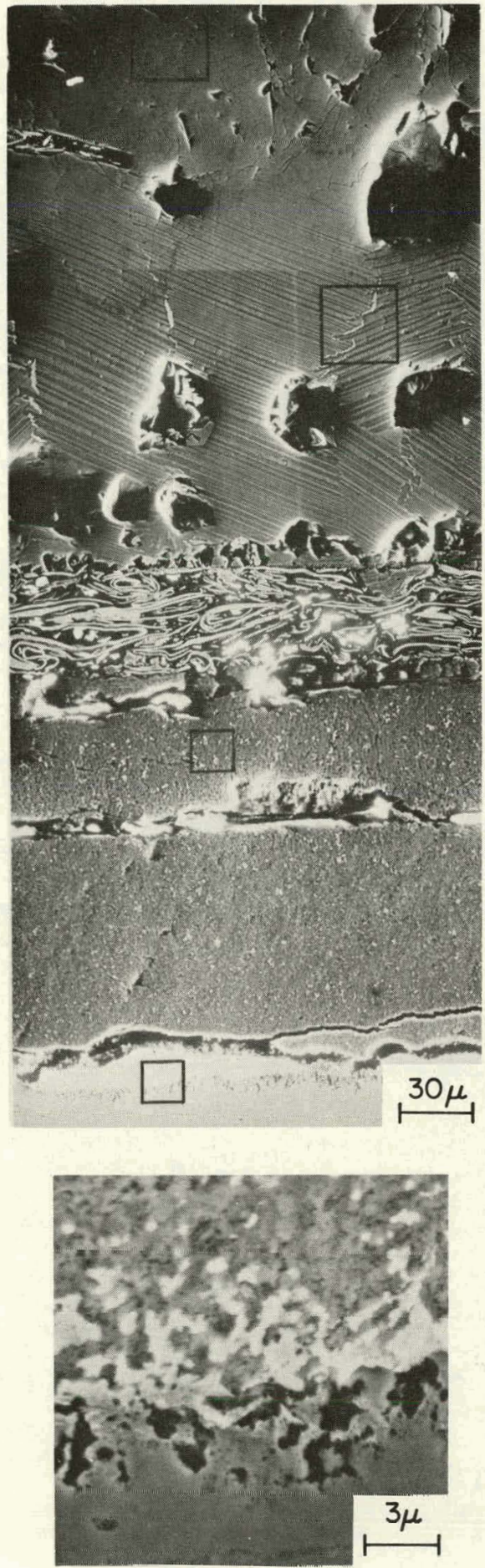

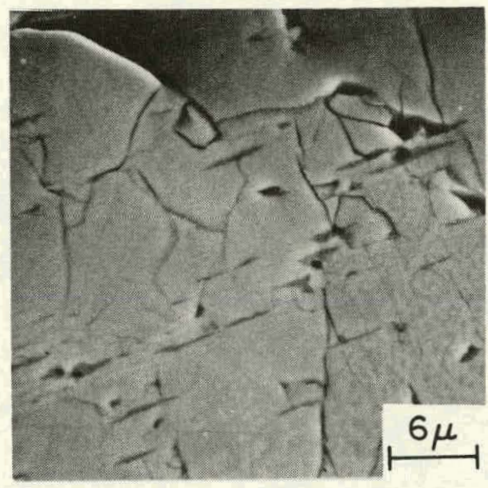

(d)
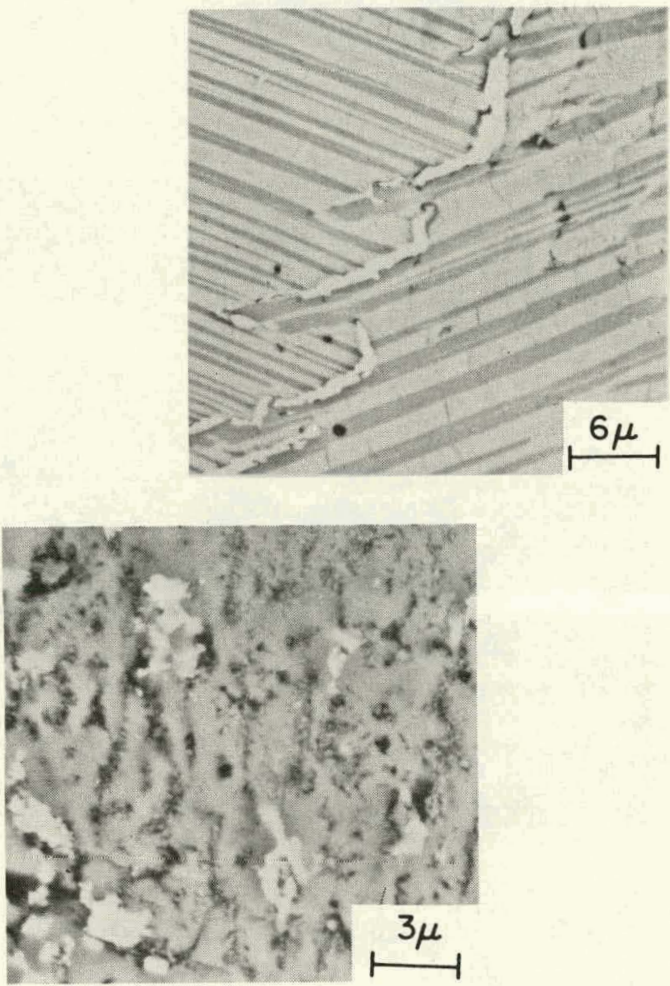

Fig. 43. SEM Photograph of Type 310 Stainless Steel Specimen after 25-h Exposure at $750^{\circ} \mathrm{C}$ to the Gas Mixture Listed in Table XII. The oxygen partial pressure during this experiment was $4.2 \times 10^{-23}$ atm. Different square-marked regions were magnified to show the details of the scale and scale/alloy interface. 

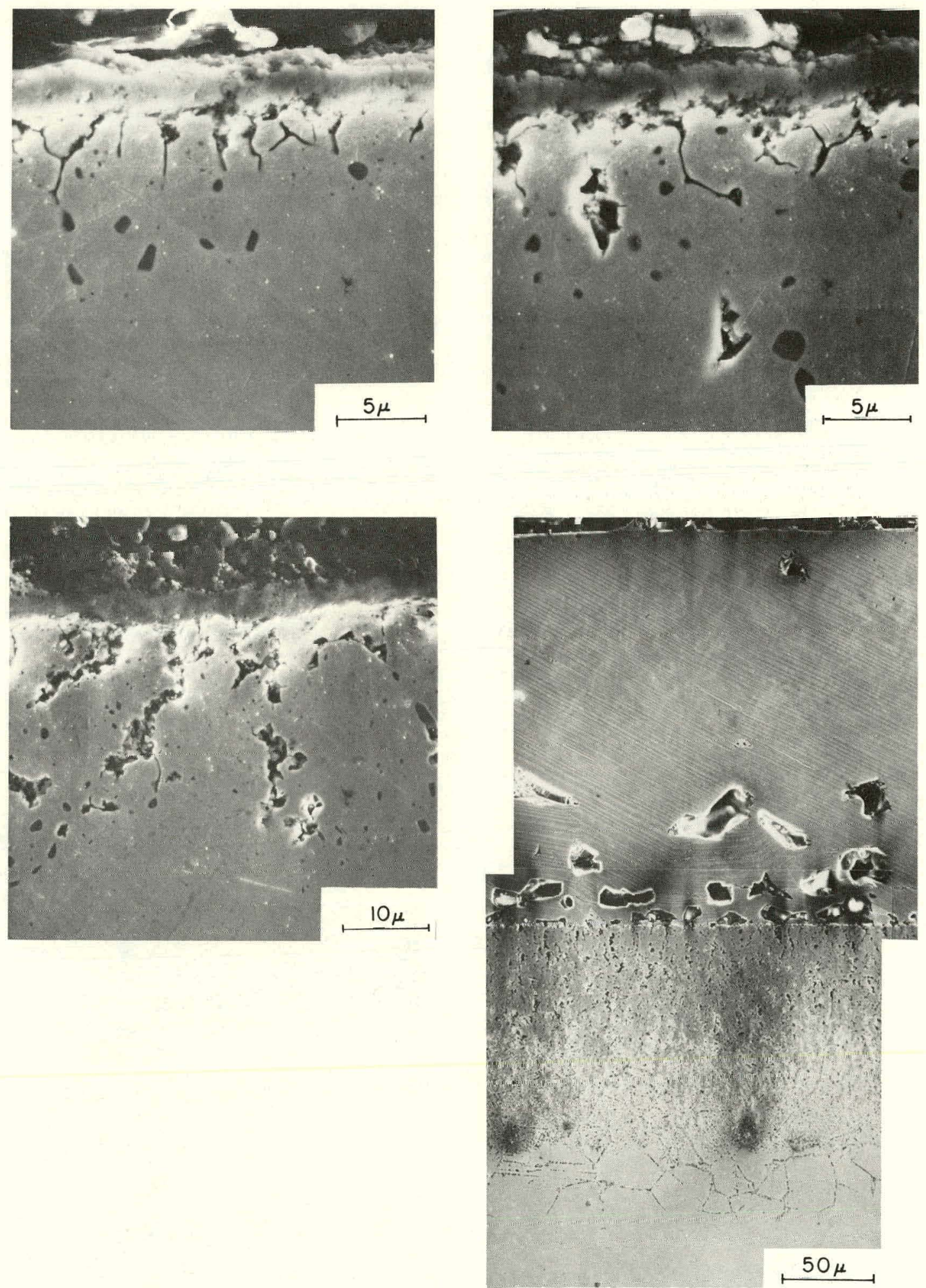

Fig. 44. SEM Photographs of Type 310 Stainless Steel Specimcns afler $25-\mathrm{h}$ Exposure at $875^{\circ} \mathrm{C}$ to the Gas Mixtures Listed in Table XII. The oxygen partial pressures in these experiments are as follows: top left, $1.9 \times 10^{-18} \mathrm{~atm}$; top right, $5.5 \times 10^{-19} \mathrm{~atm}$; bottom left, $2.4 \times 10^{-19} \mathrm{~atm}$; and bottom right, $1.7 \times 10^{-20}$ atm. 

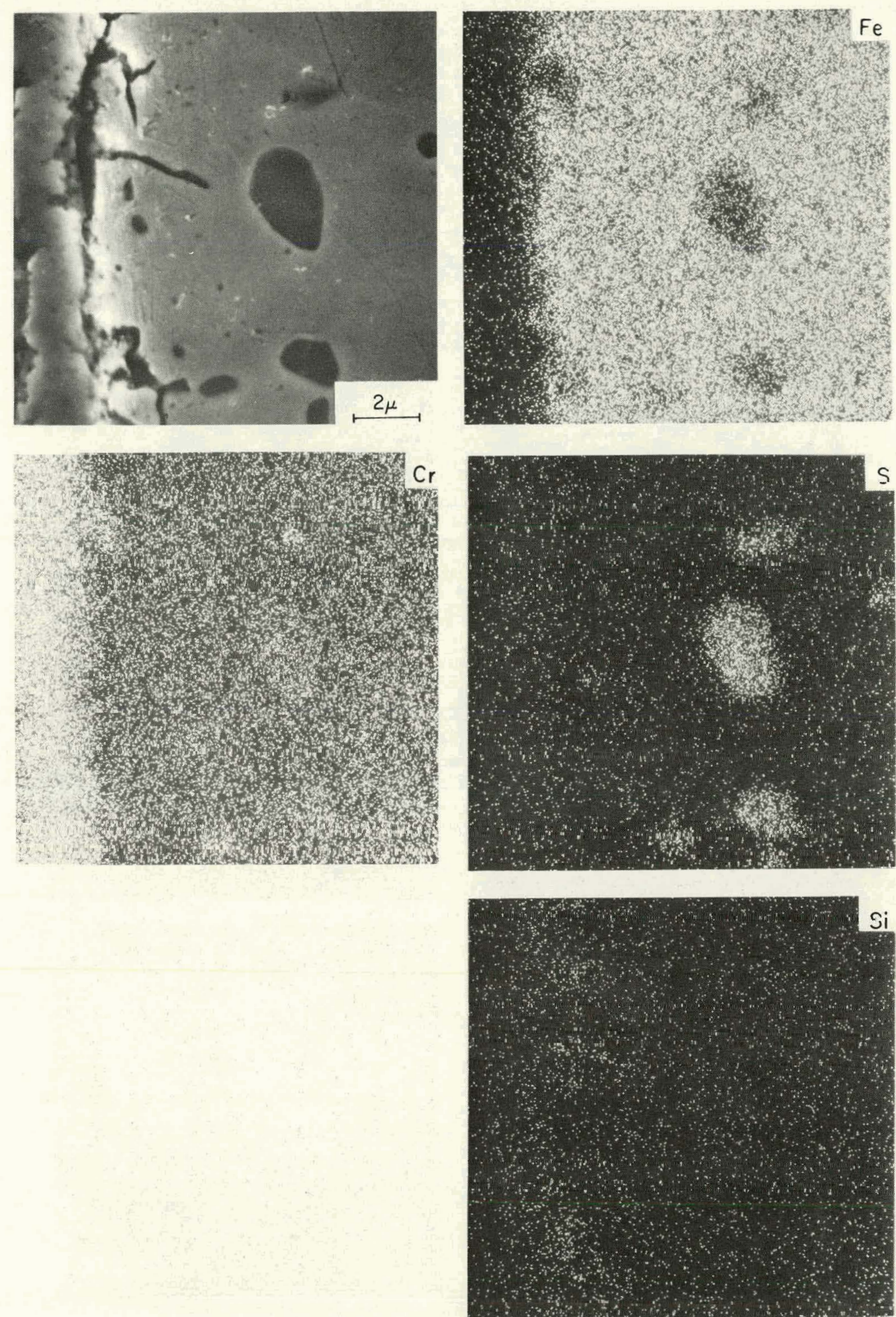

Fig. 45. X-ray Specimen Image and $\mathrm{Fe}, \mathrm{Cr}, \mathrm{S}$, and $\mathrm{Si}$ Distributions in Type 310 Stainless Steel after $25-\mathrm{h}$ Exposure at $875^{\circ} \mathrm{C}$ to the Gas Mixture without Steam Listed in Table XII (Identified by an Arrow). In the distribution photographs, the light region indicates a high concentration of the respective elements. 

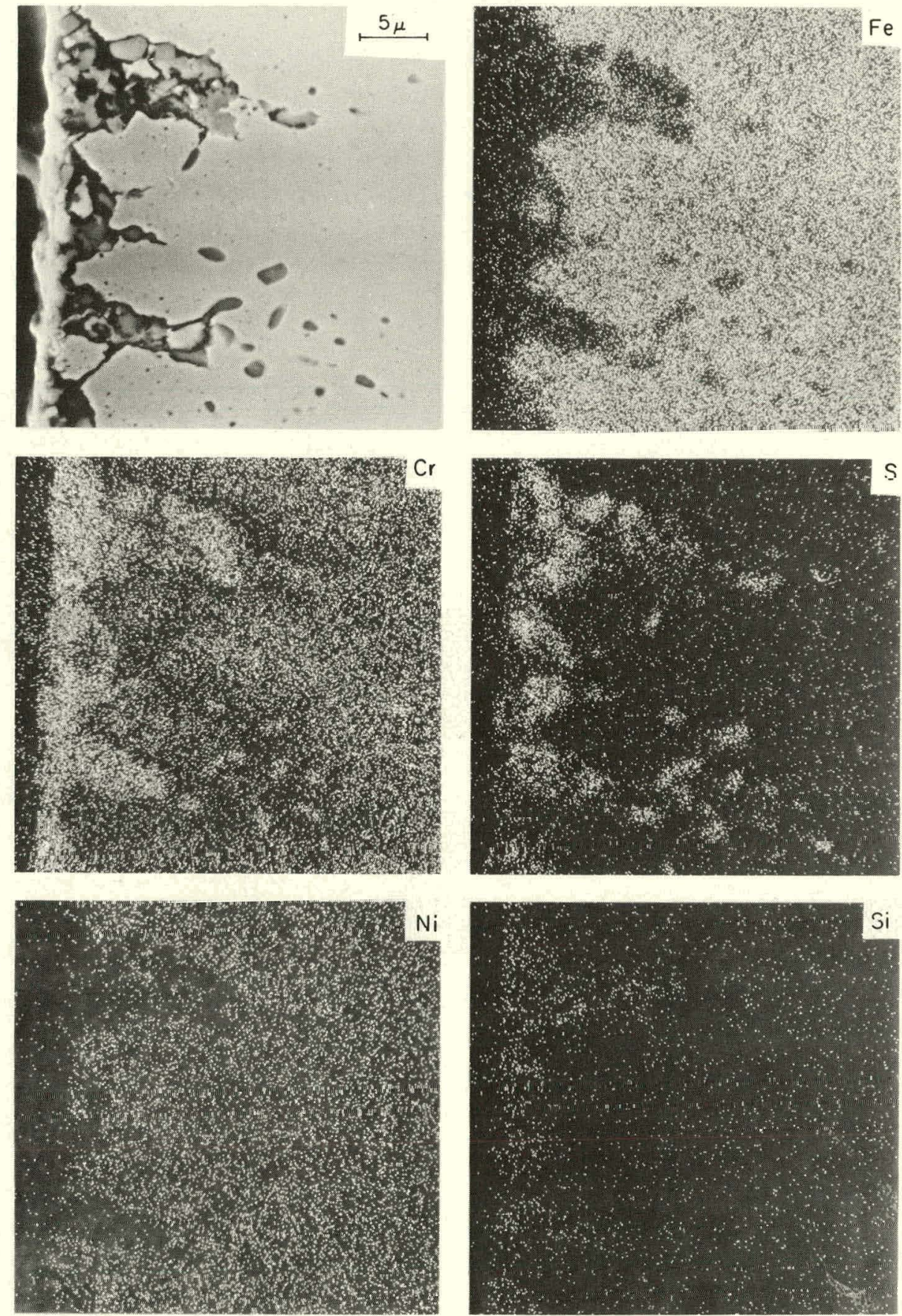

Fig. 46. X-ray Specimen Image and $\mathrm{Fe}, \mathrm{Cr}, \mathrm{S}, \mathrm{Ni}$, and $\mathrm{Si}$ Distributions in Type 310 Stainless Stcel after $25-l_{1}$ Exposure at $875^{\circ} \mathrm{C}$ to the Gas Mixture with Steam Listed in Table XII. In the distribution photographs, the light region indicates a high concentration of the respective elements. 

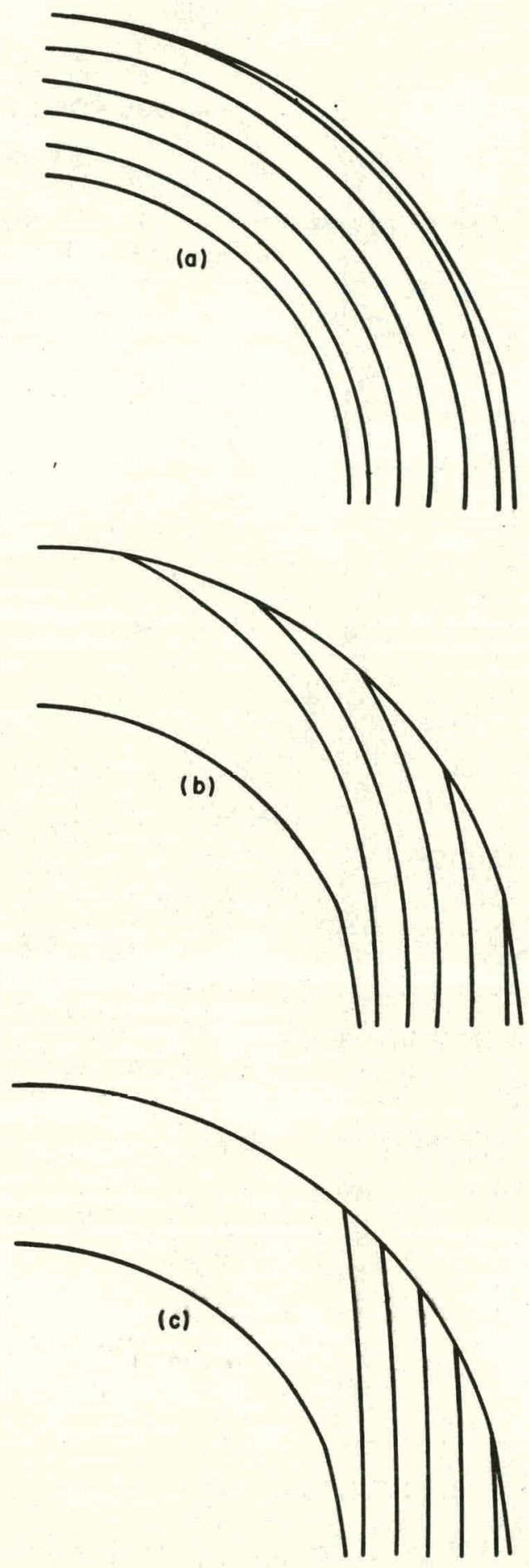

Fig. 47. Particle Trajecluries in a $90^{\circ}$ Elbow. Flow conditions:

$\mathrm{U}_{\mathrm{O}}=6 \mathrm{~m} / \mathrm{s}$, kinematic viscosity $=$ $6 \times 10^{-7} \mathrm{~m}^{2} / \mathrm{s}$, and fluid density $=$ $54 \mathrm{~kg} / \mathrm{m}^{3}$. The particle density = $3.1 \times 10^{3} \mathrm{~kg} / \mathrm{m}^{3}$ and the particle diameters are (a) $10 \mu$, (b) $100 \mu$, and (c) $1000 \mu$. ANL Neg. No. 30677-190. 


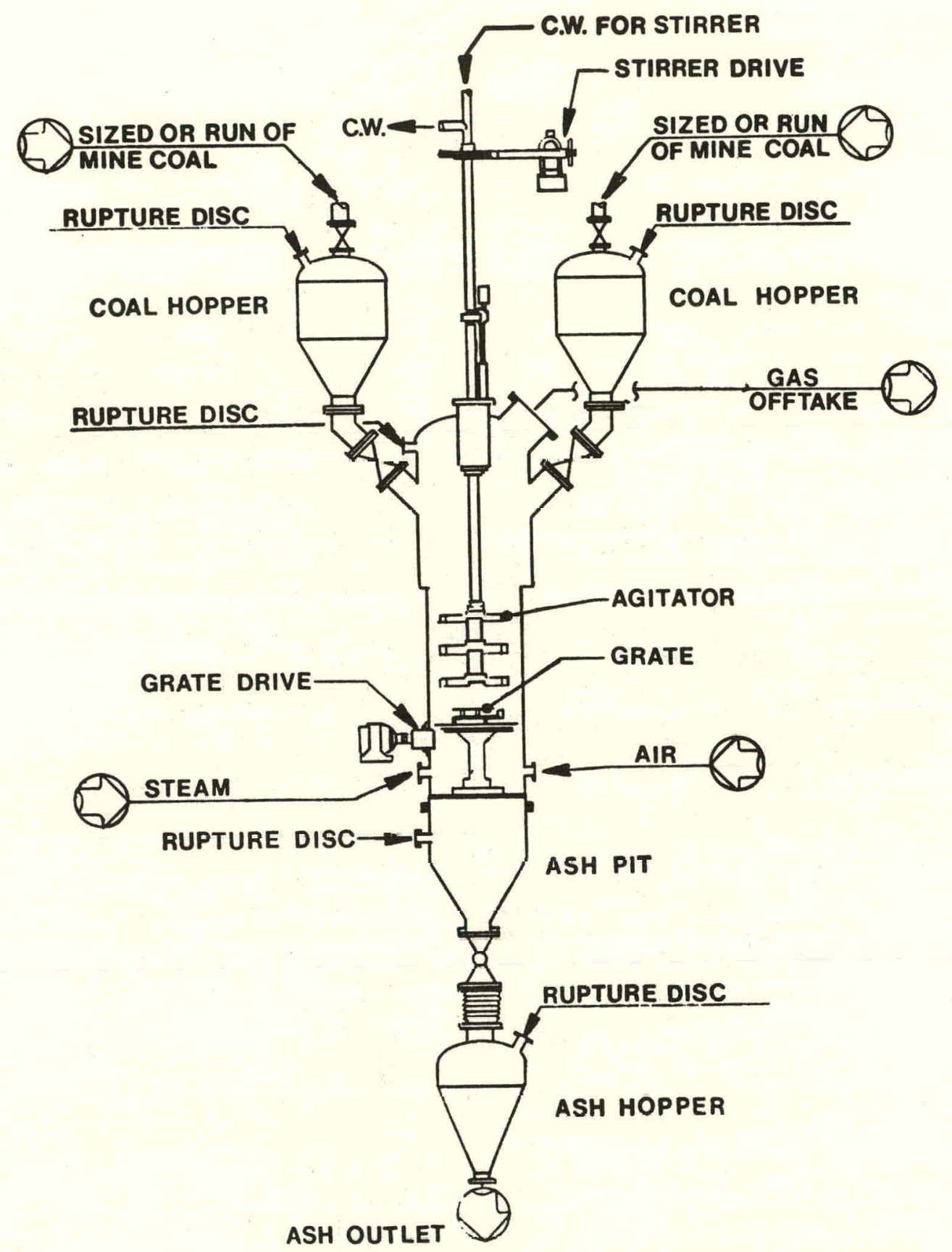

Fig. 48. ERDA-MERC Stirred-bed Gasifier. ANL Neg. No. 30677-175. 

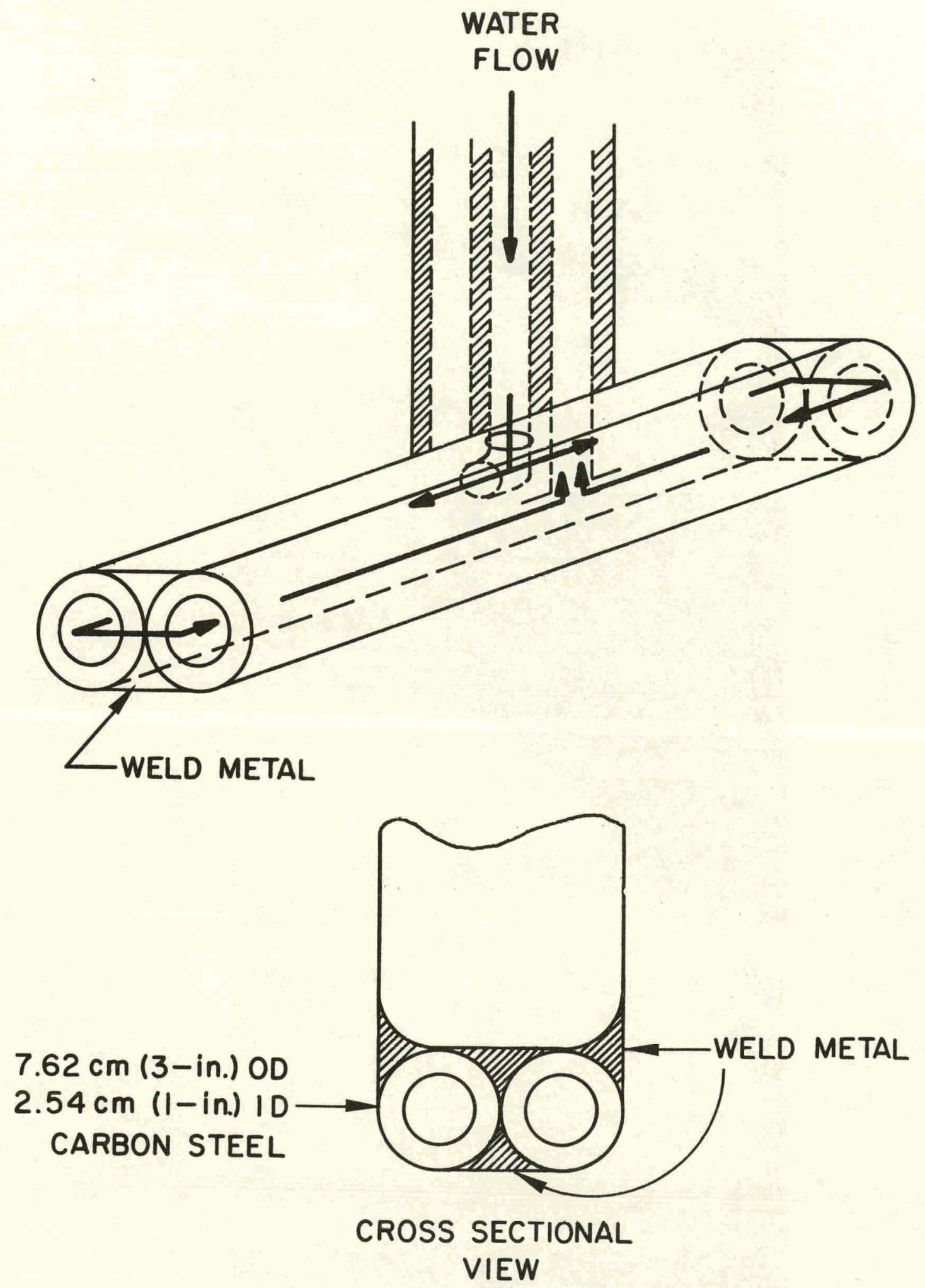

Fig. 49. Schematic of the Rabble Arm. ANL Neg. No. 306-77-183. 

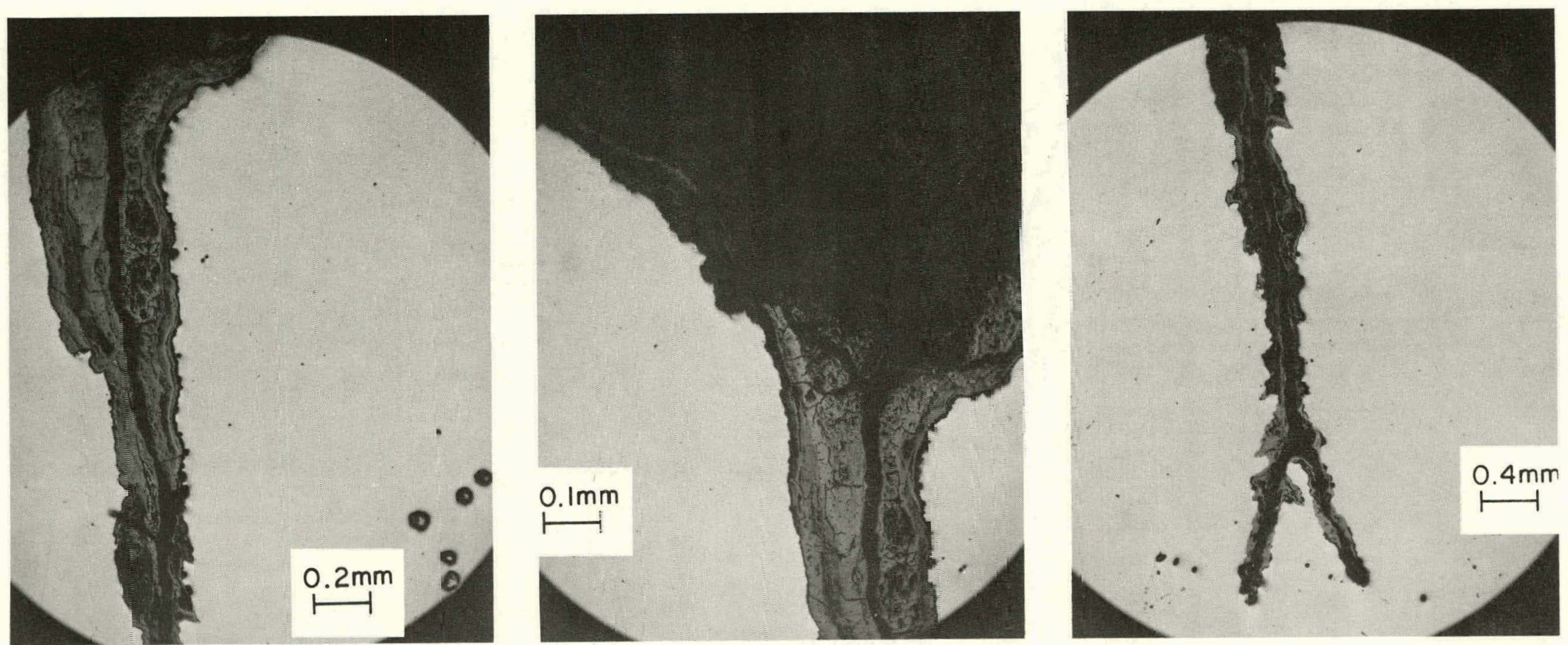

Fig. 50. Photographs of the Cracked Corrosion Scale and the Crack Tip. ANL Neg. No. 306-77-199. 

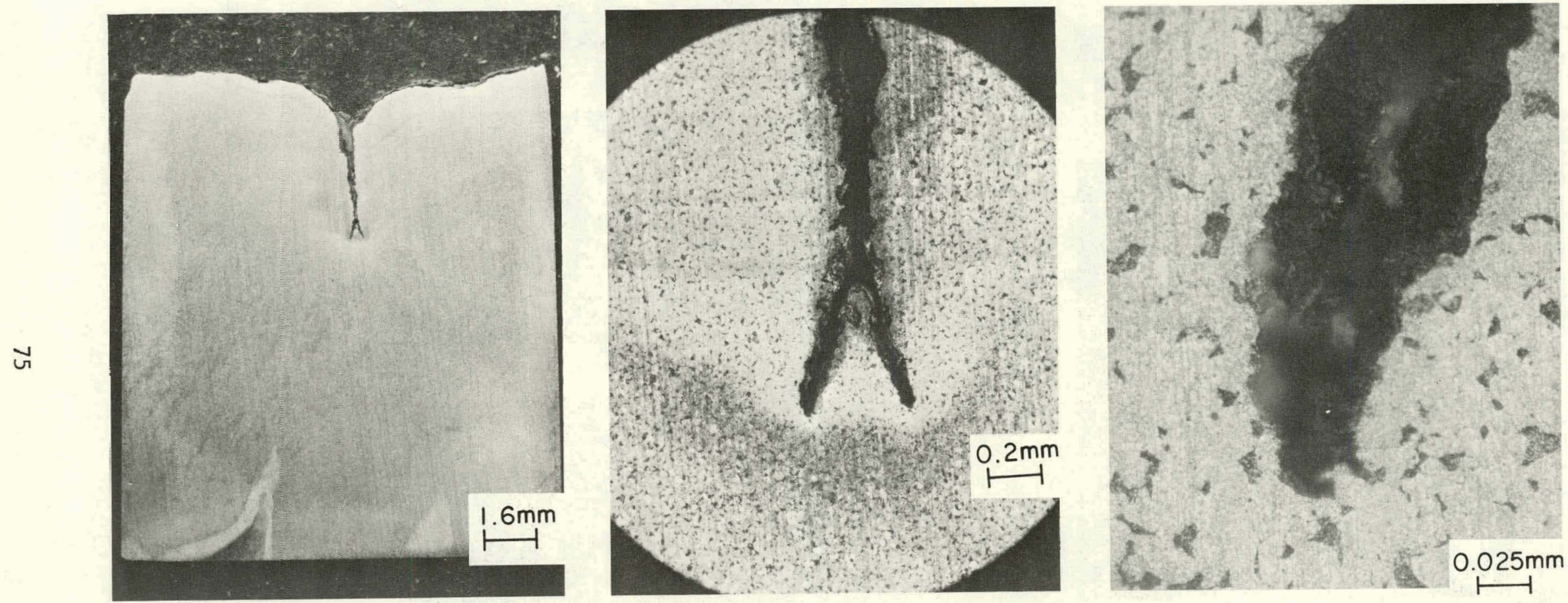

Fig. 51. Photographs of a Crack that had been Electroetched. ANL Neg. No. 306-77-197. 


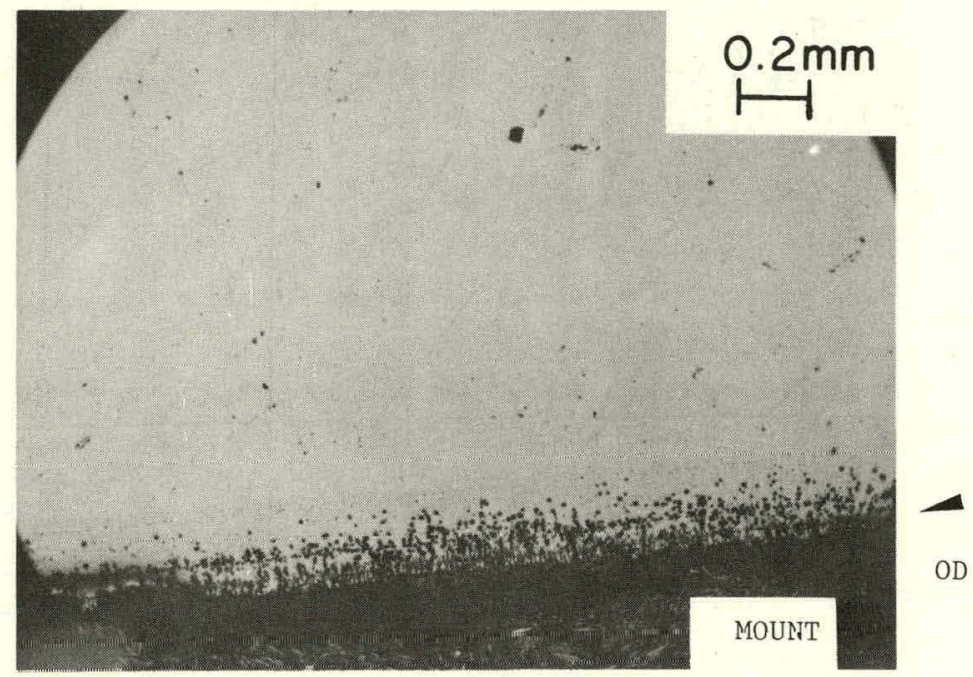

(a.)
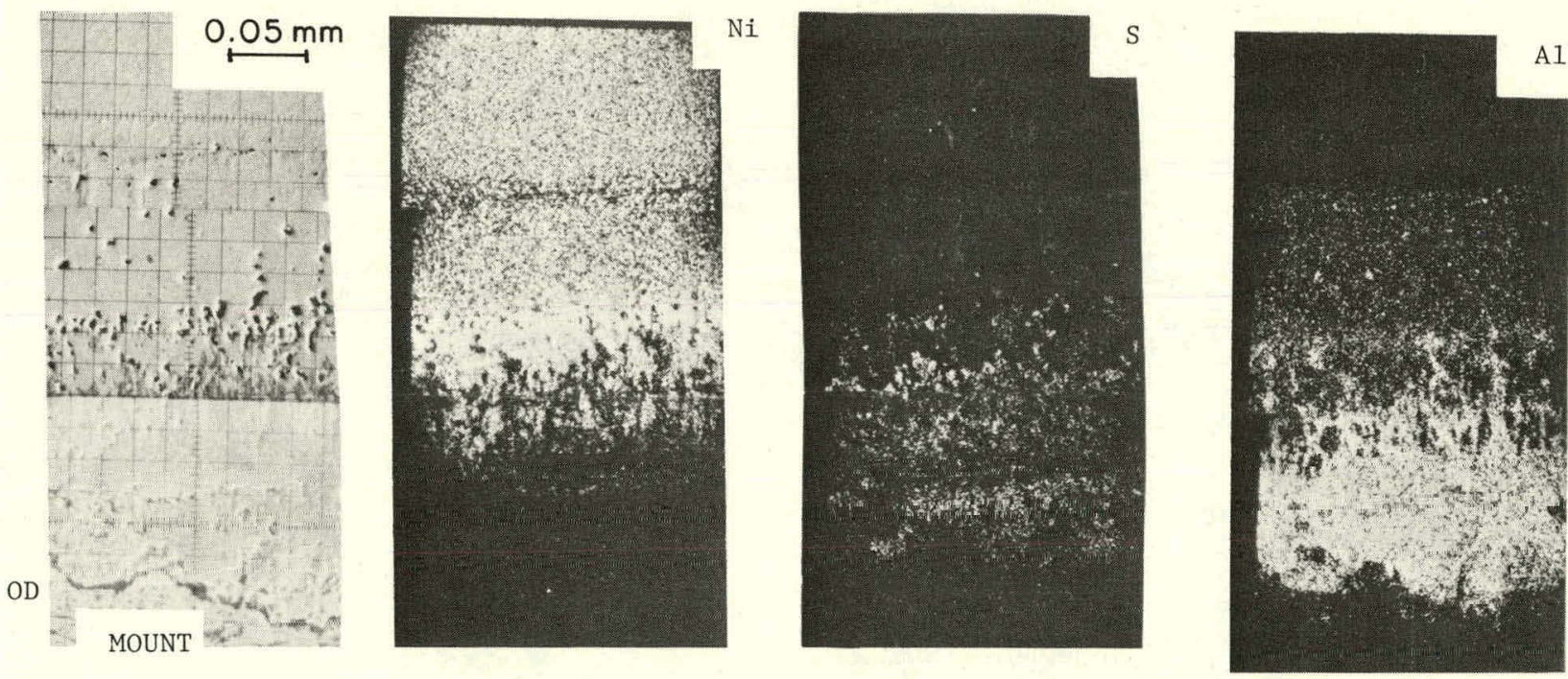

(b )

Fig. 52. Optical Photograph (a) and Electron-microprobe Data (b) of an "Alonized" Type 316 Stainless Steel Coupon That Had Been Exposed to the HYGAS Gasifier Environment and Removed after Run 61, ANL Neg. No. 306-77-4. 


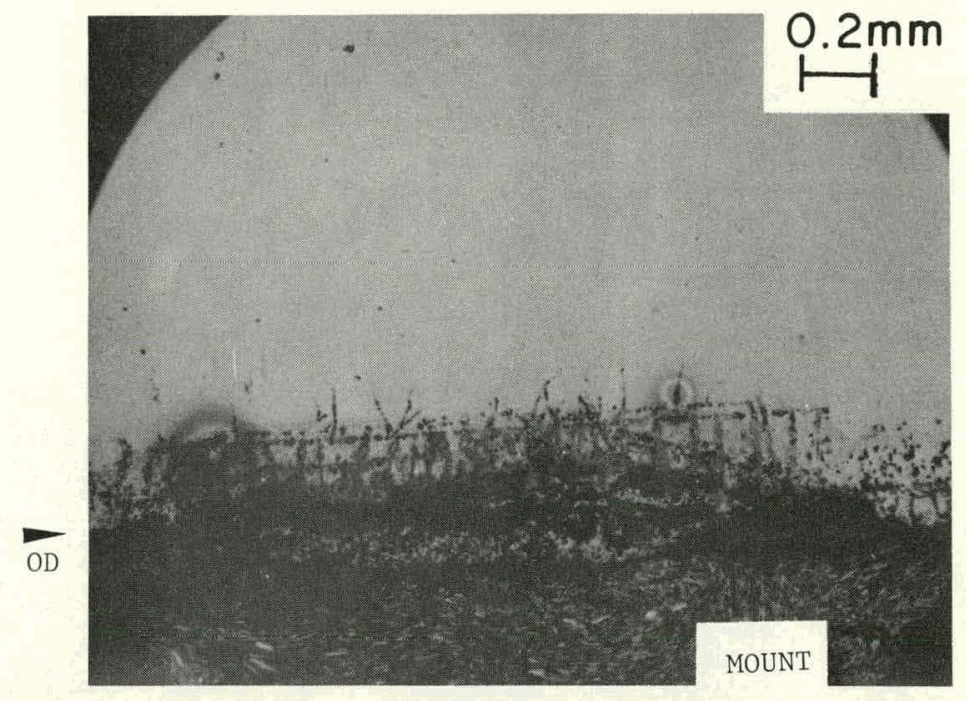

(a)
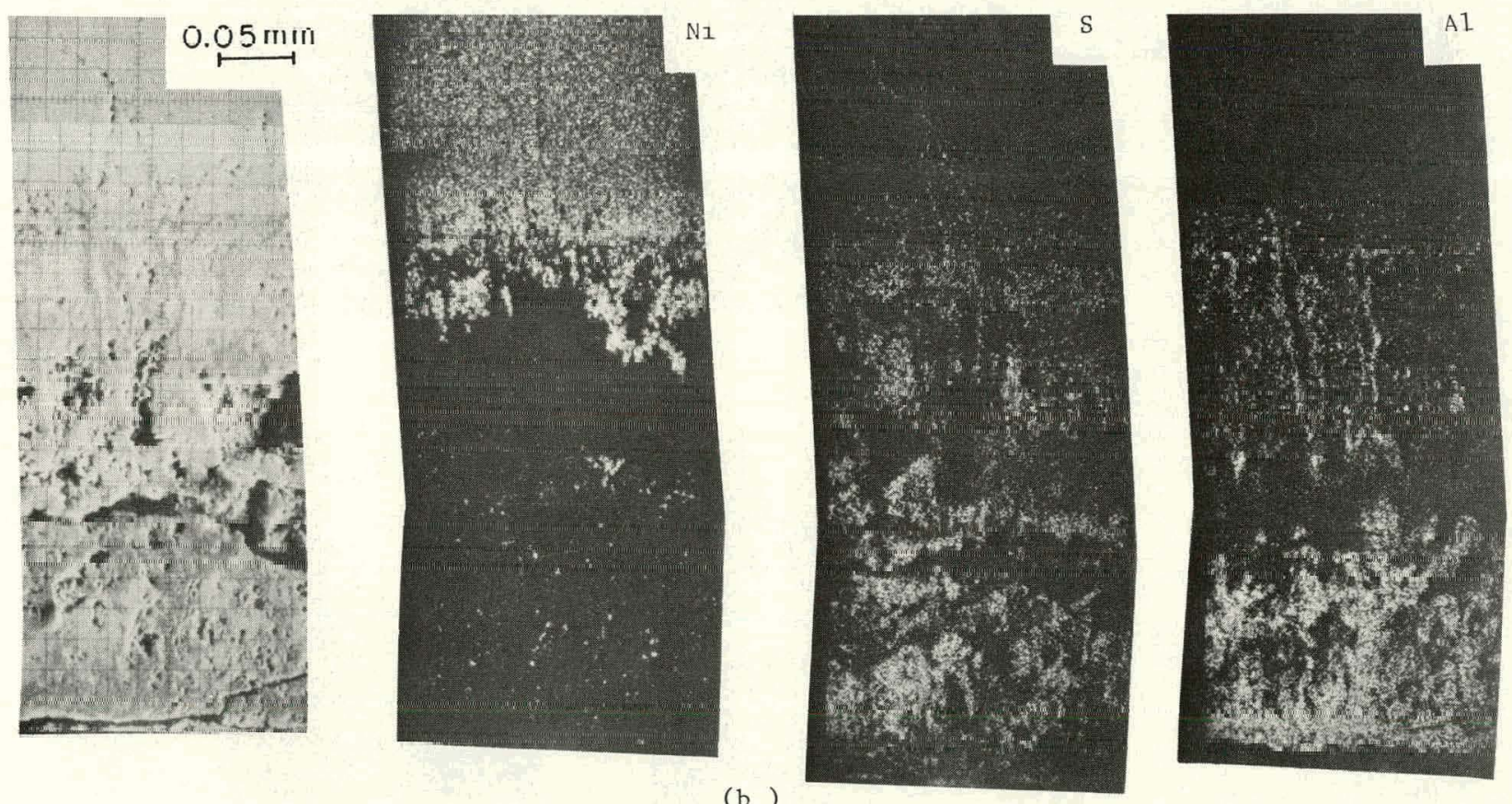

(b )

Fig. 53. Optical Photograph (a) and Electron-microprobe Data (b) of an "Alonized" Type 316 Stainless Steel Coupon That Had Been Exposed to the HYGAS Gasifier Environment and Removed after Run 67. 

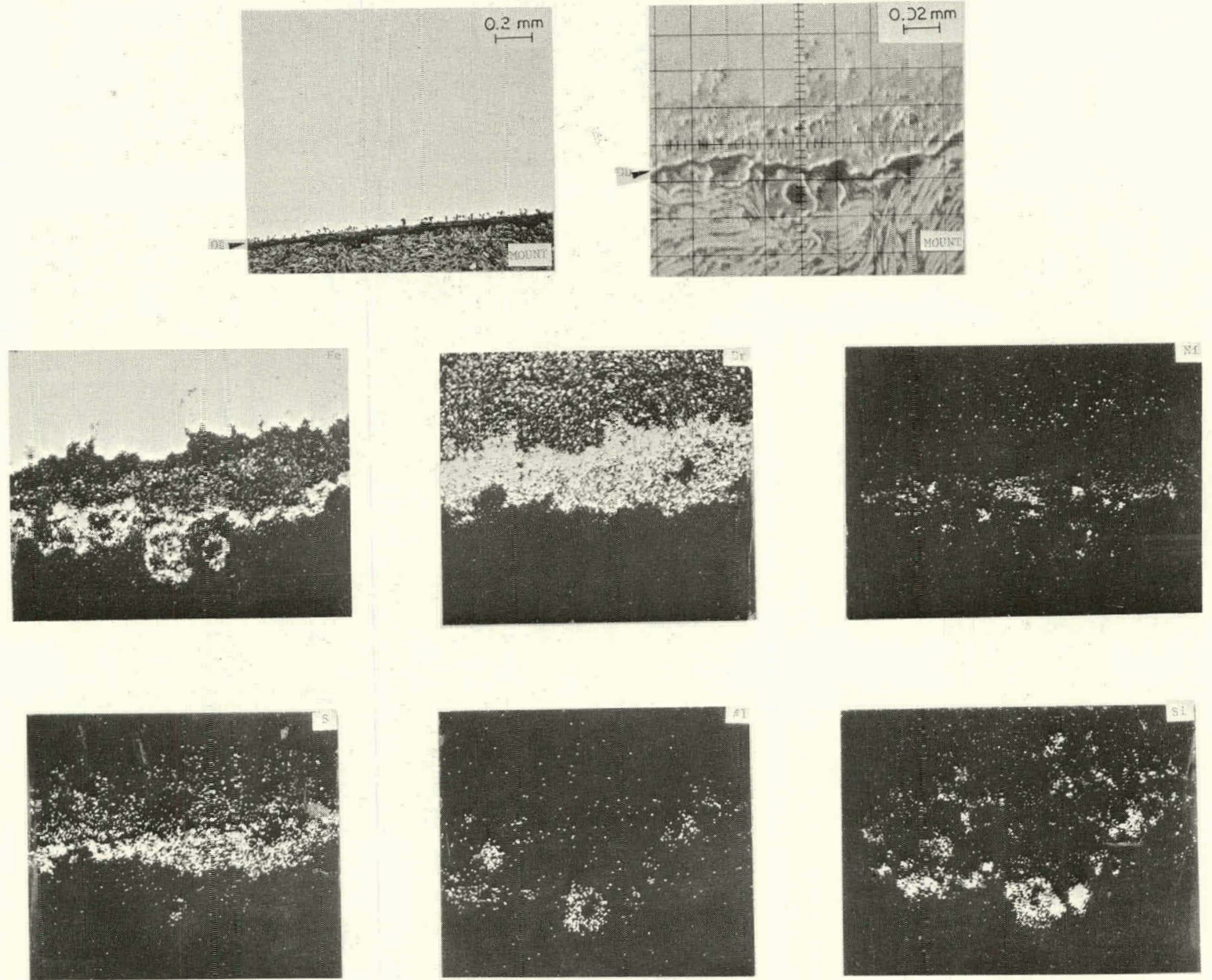

Fig. 54. Optical Photograph and Electron-microprobe Data of an "Alonized" Type 446 Stainless Steel Coupon That Jad Been Exposed to the HYGAS Gasifier Environment and Removed after Run 61. ANL Neg. No. 306-77-189. 


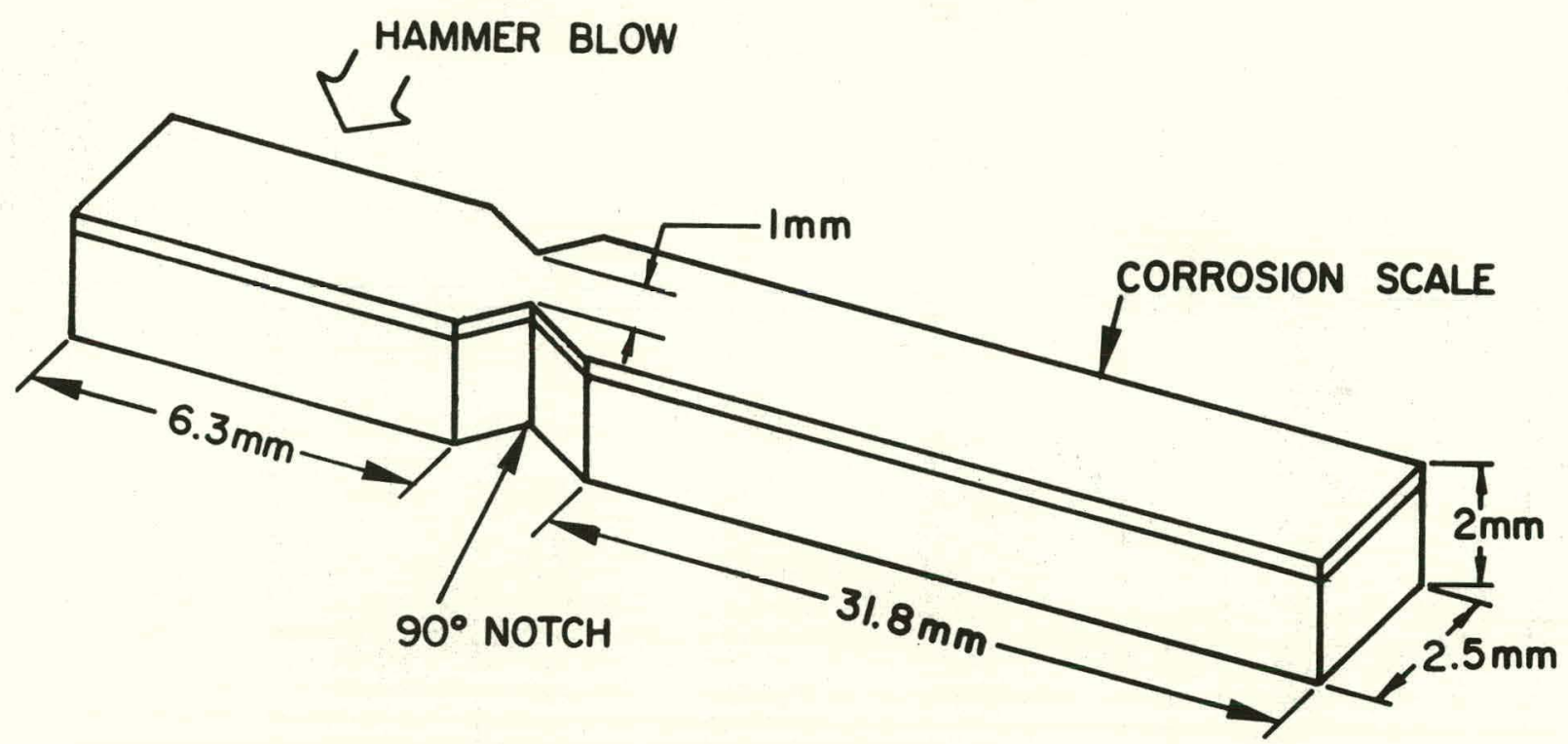

Fig. 55. Geometry of Machined Coupons Used for the Auger Experiment. ANL Neg. No. 306-77-174.

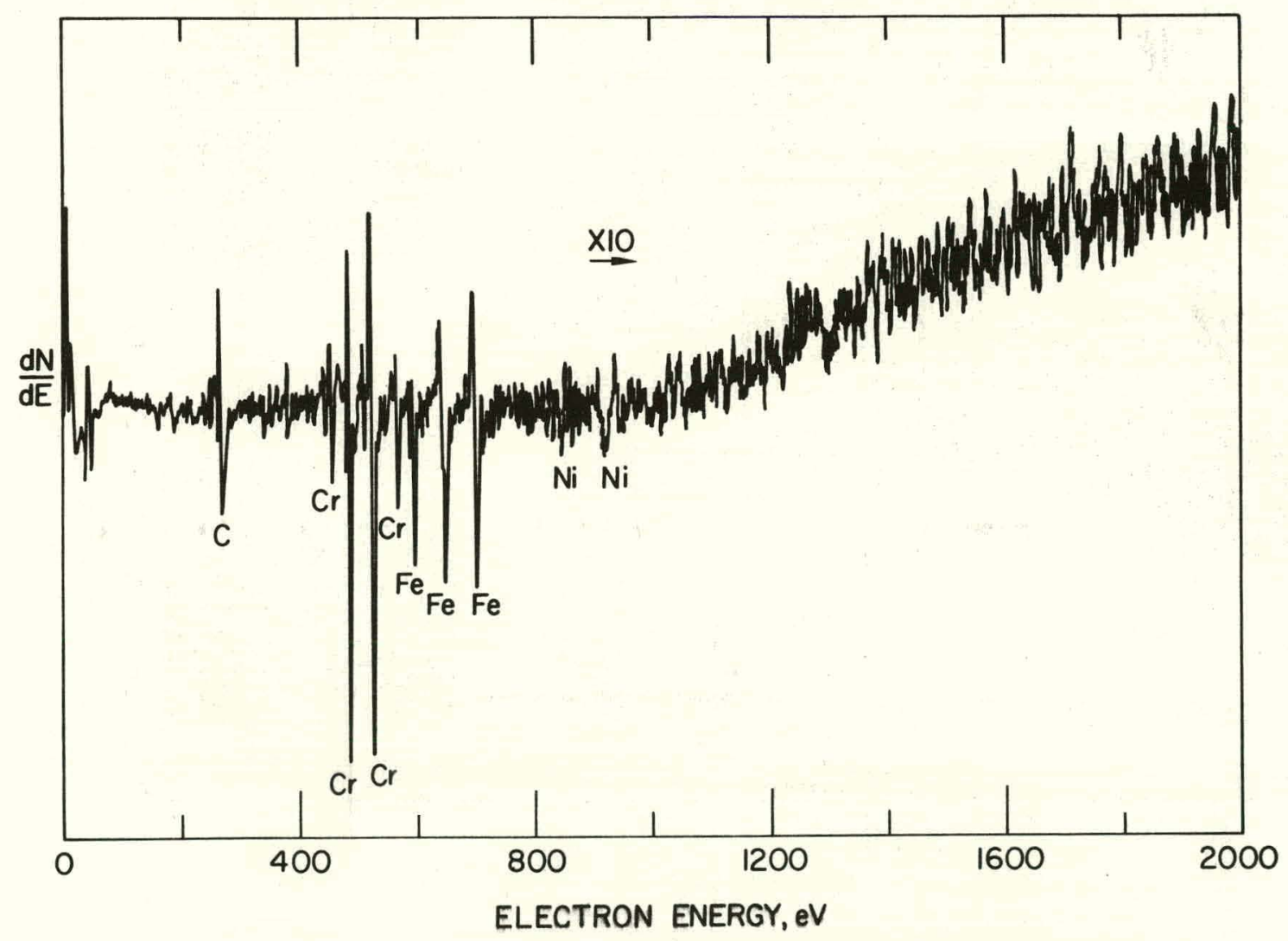

Fig. 56. Auger Spectra of the As-fractured Type 316 Stainless Steel. ANL Neg. No. 306-77-171. 


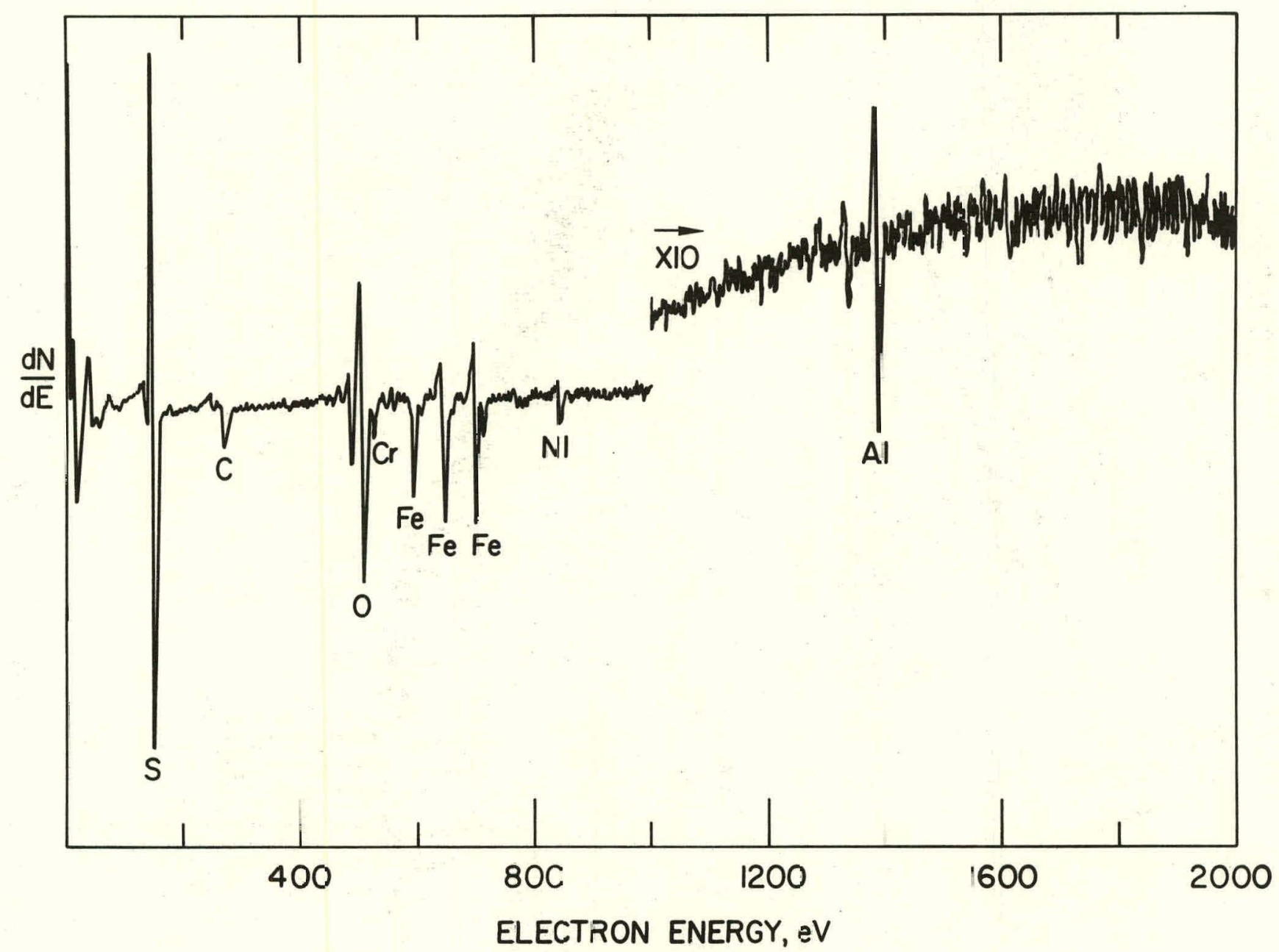

Fig. 57. Auger Spectra of the Corrosion Scale at the Type 316 Stainless Steel Surface. ANL Neg. No. 306-77-176. 

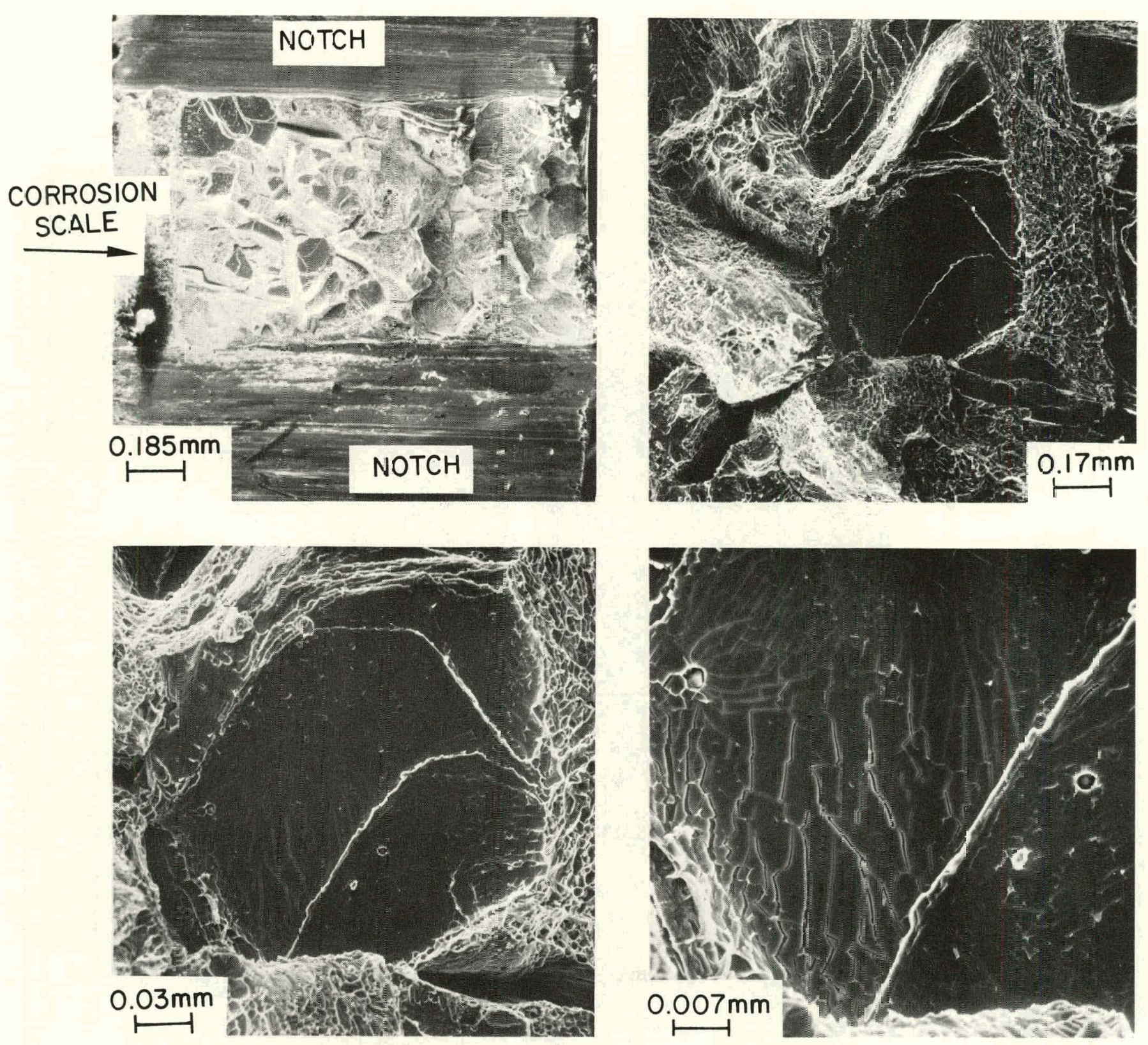

Fig. 58. SEM Micrographs of the Fracture Surface of Type $\$ 16$ Stainless Steel Showing Embri=tled Grain Boundaries. ANL Neg. No. 306-77-198. 


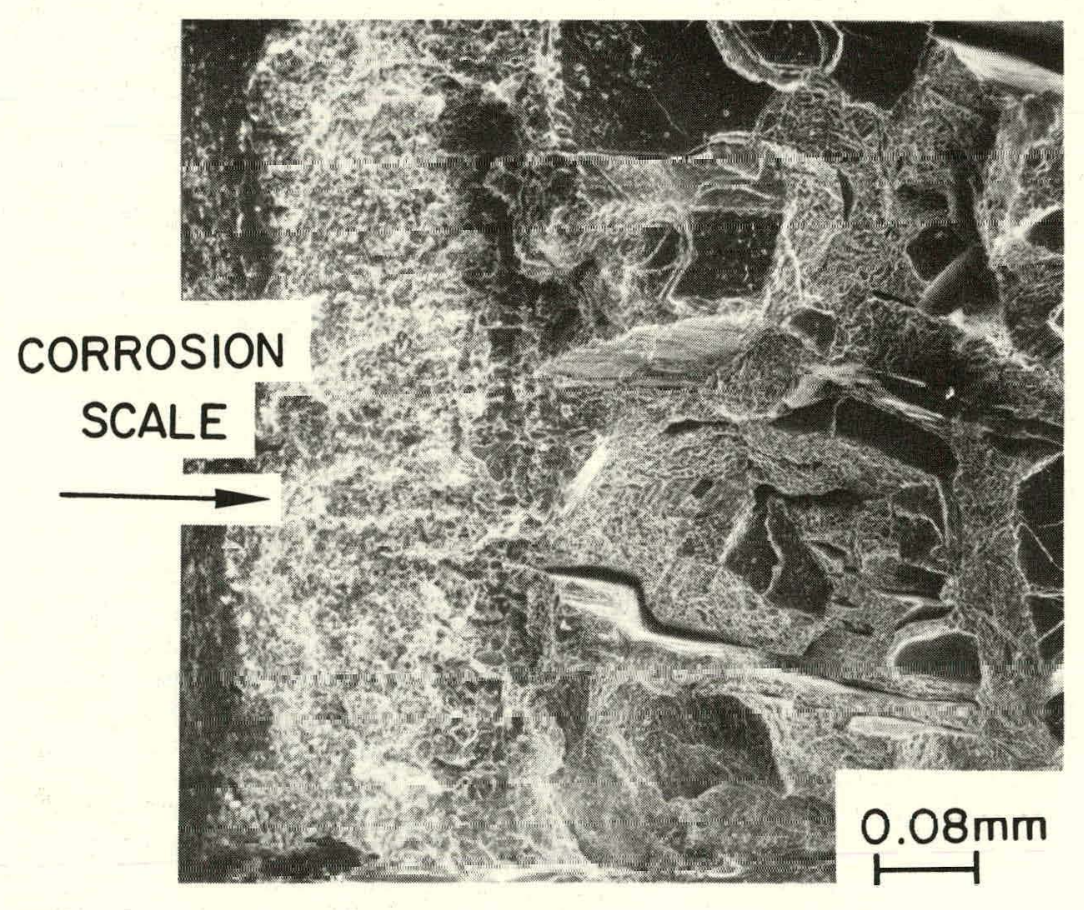

Fig. 59. SEM Micrograph of the Corrosion Scale and the Fracture Surfare of Type 316 Stainless Stcel. ANL Neg. No. 306-77-188. 

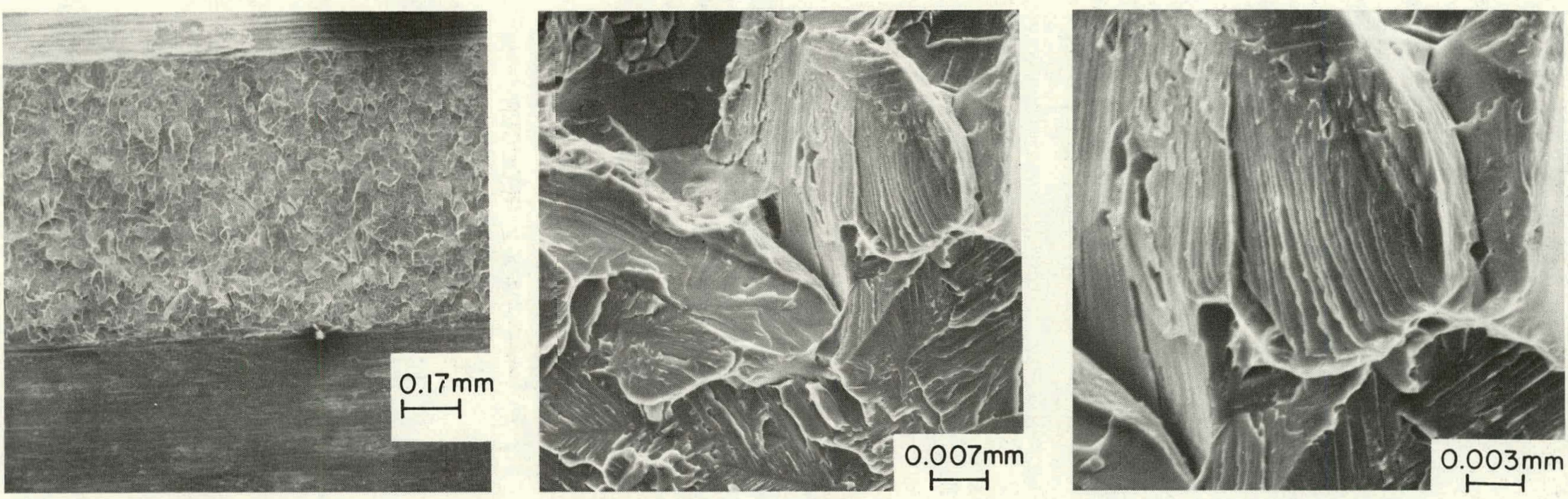

Fig. 60. SEM Micrographs of the Fractured Surface of Type 446 Stainless Steel. ANL Neg. No. 306-77-200. 


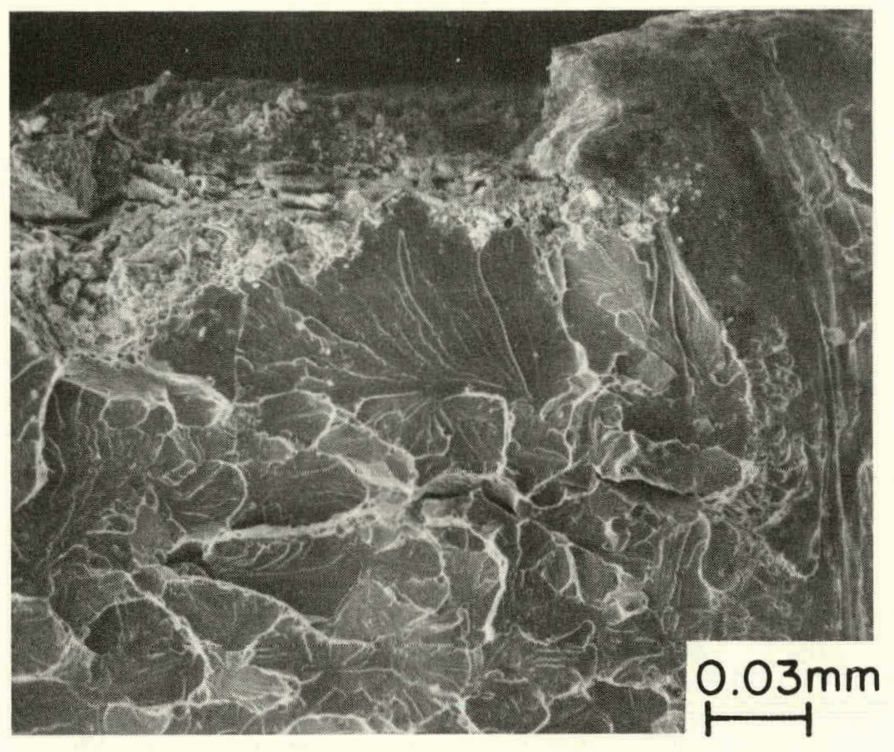

Tig. 61. SEM Micrograph of the Fraclured Surface of Type 446 Stainless Steel. ANL Neg. No. 306-77-184.

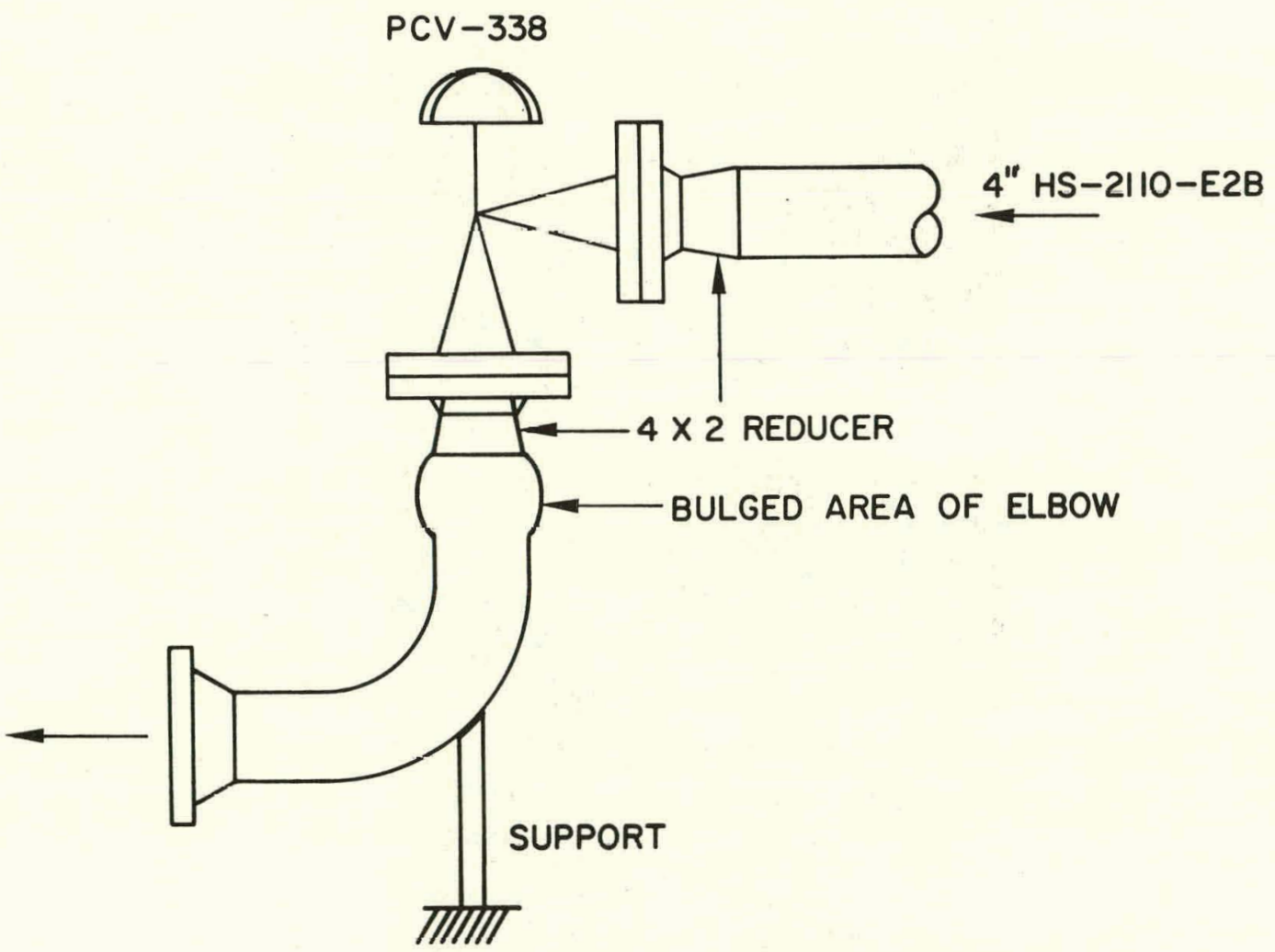

Fig. 62. Schematic Showing the Elbow, Bulged Pipe, and Letdown Valve. ANL Neg. No. 306-77-180. 
Internal:

E. G. Pewitt

R. 0 . Ivins

B. R. T. Frost

R. W. Weeks (6)

M. F. Adams

O. K. Chopra

S. Danyluk

D. R. Diercks

W. A. Ellingson (6)

J. Fischer

K. J. Reimann
A. A. Jonke

T. F. Kassner

C. R. Kennedy

K. Natesan

J. L. Nivens

J. Y. Park

R. B. Poeppe1

W. J. Shack

A. B. Krisciunas

ANL Contract Copy

ANL Libraries (5)

TIS Files (6)

\section{External:}

ERDA-TIC, for distribution per UC-90h (231)

Manager, Chicago Operations Office

Chief, Chicago Patent Group

President, Argonne Universities Association

Materials Science Division Review Committee:

G. S. Anse11, Rensselaer Polytechnic Inst.

R. W. Balluffi, Cornell Univ.

S. Doniach, Stanford Univ.

H. L. Falkenberry, Tennessee Valley Authority

C. Laird, Univ. Pennsylvania

D. Lazarus, Univ. Illinois

M. T. Simnad, General Atomic

A. R. C. Westwood, Martin Marietta Laboratories

R. R. Adams, Battelle Columbus Laboratories

E. M. Anderson, The Babcock \& Wilcox Company

W. G. Bair, Inst. of Gas Technology

W. Bakker, USERDA/FE

S. Carson, CE Lummus Co., Bruceton, Pa.

A. Conn, Amoco Oil Co., Naperville, Ill.

W. C. Corder, Battelle Columbus Laboratories

M. Crowley, Standard Oil of Indiana, Naperville, I11.

J. Flagg, Universal Oil Products Co., Des Plaines, Ill.

E. Fox, Stearns-Roger Corp., Homer City, Pa.

H. E. Frankel, USERDA/FE

S. M. Gaitonde, Commonwealth Edison Co., Maywood, Ill.

D. Glaser, Stearns Roger Corp., Denver

H. Heysteck, Tuscaloosa Metallurgy Research Center, University, Ala.

V. Hill, IIT Research Inst.

D. Hull, Phillips Petroleum Co., Homer City, Pa.

R. I. Jaffee, Electric Power Research Institute

D. L. Keairns, Westinghouse Research Labs.

H. Leavenworth, Albany Metallurgy Research Center

A. V. Levey, Lawrence Berkeley Laboratory

R. Lewis, Synthane Pilot Plant, USERDA/FE, Pittsburgh

G. Long, Northern Illinois Gas Co., Aurora

R. M. Lundberg, Commonwealth Edison Co., Chicago 
J. M. O'Donnell, The Lummus Co., Bloomfield, N.J.

A. L. Plumley, Combustion Engineering Power Systems, Windsor

J. Pope, Science Applications, Inc.

A. Schaeffer, Metals Properties Council, New York

S. J. Schneider, National Bureau of Standards

J. R. Schorr, Battelle Columbus Laboratories

J. Stevenson, Rolla Metallurgy Research Center

J. Sudbury, Consolidated Coal Co., Library, Pa.

C. Whitten, Peabody Coal Co., Columbia, Tenn.

F. Woods, Albany Metallurgy Research Center 